DANTE COAQUIRA BEGAZO

\title{
MÉTODO DE AVALIAÇÃO DE QUALIDADE DE VÍDEO POR OTIMIZAÇÃO CONDICIONADA
}




\section{MÉTODO DE AVALIAÇÃo DE QUALIDADE DE VÍDEO POR OTIMIZAÇÃO CONDICIONADA}

Tese apresentada à Escola Politécnica da Universidade de São Paulo para obtenção do Título de Doutor em Ciências. 


\section{MÉTODO DE AVALIAÇÃo DE QUALIDADE DE VÍDEO POR OTIMIZAÇÃO CONDICIONADA}

Tese apresentada à Escola Politécnica da Universidade de São Paulo para obtenção do Título de Doutor em Ciências.

Área de Concentração:

Sistemas Eletrônicos

Orientador:

Prof. Dr. Miguel Arjona Ramírez 
Este exemplar foi revisado e corrigido em relação à versão original, sob responsabilidade única do autor e com a anuência de seu orientador.

São Paulo, 23 de janeiro de 2018.

Assinatura do autor:

Assinatura do orientador:

Catalogação-na-publicação

Begazo, Dante Coaquira

Método de Avaliação de Qualidade de Vídeo por Otimização Condicionada /

D. C. Begazo -- versão corr. -- São Paulo, 2018.

$86 \mathrm{p}$.

Tese (Doutorado) - Escola Politécnica da Universidade de São Paulo. Departamento de Engenharia de Sistemas Eletrônicos.

1.Processamento de sinais de vídeo 2.Vídeo (Qualidade)

3.Processamento digital de imagens 4.Redes Multimídia 5.Otimização

I.Universidade de São Paulo. Escola Politécnica. Departamento de

Engenharia de Sistemas Eletrônicos II.t. 
Aos meus queridos pais

Mayela e Maximiliano. 


\section{AGRADECIMENTOS}

Agradeço primeiramente ao meu orientador Prof. Dr. Miguel Arjona Ramírez pelas orientações e ensinamentos durante minha jornada na Escola Politécnica.

Aos Profs. Drs. Wagner Luiz Zucchi e Mário Minami pelas sugestões no meu exame de qualificação.

Aos Profs. Drs. Mylene Christine Queiros de Farias, Mario Minami, Celso Setsuo Kurashima, Emilio del Moral Hernandez, João Mendes Filho e Marcel Stefan Wagner pelas sugestões na minha defesa de doutorado.

Aos funcionários da secretaria de pós-graduação e demais colaboradores da EPUSP.

À CAPES - Coordenação de Aperfeiçoamento de Pessoal de Nível Superior - e à FAPESP - Fundação de Amparo à Pesquisa do Estado de São Paulo - pelo suporte financeiro.

À SAS - Superintendência de Assistência Social - da USP, especialmente a Carla Cucolo pelo apoio moradia.

A todos os amigos da Elétrica pelo carinho e apreço.

Às pessoas que me ajudaram na realização desta Tese.

Aos meus amigos de Brasil e Perú pela grande amizade e pelos momentos felizes vividos juntos.

Aos meus amigos Demóstenes Zegarra Rodríguez e Renata Lopes Rosa pela valiosa ajuda nesta Tese, e pela grande amizade construída durante todos estes anos.

A Carmen Palacios por todo o carinho, dedicação e apoio dado durante todos estes anos juntos.

Aos meus irmãos Consuelo, Antonieta e Raúl, aos meus sobrinhos Valeria, Luciana, Sebastián e Abigail e especialmente aos meus pais Mayela e Maximiliano pelo apoio, fortaleza, compreensão, paciência, grande amor e felicidade dados desde sempre.

Por último, agradeço a Deus por ter me dado uma família linda e amigos verdadeiros. 
"Comece fazendo o que é necessário, depois o que é possível, e de repente você estará fazendo o impossível"

São Francisco de Assis. 


\section{RESUMO}

Esta Tese propõe duas métricas objetivas para avaliar a percepção de qualidade de vídeos sujeitos a degradações de transmissão em uma rede de pacotes. A primeira métrica usa apenas o vídeo degradado, enquanto que a segunda usa os vídeos de referência e degradado. Esta última é uma métrica de referência completa (FR - Full Reference) chamada de QCM (Quadratic Combinational Metric) e a primeira é uma métrica sem referência (NR - No Reference) chamada de VQOM (Viewing Quality Objective Metric). Em particular, o procedimento de projeto é aplicado à degradação de variação de atraso de pacotes (PDV - Packet Delay Variation). A métrica NR é descrita por uma spline cúbica composta por dois polinômios cúbicos que se encontram suavemente num ponto chamado de nó. Para o projeto de ambas métricas, colhem-se opiniões de observadores a respeito das sequências de vídeo degradadas que compõem o conjunto. A função objetiva inclui o erro quadrático total entre as opiniões e suas estimativas paramétricas, ainda consideradas como expressões algébricas. Acrescentam-se à função objetiva três condições de igualdades de derivadas tomadas no nó, cuja posição é especificada dentro de uma grade fina de pontos entre o valor mínimo e o valor máximo do fator de degradação. Essas condições são afetadas por multiplicadores de Lagrange e adicionadas à

função objetiva, obtendo-se o lagrangiano, que é minimizado pela determinação dos coeficientes subótimos dos polinômios em função de cada valor do nó na grade. Finalmente escolhe-se o valor do nó que produz o erro quadrático mínimo, determinando assim os valores finais para dos coeficientes do polinômio. Por outro lado, a métrica FR é uma combinação não-linear de duas métricas populares, a PSNR (Peak Signal-to-Noise Ratio) e a SSIM (Structural Similarity Index). Um polinômio completo de segundo grau de duas variáveis é usado para realizar a combinação, porque é sensível a ambas métricas constituintes, evitando o sobreajuste em decorrência do baixo grau. $\mathrm{Na}$ fase de treinamento, o conjunto de valores dos coeficientes do polinômio é determinado através da minimização do erro quadrático médio para as opiniões sobre a base de dados de treino. Ambas métricas, a VQOM e a QCM, são treinadas e validadas usando uma base de dados, e testadas com outra independente. Os resultados de teste são comparados com métricas NR e FR recentes através de coeficientes de correlação, obtendo-se resultados favoráveis para as métricas propostas.

Palavras-chave: Qualidade de Vídeo, Métodos de Avaliação Objetiva e Subjetiva, Variação de Atraso de Pacotes, Multiplicadores de Lagrange, Métrica Combinatória, Streaming de vídeo. 


\begin{abstract}
This dissertation proposes two objective metrics for estimating human perception of quality for video subject to transmission degradation over packet networks. The first metric just uses traffic data while the second one uses both the degraded and the reference video sequences. That is, the latter is a full reference (FR) metric called Quadratic Combinational Metric (QCM) and the former one is a no reference (NR) metric called Viewing Quality Objective Metric (VQOM). In particular, the design procedure is applied to packet delay variation (PDV) impairments, whose compensation or control is very important to maintain quality. The NR metric is described by a cubic spline composed of two cubic polynomials that meet smoothly at a point called a knot. As the first step in the design of either metric, the spectators score a training set of degraded video sequences. The objective function for designing the NR metric includes the total square error between the scores and their parametric estimates, still regarded as algebraic expressions. In addition, the objective function is augmented by the addition of three equality constraints for the derivatives at the knot, whose position is specified within a fine grid of points between the minimum value and the maximum value of the degradation factor. These constraints are affected by Lagrange multipliers and added to the objective function to obtain the Lagrangian, which is minimized by the suboptimal polynomial coefficients determined as a function of each knot in the grid. Finally, the knot value is selected that yields the minimum square error. By means of the selected knot value, the final values of the polynomial coefficients are determined. On the other hand, the FR metric is a nonlinear combination of two popular metrics, namely, the Peak Signal-to-Noise Ratio (PSNR) and the Structural Similarity Index (SSIM). A complete seconddegree two-variable polynomial is used for the combination since it is sensitive to both constituent metrics while avoiding overfitting. In the training phase, the set of values for the coefficients of this polynomial is determined by minimizing the mean square error to the opinions over the training database. Both metrics, the VQOM and the QCM, are trained and validated using one database and tested with a different one. The test results are compared with recent NR and FR metrics by means of correlation coefficients, obtaining favorable results for the proposed metrics.
\end{abstract}

Keywords: Video Quality, Objective and Subjective Assessment Methods, Packet Delay Variation, Lagrange Multipliers, Combinational Metric, Video Streaming. 


\section{LISTA DE FIGURAS}

2.1 Classificação de métodos subjetivos em relação à forma de apresentação dos vídeos. ...22

2.2 Diagrama da sequência de reprodução dos vídeos para o método ACR. ........................23

2.3 Diagrama da sequência de reprodução dos vídeos para o método DCR ........................24

2.4 Classificação de métricas objetivas em relação à informação de referência. (a) Referência Completa, (b) Referência Reduzida e (c) Sem Referência ......................................................26

2.5 Classificação de métricas objetivas de acordo com a tarefa a ser desempenhada .............34

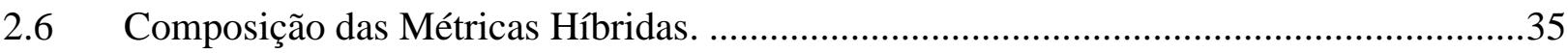

3.1 Efeito do fator de degradação PDV sobre a qualidade de vídeo avaliada usando o método ACR.

3.2 Diagrama da função de estimação de qualidade da métrica NR proposta, constituída por uma spline definida por dois polinômios cúbicos com um ponto de interseção $\xi$.

3.3 Diagrama da função de estimação de qualidade da métrica FR proposta, , representada pelo polinômio completo de segundo grau de duas variáveis.

4.1 Imagens dos vídeos de referência de Akiyo, Foreman e Football (ordenados da esquerda para a direita) . 50

4.2 Plano espaço temporal para os vídeos akiyo, foreman e football 51

4.3 Imagens dos vídeos degradados de Akiyo com variação de atraso de pacotes de 8, 12, 16 e $20 \mathrm{~ms}$ (ordenados da esquerda para a direita)

4.4 Imagens dos vídeos degradados de Foreman com variação de atraso de pacotes de 8, 12, 16 e $20 \mathrm{~ms}$ (ordenados da esquerda para a direita)

4.5 Imagens dos vídeos degradados de Football com variação de atraso de pacotes de 8, 12, 16 e $20 \mathrm{~ms}$ .53

4.6 Imagens dos vídeos de referência de Crowdrun, Duckstakeoff, Harbour, Ice, Parkjoy, Soccer, Running e Restaurant (ordenados da esquerda para a direita e de acima para baixo) .....53

4.7 Plano espaço temporal para os vídeos Crowdrun, Duckstakeoff, Harbour, Ice, Parkjoy, Soccer, Running e Restaurant da Base de Dados ReTRiEVED .............................................54

4.8 Ambiente usado na avaliação subjetiva ..................................................................56

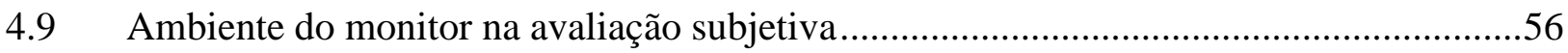

4.10 Diagrama de blocos do erro quadrático para a fase de teste .........................................58

4.11 Diagrama do método de validação cruzada k-fold para $k=4$, usado na função de estimação de qualidade da métrica com referência. 
4.12 Cenário de aplicação da métrica proposta NR

4.13 Cenário de aplicação da métrica proposta FR

5.1 Opiniões de Treinamento (boxplots) e métrica proposta (spline grossa) para $\xi=5,5 \mathrm{~ms}$, e as funções de estimação de qualidade (splines finas) para $\xi=0,5 ; 1,5 ; \ldots ; 19,5$, em função do PDV

5.2 Opiniões de Treinamento (boxplots) e métrica proposta (spline contínua) para $\xi=5,5 \mathrm{~ms}$, e spline de um polinômio cúbico (linha tracejada) em função do PDV .65

5.3 Opiniões de Treinamento (boxplot) e métrica proposta VQOM (spline contínua) para $\xi=5,5 \mathrm{~ms}$, e spline de um polinômio de grau oito (linha tracejada) em função do PDV 67

A.1 Protocolos usados no transporte de vídeo .81

A.2 Pacote IP com informação dos cabeçalhos para dados de transporte de vídeo. 82 


\section{LISTA DE TABELAS}

2.1 Escala de categorias para Qualidade........................................................................23

2.2 Escala de categorias para níveis de degradação..........................................................24

4.1 Características dos vídeos de referência da base de dados ReTRiEVED........................54

5.1 Desempenho da métrica VQOM e as funções de estimação de qualidade representadas pelos polinômios de grau três (P3) e de grau oito (P8) em relação às opiniões de treino.

5.2 Desempenho da métrica VQOM e as funções de estimação de qualidade representadas pelos polinômios de grau três (P3) e de grau oito (P8) em relação às opiniões de teste.

5.3 Desempenho das métricas VQOM, PSNR, SSIM, VQM, NIQE, BRISQUE e VMAF em relação às opiniões de teste da base de dados PDV_DB.

5.4 Desempenho da métrica QCM no treino (TR) e na validação ou teste (VT) usando o método de validação cruzada de 4 iterações (I). .70

5.5 Desempenho da métrica QCM para o teste final usando a base de dados PDV_DB.......70

5.6 Desempenho da métrica CCM no treino (TR) e na validação ou teste (VT) usando o método de validação cruzada de 4 iterações (I).

5.7 Desempenho das métricas QCM e CCM na terceira iteração da validação cruzada de 4 iterações (I) no treino (TR) e na validação ou teste (VT)

5.8 Desempenho das métricas QCM, PSNR, SSIM e VMAF em relação às opiniões de teste da base de dados PDV_DB 


\section{LISTA DE ABREVIATURAS}

A seguir são listadas as principais abreviaturas usadas na Tese.

ACR Absolute Category Rating

ACR-HR Absolute Category Rating with Hidden Reference

AGGD Asymmetric Generalized Gaussian Model

AMD Advanced Micro Devices

ANATEL Agência Nacional de Telecomunicações

AVC Advanced Video Coding

AVS Audio Video Standard

BRISQUE Blind/Referenceless Image Spatial Quality Evaluator

CCM Cubic Combinational Metric

CIF Common Intermediate Format

DCR Degradation Category Rating

DLM Detail Loss Metric

DSCQS Double Stimulus Continuous Quality Scale

DSIS Double Stimulus Impairment Scale

FR Full Reference

GoP Group of Pictures

IP Internet Protocol

IPS In Plane Switching

IPTV Internet Protocol Television

ITU International Telecommunication Union

LAN Local Area Network

LCD Liquid Crystal Display

MOS Mean Opinion Score

MPEG Moving Picture Experts Group

MPEG-TS MPEG Transport Stream

MSE Mean Squared Error

MSCN Mean Subtracted Contrast Normalized

MSU Moscow State University

MTS MPEG Transport Stream 


\begin{tabular}{|c|c|}
\hline MTU & Maximum Transmission Unit \\
\hline MVG & Multivariate Gaussian Model \\
\hline NETEM & Network Emulator \\
\hline NIQE & Naturalness Image Quality Evaluator \\
\hline NR & No Reference \\
\hline PDV & Packet Delay Variation \\
\hline PC & Pair Comparison \\
\hline PCC & Pearson Correlation Coefficient \\
\hline PDV_DB & Packet Delay Variation_Data Base \\
\hline PES & Packetized Elementary Stream \\
\hline PLR & Packet Loss Rate \\
\hline PMT & Período de Maior Tráfego \\
\hline PSNR & Peak Signal to Noise Ratio \\
\hline QCM & Quadratic Combinational Metric \\
\hline QoE & Quality of Experience \\
\hline QoS & Quality of Service \\
\hline RAM & Random Access Memory \\
\hline $\mathbf{R R}$ & Reduced Reference \\
\hline RTP & Real Time Protocol \\
\hline SDSCE & Simultaneous Double Stimulus for Continuous Evaluation \\
\hline SI & Spatial Information \\
\hline SRCC & Spearman Rank Correlation Coefficient \\
\hline SSCQE & Single Stimulus Continuous Quality Scale \\
\hline SSIM & Structural Similarity Index \\
\hline STI & Superintendência de Tecnologia da Informação \\
\hline SVM & Support Vector Machine \\
\hline TCP & Transmission Control Protocol \\
\hline TI & Temporal Information \\
\hline TS & Transport Stream \\
\hline UDP & User Datagram Protocol \\
\hline USP & Universidade de São Paulo \\
\hline VDK & VMAF Development Kit \\
\hline VIF & Visual Information Fidelity \\
\hline VLC & VideoLan Client \\
\hline
\end{tabular}


VMAF Visual Multimethod Assessment Fusion

VQM Video Quality Model

VQOM Viewing Quality Objective Metric

WLAN Wireless Local Area Network 


\section{SUMÁRIO}

INTRODUÇÃ̃

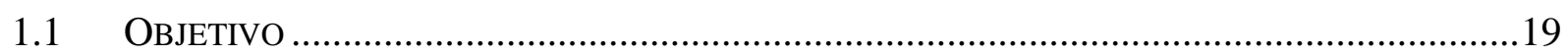

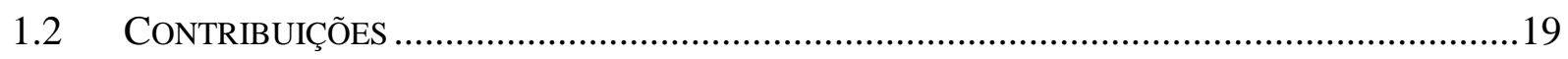

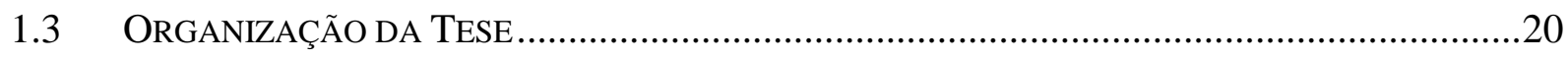

MÉTODOS DE AVALIAÇÃO DE QUALIDADE.......................................................................21

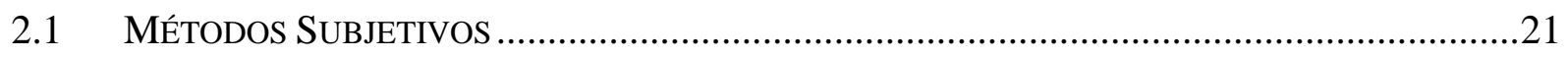

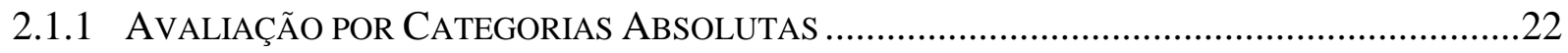

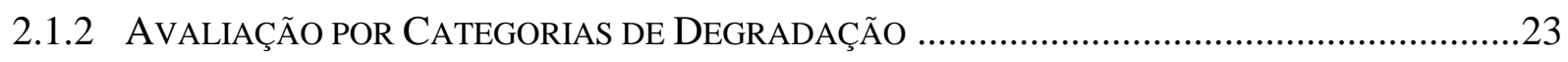

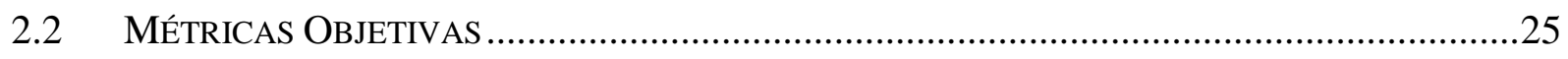

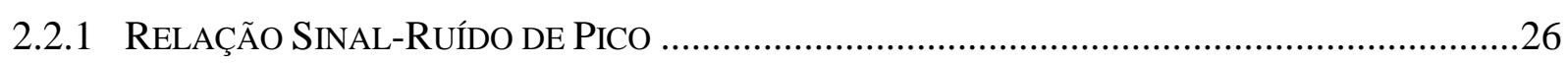

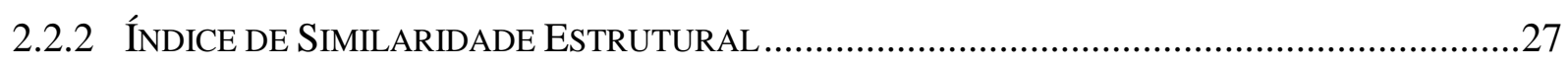

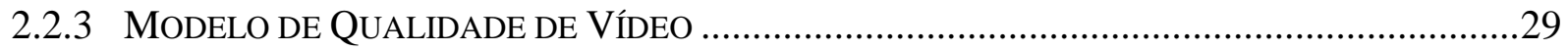

2.2.4 Fusão de AvaliaÇÃo de VÁRIos Métodos de VÍDEO ...............................................30

2.2.5 AvaliaÇão CEGA DE Qualidade DE IMAgenS …........................................................

2.2.6 AvaliaÇÃO DE QUALIDAdE DE IMAGENS PELA NATURALIDADE ...................................33

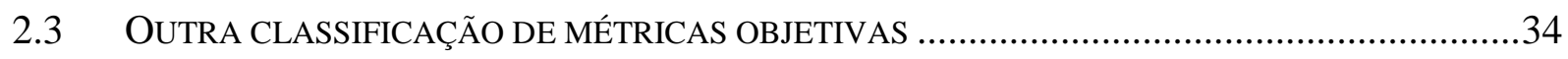

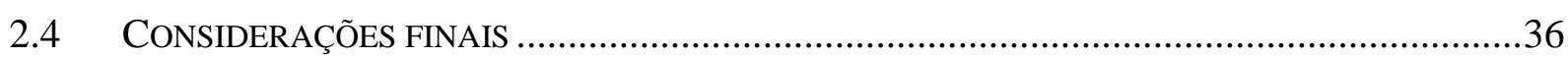

PROJETO DE MÉTRICAS DE QUALIDADE DE VÍDEO ..................................................37

3.1 FUnÇÃO DE ESTIMAÇÃO DE QUALIDADE PARA MÉTRICA NR ........................................37

3.2 FUnÇÃO DE ESTIMAÇÃO DE QUALIDADE PARA MÉTRICA FR ......................................46

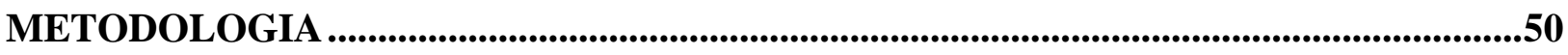

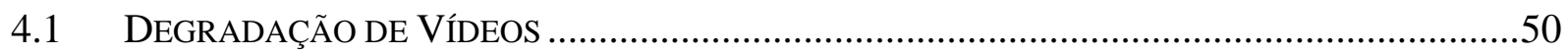

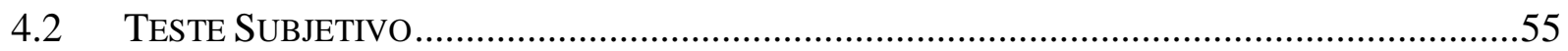

4.3 Teste da FunÇÃo de EstimaÇÃo de Qualidade ......................................................58

4.4 TREINO, VALIDAÇÃO E TESTE DA FUNÇÃO DE ESTIMAÇÃO DE QUALIDADE FR ................59

4.5 CEnÁRIOS DE APLICAÇão das MÉTRICAS Propostas .................................................60

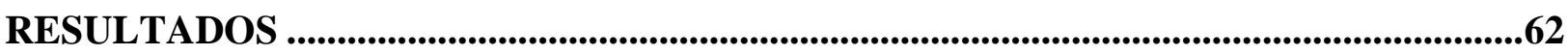

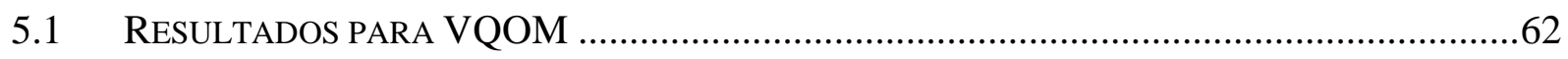

5.2 CoMPaRAÇÃO DE RESUltados PARA VQOM .........................................................65 


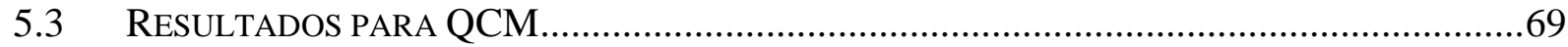

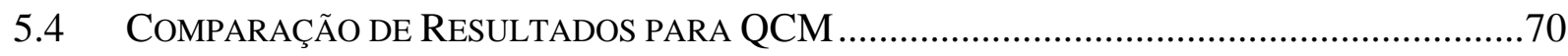

CONCLUSÕES E TRABALHOS FUTUROS .......................................................................73

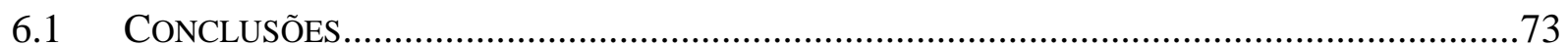

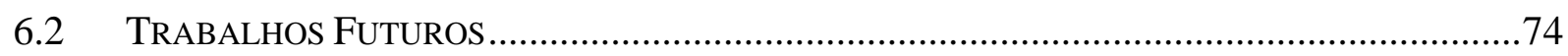

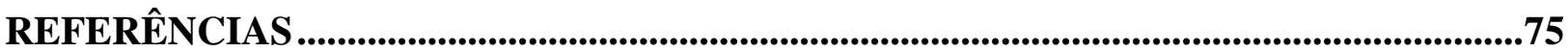

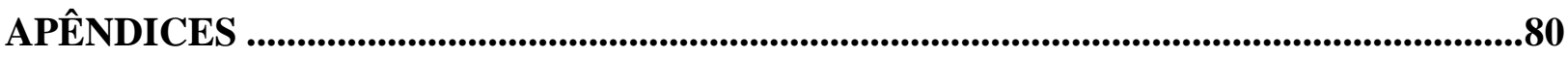

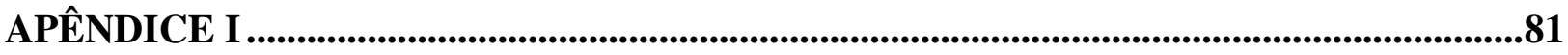

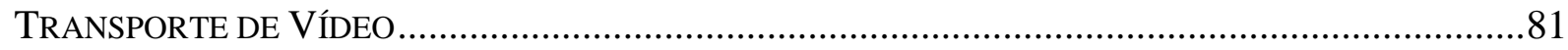

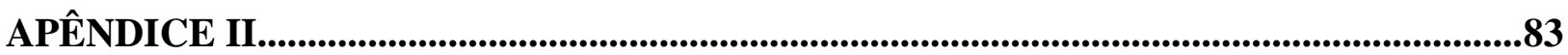

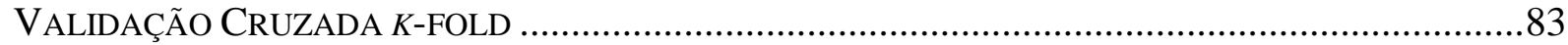

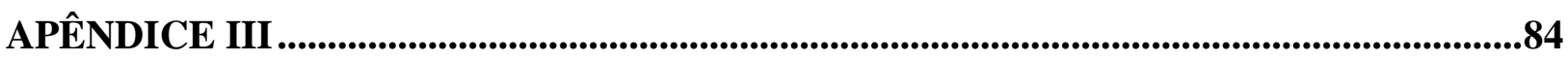

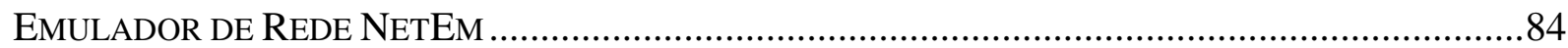

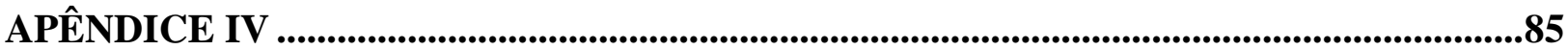

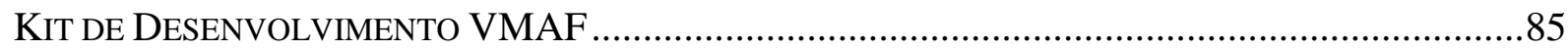

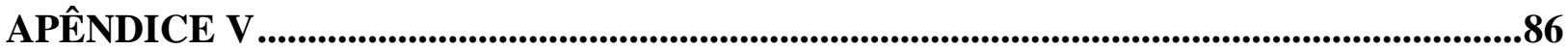

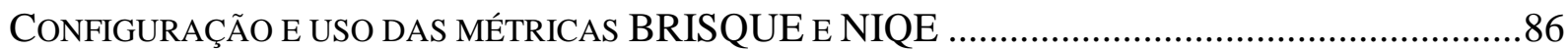




\section{INTRODUÇÃO}

O vídeo é uma sucessão de imagens, que são arranjos bidimensionais de pixels tratados como matrizes pelo computador. Para transmissão, tem que ser gerado um sinal unidimensional de vídeo que, na forma digital, é um fluxo de bits (bitstream). Nesse fluxo, tem que ser incorporados bits de sincronismo que identifiquem cada imagem ou quadro. O conteúdo do quadro, em sua forma mais simples, é uma sequência concatenada dos bits que representam cada pixel ordenados em fila por algum processo de varredura. Quando o vídeo é codificado, no lugar dos pixels são colocados os valores de parâmetros quantizados, podendo incluir pixels residuais, coeficientes de predição, vetores de movimento, etc.

Quando o vídeo é transmitido por um canal de rádio ou é armazenado numa fita magnética usa-se diretamente o fluxo de bits ou bitstream. Ao contrário, se o vídeo for transmitido através de uma rede de pacotes, o fluxo de bits deverá ser repartido entre vários pacotes, sendo que cada pacote terá que incluir um cabeçalho de endereçamento.

Em serviços de difusão de vídeos é importante a avaliação da qualidade do vídeo recebido, porque as degradações introduzidas pelos sistemas de transmissão de vídeo afetam a percepção do usuário de forma negativa, ocasionando insatisfação do cliente com o serviço prestado.

A qualidade do vídeo pode ser medida usando o vídeo em qualquer uma das formas acima, quais sejam, pacotes de rede, fluxo de bits ou sequência de imagens. Além disso, há métricas híbridas que usam mais de uma dessas formas de representação e ainda podem interpretar o conteúdo dos dados de vídeo (WINKLER, 2008).

As pessoas são capazes de avaliar a qualidade do vídeo absolutamente, o que é muito difícil para as máquinas. Assim, tradicionalmente as métricas de qualidade de vídeo são métricas com referência. Mesmo assim, têm sido desenvolvidas métricas de qualidade de vídeo sem referência (NR), que são mais práticas apesar de um desempenho inferior em relação as métricas com referência. Não obstante, esta é uma área de pesquisa mais efervescente, na qual importantes resultados têm sido conseguidos (FARIAS, 2004).

A seguir são mostrados os tópicos que apresentam a importância da Tese, junto com a organização estrutural. 


\subsection{Objetivo}

As métricas tradicionais não refletem a qualidade percebida pelas pessoas dos vídeos degradados por uma rede de pacotes. Por isso, buscou-se na pesquisa o desenvolvimento de uma métrica baseada em degradações de rede que não necessitasse do sinal de referência para maior versatilidade de aplicação.

Em consulta a operadores de IPTV (Internet Protocol Television), verificou-se que a variação de atraso de pacotes só era controlável em situações limite. Assim, considerou-se importante a avaliação da qualidade mesmo com valores de atraso de pacotes dentro da faixa de operação.

Como uma métrica sem referência (NR) baseada em parâmetros de rede depende muito da configuração da rede e da constituição do fluxo de bits, em complemento pesquisou-se também uma métrica com referência que trata da combinação de duas métricas tradicionais.

\subsection{Contribuições}

Foram propostas duas métricas, sendo uma sem referência (NR) e outra com referência (FR). A métrica sem referência (NR) auxilia na operação de serviços de transmissão de vídeo por rede de pacotes durante a execução do serviço. Nesse intervalo de tempo não é viável a execução de avaliações subjetivas em larga escala. Por outro lado, a métrica com referência (FR) é útil na fase de desenvolvimento de codificadores ou de serviços e também na fase de teste piloto.

As contribuiçõoes desta Tese são enumeradas a seguir.

1. A construção de uma métrica objetiva capaz de incorporar aspectos significativos da percepção da degradação causada por variação de atraso de pacotes;

2. A proposta para função de qualidade parametrizada de uma spline parametrizada, cujos parâmetros são determinados na fase de projeto por um método de otimização;

3. Um método de projeto que se baseia em multiplicadores de Lagrange com condições típicas do comportamento da percepção de qualidade.

4. A proposta de uma métrica com referência baseada na combinação não-linear de duas métricas populares, a PSNR e a SSIM, que, individualmente, não apresentam bom desempenho para degradações de transmissão. Entretanto, a métrica proposta, 
denominada QCM (Quadratic Combinational Metric) supera as duas que a constituem, além de outras métricas recentes também testadas dentro do conjunto de teste.

\subsection{Organização da Tese}

Além do presente Capítulo, a Tese foi organizada em cinco capítulos.

No Capítulo 2 apresenta-se uma breve revisão teórica dos métodos de avaliação objetiva e subjetiva utilizadas para avaliação de qualidade de vídeo.

No Capítulo 3 é apresentado o projeto da função de estimação de qualidade para a métrica sem referência (NR) utilizando um método de otimização baseado em multiplicadores de Lagrange, para minimização do erro quadrático; e o projeto da função de estimação de qualidade para a métrica de referência completa (FR) através da minimização do erro quadrático.

No Capítulo 4 apresenta-se a metodologia utilizada na obtenção do banco de dados de treino e de teste, passando pela descrição das características de transmissão dos vídeos degradados pela variação de atraso de pacotes e apresentando a forma como foram realizados os testes subjetivos. Finalmente, mostra o procedimento de teste das métrica propostas a partir dos dados obtidos.

No Capítulo 5 são apresentados os resultados do comportamento das métricas propostas, na fase de treinamento e de teste, e a comparação com métricas que realizam o projeto das funções de estimação de qualidade representadas por um único polinômio e com outras métricas populares.

Para finalizar, no Capítulo 6 apresentam-se as conclusões relacionadas aos resultados obtidos e as propostas de trabalhos futuros. 


\section{MÉTODOS DE AVALIAÇÃO DE QUALIDADE}

Comumente os sistemas de transmissão e processamento de vídeo causam degradações no sinal de vídeo que afetam a sua qualidade, motivo pelo qual é importante avaliar a qualidade de vídeo. Para isso, usam-se métodos que comparam as características dos vídeos degradados com os vídeos de referência, ou que mensuram as características só dos vídeos degradados.

Segundo Jayant e Noll (1984), a avaliação de fidelidade ou do grau de degradação que um determinado sistema causa em um sinal de vídeo pode ser feita de forma objetiva ou de forma subjetiva. A avaliação objetiva é feita por máquinas de forma automática, sendo importante para o desenvolvimento de codificadores e serviços de transmissão. A avaliação subjetiva é feita por pessoas e é utilizada usualmente na fase final do desenvolvimento de codificadores, devido ao tempo relativamente longo para ser realizada. Por isso, a avaliação objetiva é importante em termos operacionais, e a avaliação subjetiva é importante em termos de validação.

Neste capítulo, é realizada uma revisão bibliográfica dos métodos subjetivos e das métricas objetivas utilizados na avaliação de qualidade de imagem e de vídeo.

\subsection{Métodos Subjetivos}

Os métodos subjetivos são técnicas psico-físicas projetadas para aferir de forma subjetiva a qualidade, representando a melhor alternativa em termos de precisão na avaliação de qualidade dos sinais de vídeo. Nos métodos subjetivos, um número de observadores assiste sequências de vídeo e os avaliam em relação à qualidade ou ao nível de degradação. Estes métodos são classificados em relação à forma de apresentação aos observadores das sequências de vídeo, como métodos de estímulo único e de duplo estímulo (ITU-R BT.50013, 2012), como visto na Figura 2.1.

Nos métodos de estímulo único, usam-se sequências de vídeo degradadas para ser apresentadas uma de cada vez, sem necessidade de utilizar a sequência de vídeo de referência. A principal vantagem é o tempo de duração curto dos testes subjetivos. 
Nos métodos de duplo estímulo, as sequências de vídeo degradadas e de referência são apresentadas em sequência, uma seguida de outra, ou de forma conjunta. A principal vantagem é a maior precisão na avaliação de qualidade de vídeo.

Alguns métodos subjetivos de avaliação de qualidade de vídeo para aplicações multimídia são descritos na recomendação ITU-T P.910 (2008). Nesses métodos, as sequências de vídeo são apresentadas para cada observador e avaliadas utilizando escalas de pontuação média de opinião (MOS - Mean Opinion Score). As avaliações mais utilizadas são os índices por categorias absolutas (ACR - Absolute Category Rating) e os índices por categorias de degradação (DCR - Degradation Category Rating).

Figura 2.1 - Classificação de métodos subjetivos em relação à forma de apresentação dos vídeos.

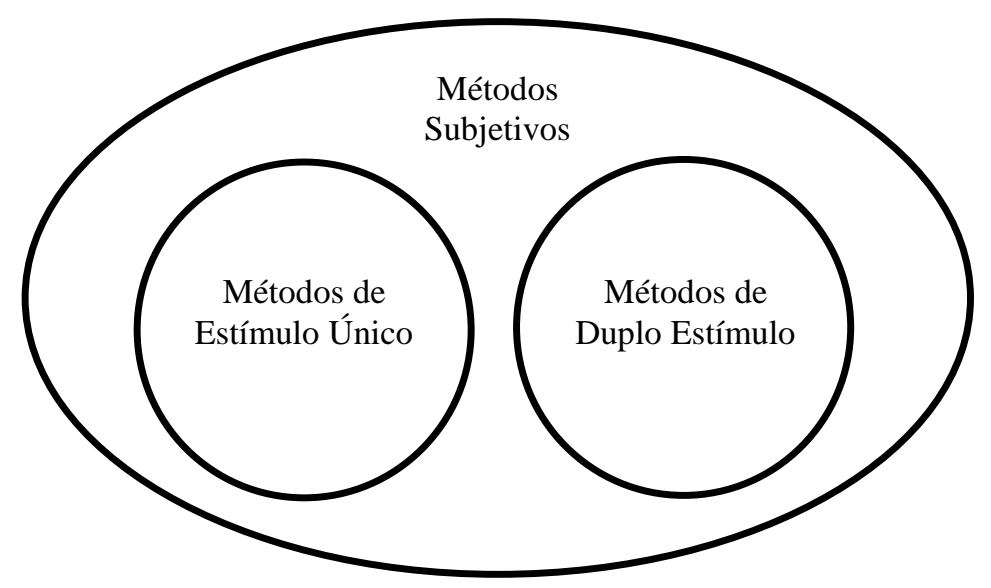

Fonte: Adaptado de (ITU-R BT.500-13, 2012).

\subsubsection{Avaliação por Categorias Absolutas}

O método ACR é classificado como de estímulo único, porque são usadas unicamente as sequências de vídeo degradado e apresentadas uma de cada vez. Os observadores atribuem uma pontuação para cada sequência de vídeo utilizando uma escala MOS de cinco níveis como visto na Tabela 2.1.

No método ACR, os vídeos degradados têm um tempo máximo de reprodução de $10 \mathrm{~s} \mathrm{e,}$ um tempo para realizar a avaliação menor que $10 \mathrm{~s}$. 
Tabela 2.1 - Escala de categorias para Qualidade.

\begin{tabular}{c|c}
\hline Pontuação & Qualidade \\
\hline 5 & Excelente \\
4 & Bom \\
3 & Razoável \\
2 & Ruim \\
1 & Péssima \\
\hline
\end{tabular}

Fonte: Adaptado de (ITU-T P.910, 2008).

Na Figura 2.2 é apresentado o diagrama da sequência de reprodução dos vídeos com os tempos de duração de cada atividade para o método ACR. A principal vantagem desta métrica é a rapidez com que é realizada a avaliação de qualidade.

Figura 2.2 - Diagrama da sequência de reprodução dos vídeos para o método ACR.

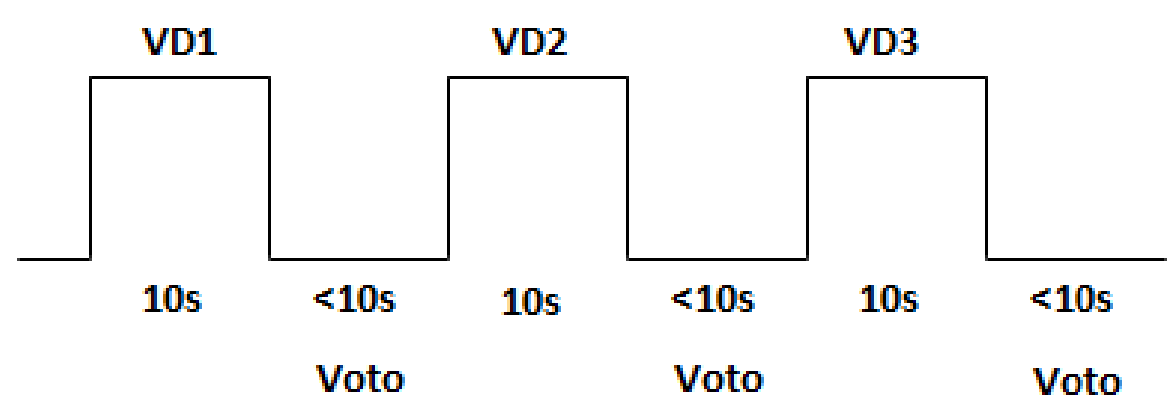

Fonte: Adaptado de (ITU-T P.910, 2008).

\subsubsection{Avaliação por Categorias de Degradação}

O método DCR, é classificado como de duplo estímulo, porque são utilizados os vídeos de referência e degradado. As sequências de vídeo podem ser reproduzidas juntas o uma seguida de outra. Pontuações são atribuídas por observadores para cada par de sequências utilizando uma escala MOS de cinco níveis como visto na Tabela 2.2.

No método DCR, os pares das sequências de vídeo de referência e degradado têm um tempo máximo de reprodução de $10 \mathrm{~s}$ para cada sequência e um intervalo de $2 \mathrm{~s}$ entre estas, o tempo para realizar a avaliação de cada par é menor que $10 \mathrm{~s}$. 
Tabela 2.2 - Escala de categorias para níveis de degradação.

\begin{tabular}{c|c}
\hline Pontuação & Níveis de Degradação \\
\hline \hline 5 & Imperceptível \\
4 & Perceptível, mas não incômoda \\
3 & Levemente incômoda \\
2 & Incômoda \\
1 & Muito incômoda \\
\hline
\end{tabular}

Fonte: Adaptado de (ITU-T P.910, 2008).

Na Figura 2.3 é apresentado o diagrama da sequência de reprodução dos vídeos com os tempos de duração de cada atividade para o método DCR.

Figura 2.3 - Diagrama da sequência de reprodução dos vídeos para o método DCR.

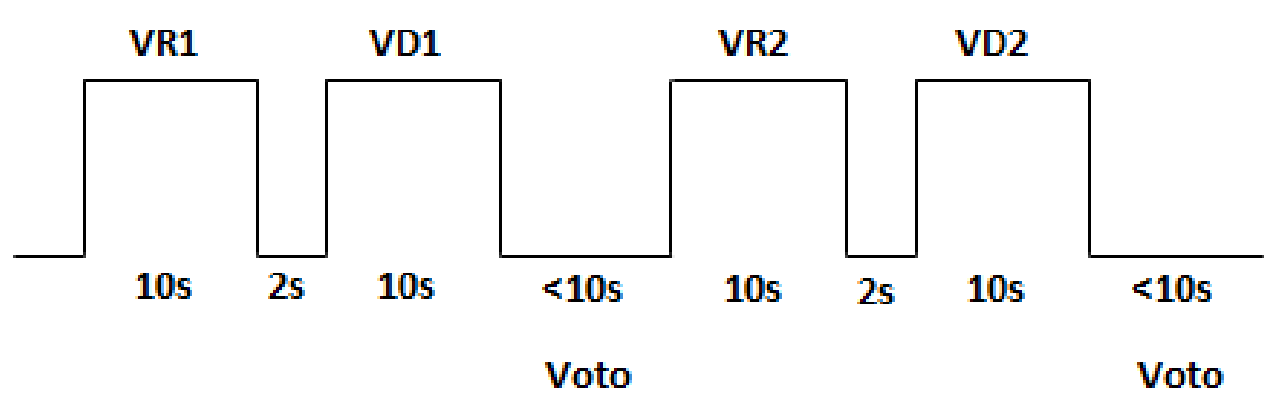

Fonte: Adaptado de (ITU-T P.910, 2008).

Existem outros métodos subjetivos descritos na recomendação ITU-R BT.500-13 (2012), que são usados na avaliação de qualidade de vídeo como o método de escala de degradação com duplo estímulo (DSIS - Double Stimulus Impairment Scale), que é muito parecido ao método DCR descrito acima. O método de avaliação de qualidade contínua de estímulo único (SSCQE - Single Stimulus Continuous Quality Scale) e o método de avaliação de qualidade contínua de duplo estímulo simultâneo (SDSCE - Simultaneous Double Stimulus for Continuous Evaluation) ambos usam uma escala de 0 a 100 com os mesmos níveis de qualidade usadas no método ACR, a diferença entre ambos métodos é o número de estímulos, sendo que o primeiro método é reproduzido um único vídeo de 20 a 30 minutos de duração que foi processado pelo sistema em teste, e no segundo método são reproduzidos ao mesmo tempo as sequências de vídeo de referência e degradado. O método de escala de qualidade contínua de duplo estímulo (DSCQS - Double Stimulus Continuous Quality Scale) é semelhante ao método DCR na execução com as diferenças que no método DSCQS os 
avaliadores não são informados sobre qual é o vídeo de referência e o vídeo degradado, e usa os níveis de qualidade e não de degradação.

Também, são descritos na recomendação ITU-T P.910 (2008) os métodos subjetivos de índices por categorias absolutas com referência oculta (ACR-HR - Absolute Category Rating with Hidden Reference) que é semelhante ao método ACR com a diferença que é incluído o vídeo de referência entre os vídeos degradados sem informar aos avaliadores da sua localização na sequência, e o método de comparação por pares (PC - Pair Comparison) que compara degradações causadas por dois sistemas diferentes para um mesmo sinal de vídeo de referência, e cada vídeo é reproduzido em série, um seguido de outro.

Nesta Tese é utilizado o método ACR por ser mais rápido em comparação com outros métodos subjetivos que avaliam a qualidade de vídeo, que usam tanto o vídeo de referência quanto o vídeo degradado.

\subsection{Métricas Objetivas}

As métricas objetivas baseiam-se em modelos matemáticos de estimação das opiniões de usuários. Tradicionalmente as métricas objetivas são classificadas em relação ao emprego ou não do sinal do vídeo de referência (WANG; SHEIKH; BOVIK, 2003), como mostrado na Figura 2.4. Tais métricas são agrupadas em três conjuntos: as métricas de Referência Completa (FR - Full Reference) são usadas quando o vídeo de referência está disponível em sua totalidade, realizando a comparação pixel a pixel entre o vídeo de referência e o vídeo recebido; as métricas de Referência Reduzida ( $\mathrm{RR}$ - Reduced Reference) são usadas quando o vídeo de referência não está completamente disponível, extraindo algumas características de ambos vídeos; e as métricas Sem Referência (NR - No Reference), também chamadas de avaliação cega, são utilizadas quando o vídeo de referência não está disponível.

Na maior parte dos casos, as métricas com sinal de referência FR apresentam uma maior complexidade computacional, mas, em compensação, são mais precisas em comparação com as métricas sem o sinal de referência NR e de referência reduzida RR. Para aplicações de transmissões em tempo real as métricas mais usadas para avaliar a qualidade são as sem referência (NR). 
Figura 2.4 - Classificação de métricas objetivas em relação à informação de referência. (a) Referência Completa, (b) Referência Reduzida e (c) Sem Referência.

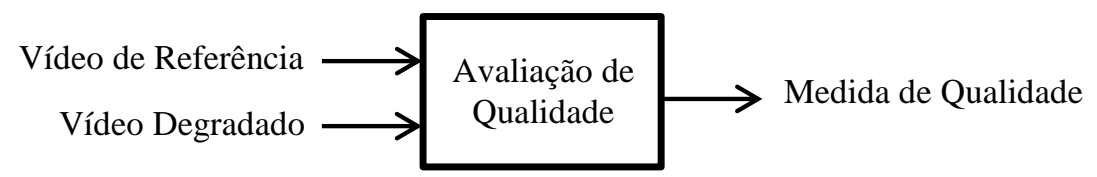

(a)

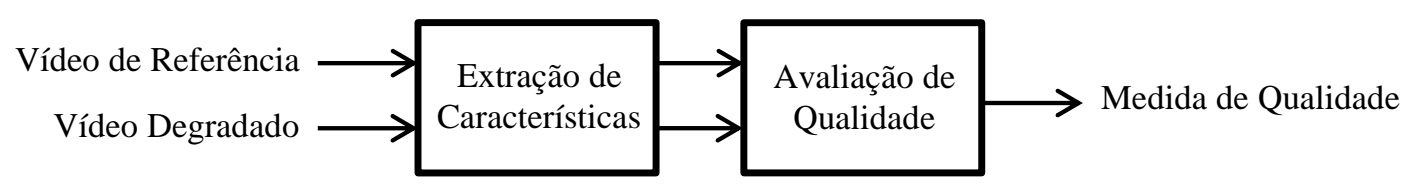

(b)

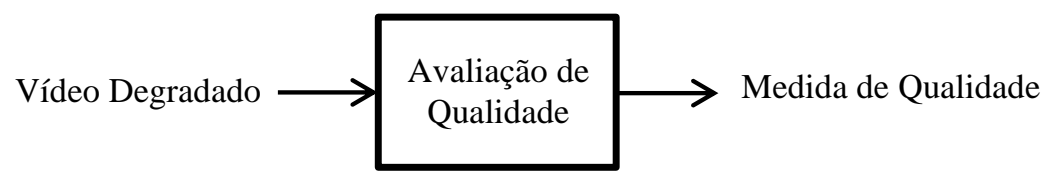

(c)

Fonte: Adaptado de (CHIKKERUR et al., 2011).

A seguir são apresentadas as métricas objetivas utilizadas nesta Tese nos seus aspectos constitutivos, sendo também comparadas com outras métricas populares.

\subsubsection{Relação Sinal-Ruído de Pico}

A relação sinal-ruído de pico (PSNR - Peak Signal to Noise Ratio) é uma métrica de referência completa (FR), baseia-se na comparação pixel a pixel para cada quadro das sequências de vídeo de referência e degradado. Define-se esta métrica como o erro quadrático tomado sobre todos os pixels por quadro dos vídeos de referência e degradado. $\mathrm{O}$ erro quadrático médio MSE (Mean Squared Error) é expresso como

$$
\text { MSE }=\frac{1}{R S T} \sum_{r=1}^{R} \sum_{s=1}^{S} \sum_{t=1}^{T}[Q(r, s, t)-\hat{Q}(r, s, t)]^{2} \text {, }
$$

em que $Q(r, s, t)$ e $\hat{Q}(r, s, t)$ representam os pixels posicionados no ponto $(r, s)$ do quadro $t$ para as sequências de referência e degradada, respectivamente. As sequências de vídeo são constituídas por $T$ quadros, de dimensões $R$ e $S$ que representam a largura e a altura, respectivamente. 
Pode ser definida em função do erro quadrático como

$$
\operatorname{PSNR}=10 \log _{10} \frac{U^{2}}{\mathrm{MSE}}
$$

em que $U$ representa o valor máximo possível dos pixels por quadro, sendo que na representação numérica de um byte de tipo sem sinal (unsigned) algébrica, $U$ é igual a 255.

A métrica PSNR é a razão tomada em decibels $(\mathrm{dB})$ e para imagens com uma profundidade de 8 bits, assume-se valores entre 0 e $55 \mathrm{~dB}$ para transporte de vídeo em redes de pacotes (BONDZULIC et al., 2016), sendo $0 \mathrm{~dB}$ o pior valor e $55 \mathrm{~dB}$ o melhor valor (BEGAZO, 2012). Estes valores são tomados como limites, em que para valores acima de 55 $\mathrm{dB}$ as sequências de vídeo são quase indistinguíveis do original, e para valores abaixo de $0 \mathrm{~dB}$ a degradação do vídeo é muito alta (GOUDARZI et al., 2010).

\subsection{2 Índice de Similaridade Estrutural}

O índice de similaridade estrutural (SSIM - Structural Similarity Index) (PINSON et al., 2004) é uma métrica de referência completa (FR), baseia-se na ideia da informação estrutural (WANG et al., 2004), em que os pixels espacialmente próximos apresentam uma forte interdependência. As mudanças percebidas na informação estrutural são consideradas como degradações nas imagens, as quais incorporam fenômenos perceptivos importantes como o mascaramento de luminância em que as distorções tornam-se pouco visíveis em regiões com brilho e, o mascaramento de contraste em que as distorções tornam-se pouco visíveis em regiões da imagem com texturas (BRUNET; VRSCAY; WANG, 2012).

Para estimar a similaridade entre os vídeos de referência e degradado, a métrica SSIM realiza comparações de três medidas em janelas pequenas de tamanho $N \times N$, para os quadros $r$ e $d$ dos vídeos de referência e degradado. As três medidas representam a luminância $l(r, d)$ expressa como

$$
l(r, d)=\frac{2 \mu_{r} \mu_{d}+C_{1}}{\mu_{r}^{2}+\mu_{d}^{2}+C_{1}},
$$

o contraste $c(r, d)$ representado por 


$$
c(r, d)=\frac{2 \sigma_{r} \sigma_{d}+C_{2}}{\sigma_{r}^{2}+\sigma_{d}^{2}+C_{2}}
$$

e a estrutura $e(r, d)$ expressa como

$$
e(r, d)=\frac{\sigma_{r d}+C_{3}}{\sigma_{r} \sigma_{d}+C_{3}}
$$

em que $\mu_{r}$ e $\mu_{d}$ são as médias dos quadros $r$ e $d$, respectivamente, $\sigma_{r}$ e $\sigma_{d}$ são os desvios padrão dos quadros $r$ e $d$, as variâncias dos quadros $r$ e $d$ são $\sigma_{r}^{2}$ e $\sigma_{d}^{2}$, respectivamente, $\sigma_{r d}$ é a covariância entre os quadros $r$ e $d$. As constantes $C_{1}, C_{2}$ e $C_{3}$ são usadas para estabilizar as equações da luminância, do contraste e da estrutura, quando o denominador tende a zero. A constante $C_{1}$ é definida como

$$
C_{1}=\left(K_{1} \cdot U\right)^{2}
$$

a constante $C_{2}$ está representada por

$$
C_{2}=\left(K_{2} \cdot U\right)^{2}
$$

e a constante $C_{3}$ é expressa como

$$
C_{3}=\frac{C_{2}}{2}
$$

em que $U$ representa o valor máximo dos pixels por quadro, sendo que para imagens em escala de cinzas é igual a $255, K_{1}$ e $K_{2}$ são valores menores que $1, K_{1}=0,01$ e $K_{2}=0,03$. A métrica SSIM é expressa como

$$
\operatorname{SSIM}(r, d)=[l(r, d)]^{\alpha} \cdot[c(r, d)]^{\beta} \cdot[e(r, d)]^{\gamma},
$$

em que $\alpha, \beta$ e $\gamma$ representam os parâmetros que definem a importância relativa dos componentes de luminância, contraste e estrutura, respectivamente. Para $\alpha, \beta$ e $\gamma$ iguais a 1 , chega-se a

$$
\operatorname{SSIM}(r, d)=\frac{\left(2 \mu_{r} \mu_{d}+C_{1}\right)\left(2 \sigma_{r d}+C_{2}\right)}{\left(\mu_{r}^{2}+\mu_{d}^{2}+C_{1}\right)\left(\sigma_{r}^{2}+\sigma_{d}^{2}+C_{2}\right)}
$$

A métrica SSIM assume valores de 0 a 1 , sendo 0 o pior valor e 1 o melhor valor. 


\subsubsection{Modelo de Qualidade de Vídeo}

O modelo de qualidade de vídeo (VQM - Video Quality Model) é uma métrica de referência completa (FR). Esta métrica está descrita na recomendação ITU-T J.144 (2004) como uma técnica objetiva de avaliação de qualidade de vídeo perceptual. A métrica VQM está representada por quatro fases (PINSON et al., 2004).

$\mathrm{Na}$ fase de calibração, o vídeo degradado é calibrado através de deslocamentos espaço temporais, de contraste e de brilho para comparar os vídeos de referência e degradado.

$\mathrm{Na}$ fase de extração de características, extraem-se as características de qualidade de subregiões espaço temporais das sequências de vídeo de referência e degradado. Esta fase está constituída por quatro passos, no primeiro passo é usado um filtro perceptual para realçar as características de qualidade dos vídeos. No segundo passo, dividem-se as sequências de vídeo em sub-regiões espaço temporais representadas pelos blocos $b(s, t)$. No terceiro passo, extraem-se as características dos vídeos de referência $f_{r}(s, t)$ e degradado $f_{d}(s, t)$ de cada um dos blocos $b(s, t)$ usando a média e o desvio padrão. O número de amostras é igual ao número de quadros dividido pela extensão temporal dos blocos $b(s, t)$. No quarto passo é aplicada uma função de corte para reduzir a sensibilidade das degradações imperceptíveis, expressa como

$$
f_{\text {clip }}=\left\{\begin{array}{cccc}
\max (f, T) & \text { para } & f & \text { positivo } \\
\min (f, T) & \text { para } & f & \text { negativo }
\end{array}\right.
$$

em que $f$ e $f_{\text {clip }}$ são as características antes e depois do corte, respectivamente, e $T$ é o limiar de corte.

$\mathrm{Na}$ fase de estimação de parâmetros de qualidade, calculam-se os parâmetros de qualidade $p(s, t)$ através da comparação das características extraídas das sequências de vídeo de referência $f_{r}(s, t)$ e degradado $f_{d}(s, t)$. O parâmetro de qualidade $q(s, t)$ é representado como

$$
q(s, t)=\log _{10} \frac{f_{d}(s, t)}{f_{r}(s, t)} .
$$


Na fase de estimação de qualidade da métrica, calcula-se a métrica de qualidade através de uma combinação linear dos parâmetros calculados na fase anterior. A métrica VQM é expressa como

$$
\begin{aligned}
\mathrm{VQM}= & -0,2097 P_{a}+0,5969 P_{b}+0,2483 P_{c}+0,0192 P_{d}-2,3416 P_{e} \\
& +0,0431 P_{f}+0,0076 P_{g},
\end{aligned}
$$

em que $P_{a}$ é a perda da informação espacial, $P_{b}$ é a perda ocasionada pelo desfoque nas orientações horizontal e vertical, $P_{c}$ é a perda ocasionada pelo efeito de bloco nas diagonais horizontal e vertical, $P_{d}$ é a perda ocasionada pela degradação das cores, $P_{e}$ é o ganho obtido com as melhorias em nitidez, $P_{f}$ é a perda ocasionada pelo ruído, e $P_{g}$ é a perda ocasionada pela degradação localizada das cores.

A métrica VQM assume valores de 0 a 1 , sendo 0 o melhor valor e 1 o pior valor.

\subsubsection{Fusão de Avaliação de Vários Métodos de Vídeo}

A métrica VMAF (Visual Multimethod Assessment Fusion) (LI et al., 2016) foi projetada utilizando a técnica de aprendizado de máquina chamada de máquina de vetores de suporte SVM (Support Vector Machine), que é usada na modelagem da percepção humana da qualidade de vídeo. Esta métrica é de referência completa (FR) porque realiza a fusão três métricas de qualidade da mesma classificação. Cada métrica individual tem pontos fortes e pontos fracos na estimação de qualidade de vídeo, dependendo do tipo de degradação. Na fusão são atribuídos pesos para cada uma através do regressor SVM, com o intuito de manter os seus pontos fortes na métrica resultante da fusão. A SVM é treinada e testada usando as opiniões obtidas através da avaliação subjetiva prévia.

Entre as métricas que são utilizadas na fusão feita pelo regressor SVM temos a VIF (Visual Information Fidelity), que realiza a fusão da quantificação da perda de informação em uma imagem com distorção e da quantificação da informação da imagem de referência sem distorção (SHEIKH; BOVIK, 2006). A métrica VIF é expressa como a fusão das perdas de fidelidade de quatro escalas, mas a métrica VMAF considera cada perda de fidelidade como uma métrica individual. Outra métrica que compõe a VMAF é a DLM (Detail Loss Metric), que avalia separadamente as perdas de detalhes e as degradações aditivas que afetam o conteúdo visual e distraem a atenção do observador (LI et al., 2011). Adicionalmente, a 
característica Motion é a última métrica que compõe a VMAF e foi inserida com o intuito de incorporar a característica temporal de vídeo, que é obtida da diferença entre pixels correspondentes de quadros consecutivos.

A métrica VMAF assume valores de 0 a 100, sendo 0 o pior valor e 100 o melhor valor.

\subsubsection{Avaliação Cega de Qualidade de Imagens}

BRISQUE (Blind/Referenceless Image Spatial Quality Evaluator) (MITTAL et al., 2011) é uma métrica sem referência (NR) baseada em estatísticas de cenas ou imagens naturais. Entende-se por imagem natural como as imagens capturadas por câmeras óticas e sem processamento realizado através do computador. Esta métrica usa os coeficientes de luminância normalizados no domínio espacial e os produtos em pares dos coeficientes de luminância normalizados adjacentes os quais fornecem informação da orientação da distorção. Estes coeficientes são chamados de MSCN (Mean Subtracted Contrast Normalized).

Os coeficientes de luminância, podem ser representados em relação à intensidade da imagem $\mathrm{I}(i, j)$, são obtidos a partir da expressão

$$
\hat{\mathrm{I}}(i, j)=\frac{\mathrm{I}(i, j)-\mu(i, j)}{\sigma(i, j)+C},
$$

em que $i$ e $j$ são índices espaciais que assumem valores de 1 até $M$, e de 1 até $N$, respectivamente, sendo $M$ a altura da imagem e $N$ a largura da imagem, a constante $C$ é igual a 1 ,

$$
\mu(i, j)=\sum_{k=-K}^{K} \sum_{l=-L}^{L} w_{k, l} I_{k, l}(i, j)
$$

e

$$
\sigma(i, j)=\sqrt{\sum_{k=-K}^{K} \sum_{l=-L}^{L} w_{k, l}\left(I_{k, l}(i, j)-\mu(i, j)\right)^{2}},
$$

em que $w$ é o filtro gaussiano circularmente simétrico, e $K$ e $L$ assumem o valor de 3. 
Os coeficientes MSCN têm propriedades estatísticas específicas que são perturbadas pela distorção e através da modelagem destes é possível predizer o tipo e grau de distorção (MITTAL et al., 2012). A distorção é quantizada usando uma distribuição AGGD (Asymmetric Generalized Gaussian Model) para ajustar as estatísticas de MSCN das imagens de referência e das imagens com distorção, sendo que para cada imagem tem-se dois parâmetros, que formam o primeiro conjunto de características. Uma vez os coeficientes MSCN são homogêneos, obtém-se uma estrutura regular. Para quantificar a dependência entre vizinhos, é realizado a modelagem de relações direcionais através dos produtos em pares dos coeficientes MSCN adjacentes com uma distância de 1 pixel ao longo de quatro orientações, a horizontal $H$ representada por

$$
H(i, j)=\operatorname{MSCN}(i, j) \times \operatorname{MSCN}(i,(j+1) \times \bmod N),
$$

a vertical expressa como

$$
V(i, j)=\operatorname{MSCN}(i, j) \times \operatorname{MSCN}((i+1) \times \bmod M, j),
$$

a diagonal principal $P$ definida como

$$
P(i, j)=\operatorname{MSCN}(i, j) \times \operatorname{MSCN}((i+1) \times \bmod M,(j+1) \times \bmod N),
$$

e a diagonal secundária $S$ representada por

$$
S(i, j)=\operatorname{MSCN}(i, j) \times \operatorname{MSCN}((i+1) \times \bmod M,(j-1) \times \bmod N),
$$

As distribuições destes coeficientes são parametrizadas para ser usadas como características estatísticas obtendo resultados correlacionados com os resultados das avaliações subjetivas para as imagens. As distribuições dos produtos em pares são parametrizadas usando AGGD, para utilizar a média destas (MITTAL et al., 2011).

A métrica BRISQUE assume valores de 0 a 100, sendo 0 o melhor valor e 100 o pior valor. 


\subsubsection{Avaliação de Qualidade de Imagens pela Naturalidade}

NIQE (Naturalness Image Quality Evaluator) (MITTAL et al., 2013) é uma métrica sem referência (NR) e é baseada na construção de características estatísticas de qualidade através de um modelo estatístico simples de uma imagem natural no domínio espacial. Esta métrica não está vinculada a nenhum tipo de distorção específica. A métrica NIQE usa o mesmo préprocessamento da imagem usado na métrica BRISQUE, em que os coeficientes de luminância são definidos em (2.14), para valores de

$$
\mu(i, j)=\sum_{k=-K}^{K} \sum_{l=-L}^{L} w_{k, l} I_{k, l}(i+k, j+l),
$$

$\mathrm{e}$

$$
\sigma(i, j)=\sqrt{\sum_{k=-K}^{K} \sum_{l=-L}^{L} w_{k, l}\left[\left(I_{k, l}(i+k, j+l)-\mu(i, j)\right)^{2}\right]}
$$

em que $w$ é o filtro gaussiano circularmente simétrico, e $K$ e $L$ assumem o valor de 3.

Em seguida, a imagem é dividida em fragmentos do mesmo tamanho para ser usadas na construção do modelo gaussiano multivariado, sendo que não todos os fragmentos são utilizados devido à ausência de distorções específicas geradas pela nitidez. $\mathrm{O}$ valor da nitidez é obtido a partir da suma dos desvios padrões $\sigma(i, j)$ de cada fragmento. Na seleção de fragmentos, usa-se um valor de pico $p$ de 0,75 como o menor valor possível para a nitidez.

A métrica NIQE usa o mesmo modelo gaussiano AGGD usado na métrica BRISQUE, para parametrizar as distribuições dos produtos em pares dos coeficientes adjacentes do modelo natural. Também, usa-se um modelo gaussiano multivariado (MVG - Multivariate Gaussian Model) (MITTAL et al., 2013) para a construção das características estatísticas de qualidade extraídas da imagem com distorção.

Finalmente, a métrica NIQE é expressa como a distância entre as características estatísticas do modelo natural e as características estatísticas da imagem com distorção obtidas do modelo MVG. A métrica NIQE é expressa com 


$$
D\left(v_{1}, v_{2}, c_{1}, c_{2}\right)=\sqrt{\left(v_{1}-v_{2}\right)^{T}\left(\frac{c_{1}+c_{2}}{2}\right)^{-1}\left(v_{1}-v_{2}\right)}
$$

em que $v_{1}$ e $v_{2}$ são os vetores da média, e $c_{1}$ e $c_{2}$ são as matrizes de covariância do modelo natural e do modelo MVG .

A principal vantagem da métrica NIQE é que não requer dados de treinamento com avaliações subjetivas. Em vez disso, o modelo é feito através de características construídas a partir de um grupo de imagens naturais não distorcidas.

\subsection{Outra classificação de métricas objetivas}

Atualmente, as métricas objetivas de qualidade de imagem e de vídeo são classificadas em dois grupos de acordo com a tarefa a ser desempenhada (WINKLER, 2008), como visto na Figura 2.5. No primeiro grupo, usam-se as métricas para a análise de vídeo decodificado, e esta composta pelas métricas de dados e as métricas de imagem.

Figura 2.5 - Classificação de métricas objetivas de acordo com a tarefa a ser desempenhada.
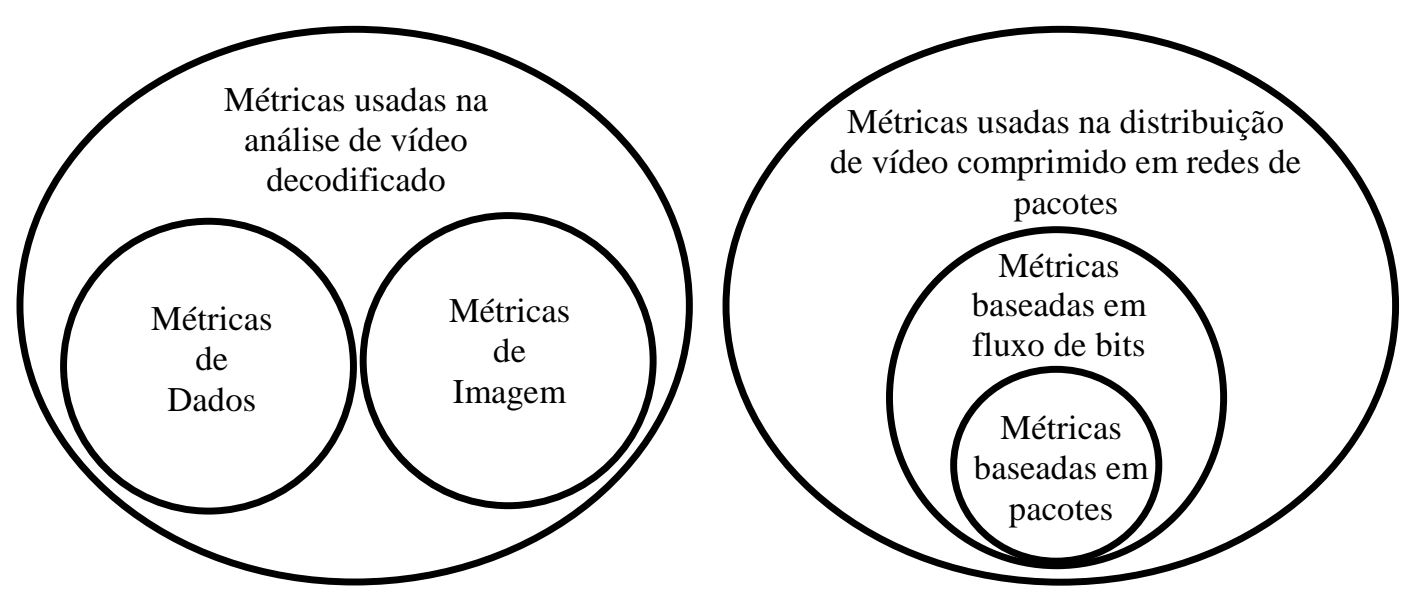

Fonte: Adaptado de (WINKLER, 2008).

As métricas de dados avaliam a qualidade do sinal de vídeo sem considerar os parâmetros de informação visual usados pelos observadores na avaliação perceptual. Estas métricas comparam os dados pixel por pixel entre os quadros do vídeo de referência e do vídeo degradado, sem considerar a relação espacial entre pixels. As principais vantagens destas 
métricas são a simplicidade na implementação e a rapidez na execução. Entre as métricas de dados mais utilizadas temos a MSE (Mean Squared Error) e a PSNR.

As métricas de imagem avaliam a qualidade do sinal de vídeo considerando os parâmetros do comportamento da visão humana como a sensibilidade à luminância e ao contraste (WINKLER, 2005). Por outro lado, são usadas as características específicas dos elementos que formam a estrutura da imagem como as bordas e os contornos, e as distorções específicas como o efeito de bloco (blockiness) e o efeito de desfoque (blur). A SSIM e a VQM são as métricas de imagem mais usadas para avaliação de qualidade de vídeo.

No segundo grupo, estão agrupadas as métricas usadas na distribuição de vídeo comprimido em redes de pacotes, e está constituído pelas métricas baseadas em pacotes e em fluxo de bits (bitstream). Estas métricas surgiram pela necessidade de avaliar a qualidade de vídeo em redes de pacotes sem a necessidade de decodificar completamente o sinal de vídeo, e são baseadas em parâmetros extraídos do fluxo de bits como vetores de movimento, ou do fluxo de transporte como informação dos cabeçalhos dos pacotes. Entende-se por fluxo de bits como o sinal de vídeo codificado, e por fluxo de transporte como o sinal de vídeo codificado encapsulada em pacotes (VERSCHEURE et al., 1999).

Figura 2.6 - Composição das Métricas Híbridas.

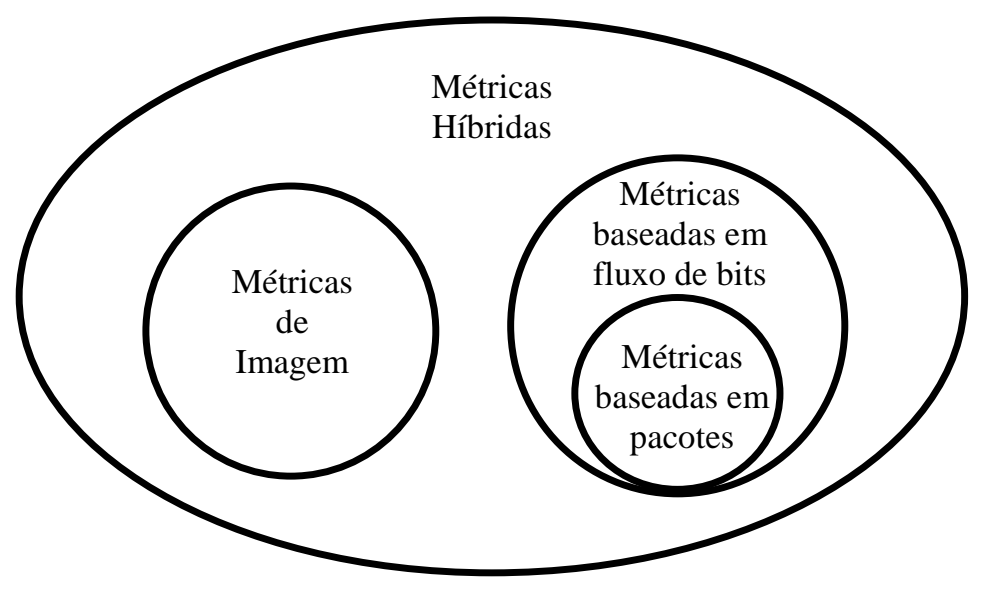

Fonte: Adaptado de (WINKLER, 2008).

Também, as métricas descritas acima são combinadas resultando em uma nova classe que agrupa as métricas híbridas porque usam a combinação dos parâmetros extraídos dos fluxos de bits e de transporte junto com os parâmetros do vídeo decodificado das métricas de imagem, como representada na Figura 2.6. A principal vantagem destas métricas é a menor 
complexidade computacional em comparação com as métricas que extraem características do vídeo decodificado.

\subsection{Considerações finais}

A avaliação subjetiva e a avaliação objetiva são complementares e são utilizadas nos processos de validação e de operação, respectivamente.

$\mathrm{Na}$ avaliação de qualidade de vídeo para serviços de transporte de vídeo em tempo real as métricas sem referência (NR) são as mais usadas porque não requerem o vídeo de referência para estimar a qualidade e porque apresentam uma menor complexidade computacional, adequando-se aos requisitos desde tipo de serviço.

Também, as métricas híbridas são usadas em serviços de transporte de vídeo, porque estimam a qualidade de vídeo a partir da informação do vídeo decodificado, do fluxo de bits e dos pacotes. Estas métricas apresentam menor complexidade computacional porque usam informação específica do vídeo decodificado.

Além disso, usam-se métricas FR na avaliação de qualidade de vídeo para serviços de transporte, que combinam ou realizam a fusão de outras métricas individuais FR, cada uma com resultados diferentes na estimação de qualidade em relação ao tipo de degradação, sendo que ao ser combinadas mantém-se os pontos fortes de cada métrica individual FR cada uma. 


\section{PROJETO DE MÉTRICAS DE QUALIDADE DE VÍDEO}

Neste capítulo, propõem-se duas métricas uma sem referência (NR) e outra com referência completa (FR), sendo ambas desenvolvidas através de algoritmos de treinamento.

A métrica NR baseia-se em um único parâmetro de transmissão e é treinada com condições sobre o seu comportamento no domínio de variação deste parâmetro, que são incorporadas ao treinamento através de multiplicadores de Lagrange. No caso as condições são de suavidade da função de qualidade, que assume a forma de uma spline cúbica.

Por outro lado, a métrica FR é proposta como uma função de dois parâmetros baseados nos quadros das sequências de vídeo de referência e degradada. Tendo em vista o comportamento da qualidade em função dos parâmetros de vídeo, optou-se por um polinômio completo de segundo grau de duas variáveis como base para a função de qualidade. Como parâmetros de vídeo optou-se por duas métricas FR populares, que são a PSNR e a SSIM. Esta métrica é treinada para a minimização do erro quadrático sem condições adicionais.

Além disso, os dois processos de treinamento particionam a base de dados em $K$ subconjuntos para proceder a $k$ subprocessos de treinamento em que alternativamente cada subconjunto é usado para validação, e a união dos subconjuntos restantes é usada para treinamento.

\subsection{Função de estimação de qualidade para métrica NR}

A relação entre o fator de degradação de rede PDV e a qualidade dos vídeos recebidos está dividida em três regiões, a primeira região correspondente a qualidade alta e PDV baixo e, a segunda região correspondente a baixa qualidade e alto PDV, sendo que ambas regiões estão conectadas por uma terceira região de transição correspondente a qualidade média e PDV médio. (BEGAZO, 2016), como visto na Figura 3.1. 
Figura 3.1 - Efeito do fator de degradação PDV sobre a qualidade de vídeo avaliada usando o método ACR.

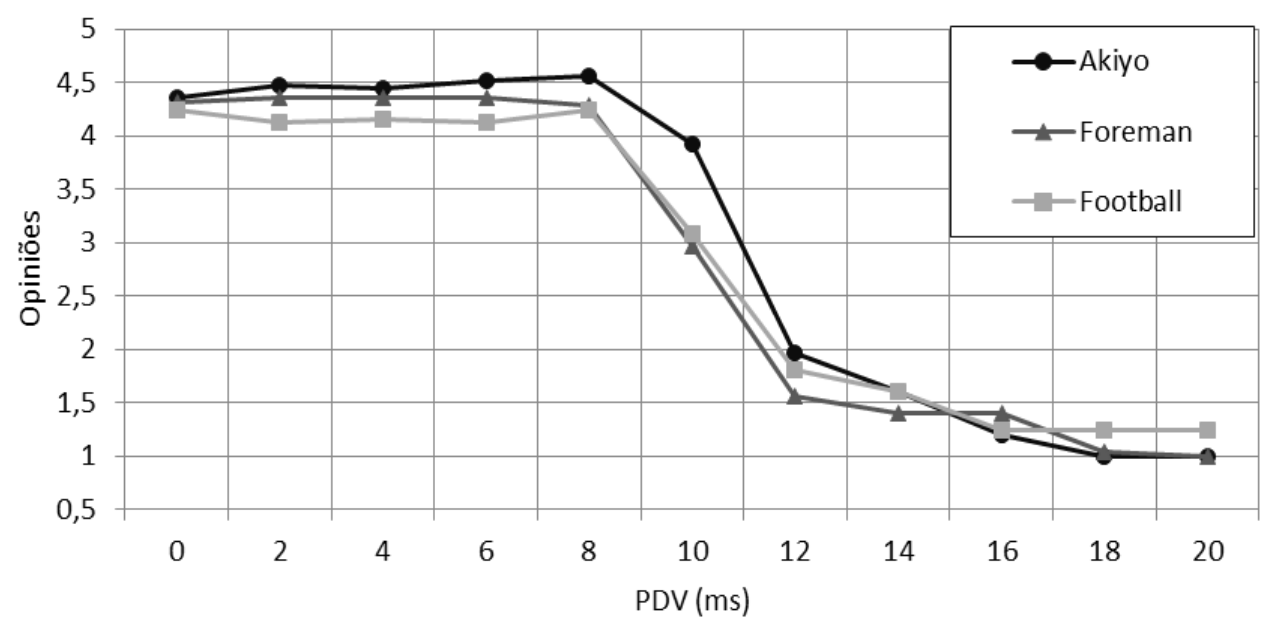

Fonte: Autor.

Para representar a função de estimação de qualidade não foram utilizados polinômios de alto grau devido a sua natureza oscilatória, esta ocorrência que produz erros na estimação, motivo pelo qual o seu uso é restringido, como será visto no Capítulo 5.

Para modelar o comportamento da qualidade em função do PDV, propõe-se o modelo estatístico da spline cúbica, que está composta por polinômios cúbicos de terceiro grau unidos por um nó, formando no conjunto uma função contínua com uma interseção suave e imperceptível (REINSCH, 1967), (SCHOENBERG, 1964), ou seja, a junção dos polinômios não é vista, devido que no nó as derivadas dos polinômios cúbicos que formam a spline são nulas (DE BOOR, 1978). Além disso, na spline cúbica cada polinômio é mais restrito permitindo que as curvas que representam cada polinômio sejam diferentes entre si, por conseguinte, não apresenta uma natureza oscilatória ou flutuante (HAMMING, 1986). Cabe ressaltar que as splines cúbicas são utilizadas amplamente na estimação de funções pela sua característica adaptativa e por ser mais eficientes computacionalmente (GREEN; SILVERMAN, 1994).

A seguir é descrito o algoritmo de minimização do erro quadrático entre a função de estimação de qualidade $\hat{y}(x)$ e as opiniões em relação à variável $x$ que é a variação de atraso 
de pacotes (PDV). Constrói-se uma função objetiva incluindo os desvios quadráticos e as condições, que são inseridas por intermédio de multiplicadores de Lagrange. Usa-se um método variacional para obter equações lineares nos coeficientes da função de estimação de qualidade.

A função de estimação de qualidade $\hat{y}(x)$ é definida por dois polinômios cúbicos com um ponto de interseção, chamado de nó, cuja abscissa é $x=\xi$. O polinômio à esquerda do nó $\xi$ é

$$
p_{e}(x)=\sum_{i=0}^{3} a_{i} x^{i}
$$

e o polinômio à direita do nó $\xi$ é

$$
p_{d}(x)=\sum_{i=0}^{3} b_{i} x^{i},
$$

em que $a_{i}$ e $b_{i}$ são os coeficientes dos dois polinômios cúbicos para $i=0,1,2,3$, sendo que $\boldsymbol{a}=\left[\begin{array}{llll}a_{0} & a_{1} & a_{2} & a_{3}\end{array}\right]^{T}$ e $\boldsymbol{b}=\left[\begin{array}{llll}b_{0} & b_{1} & b_{2} & b_{3}\end{array}\right]^{T}$ são os vetores que contêm esses coeficientes. Por vezes será interessante considerar todos os coeficientes juntos em um único vetor $\boldsymbol{c}=\left[\begin{array}{l}\boldsymbol{a} \\ \boldsymbol{b}\end{array}\right]$.

Nosso problema será a determinação do conjunto de parâmetros $\boldsymbol{\Psi}=\{\boldsymbol{a}, \boldsymbol{b}, \xi\}$ da função de estimação de qualidade.

Para construir a função objetiva é conveniente utilizar uma combinação linear das funções de potência truncadas à direita, expressas como

$$
e_{i}(x)=\left\{\begin{aligned}
x^{i}, & \text { para } x \leq \xi \\
0, & \text { para } x>\xi
\end{aligned}\right.
$$

associadas ao polinômio da esquerda, sendo que $i=0,1,2,3$, e às funções de potência truncadas à esquerda, expressas como

$$
d_{i}(x)=\left\{\begin{array}{c}
0, \quad \text { para } x<\xi \\
x^{i}, \quad \text { para } x \geq \xi
\end{array},\right.
$$

associadas ao polinômio da direita, sendo que $i=0,1,2,3$. 
Assim, pode-se representar a função de combinação linear das potências truncadas à direita como

$$
\hat{y}_{e}(x)=\sum_{i=0}^{3} a_{i} e_{i}(x)
$$

e a função de combinação linear das potências truncadas à esquerda como

$$
\hat{y}_{d}(x)=\sum_{i=0}^{3} b_{i} d_{i}(x)
$$

Portanto, a nossa função de estimação de qualidade está definida por

$$
\hat{y}(x)=\hat{y}_{e}(x)+\hat{y}_{d}(x)
$$

$\mathrm{Na}$ fase de treinamento, tomam-se os pontos de treino $\left(x_{n}, y_{n}\right)$, ordenados em ordem crescente de $x_{n}$, para $n=0,1, \ldots, N-1$, em que $x_{n}$ é o valor da variável de controle, neste caso a variação de atraso de pacotes, e $y_{n}$ é a opinião do observador nessa condição. Para esses valores da variável de controle, determinam-se algebricamente os valores correspondentes da função de qualidade, que ficam dados em função dos parâmetros $\boldsymbol{c}$. Dessa forma, a diferença entre a função de qualidade e as opiniões é definida como

$$
\delta\left(x_{n}\right)=\hat{y}\left(x_{n}\right)-y_{n}
$$

Substituindo a função de qualidade pelas funções de potência truncada à direita e à esquerda, obtém-se

$$
\delta\left(x_{n}\right)=\sum_{i=0}^{3} a_{i} e_{i}(x)+\sum_{i=0}^{3} b_{i} d_{i}(x)-y_{n}
$$

Assim, o erro quadrático total pode-se escrever em função do desvio $\delta\left(x_{n}\right)$ como

$$
\varepsilon(\boldsymbol{c})=\sum_{n=0}^{N-1}\left(\delta\left(x_{n}\right)\right)^{2}
$$

Definindo o índice $M$ tal que $x_{M} \leq \xi$ e $x_{M+1}>\xi$, podemos separar em dois vetores os valores de $x_{n}$, no vetor $\boldsymbol{x}_{\boldsymbol{u}}$ conformado por $M$ valores que correspondem ao polinômio da esquerda, e no vetor $\boldsymbol{x}_{\boldsymbol{d}}$ conformado pelos restantes $N-M$ valores que correspondem ao 
polinômio da direita. Assim, os valores da variável de controle são expressas, em um único vetor, como $x=\left[\begin{array}{l}x_{u} \\ x_{d}\end{array}\right]$.

$\mathrm{O}$ vetor das opiniões está representado como $\boldsymbol{y}=\left[\begin{array}{ll}y\left(x_{0}\right) & y\left(x_{1}\right) \ldots y\left(x_{N-1}\right)\end{array}\right]^{T}$. Da mesma forma que o vetor $\boldsymbol{x}$ é obtido, define-se o vetor das opiniões como $\boldsymbol{y}=\left[\begin{array}{l}\boldsymbol{y}_{\boldsymbol{u}} \\ \boldsymbol{y}_{\boldsymbol{d}}\end{array}\right]$, sendo que o vetor $\boldsymbol{y}_{\boldsymbol{u}}$ corresponde às opiniões do polinômio da esquerda, e o vetor $\boldsymbol{y}_{\boldsymbol{d}}$ corresponde às opiniões do polinômio da direita.

Os valores hipotéticos da função de estimação de qualidade são designados por $\hat{y}\left(x_{n}\right)$ e agrupados no vetor $\hat{\boldsymbol{y}}=\left[\hat{y}\left(x_{0}\right) \hat{y}\left(x_{1}\right) \ldots \hat{y}\left(x_{N-1}\right)\right]^{T}$. Para representá-los, tomam-se nos pontos de treino os valores das funções de potência truncadas à direita representados na matriz $\boldsymbol{X}_{\boldsymbol{u}}$ como

$$
\boldsymbol{X}_{\boldsymbol{u}}=\left[\begin{array}{cccc}
1 & x_{0} & x_{0}^{2} & x_{0}^{3} \\
1 & x_{1} & x_{1}^{2} & x_{1}^{3} \\
\vdots & \vdots & \vdots & \vdots \\
1 & x_{M} & x_{M}^{2} & x_{M}^{3}
\end{array}\right]
$$

e os valores das funções de potência truncadas à esquerda representados na matriz $\boldsymbol{X}_{\boldsymbol{d}}$ como

$$
\boldsymbol{X}_{\boldsymbol{d}}=\left[\begin{array}{cccc}
1 & x_{M+1} & x_{M+1}^{2} & x_{M+1}^{3} \\
1 & x_{M+2} & x_{M+2}^{2} & x_{M+2}^{3} \\
\vdots & \vdots & \vdots & \vdots \\
1 & x_{N-1} & x_{N-1}^{2} & x_{N-1}^{3}
\end{array}\right]
$$

Considerando as matrizes $\boldsymbol{X}_{\boldsymbol{u}}$ e $\boldsymbol{X}_{\boldsymbol{d}}$, são definidas as matrizes $\boldsymbol{E}$ e $\boldsymbol{D}$ que representam os valores de potência truncadas à direita e à esquerda, respectivamente, para todos os valores de $x_{n}$, sendo a matriz $\boldsymbol{E}$ dada por

$$
\boldsymbol{E}=\left[\begin{array}{l}
\boldsymbol{X}_{\boldsymbol{u}} \\
\mathbf{0}_{(N-M) \times 4}
\end{array}\right]
$$

e a matriz $\boldsymbol{D}$ expressa como

$$
\boldsymbol{D}=\left[\begin{array}{l}
\mathbf{0}_{M \times 4} \\
\boldsymbol{X}_{\boldsymbol{d}}
\end{array}\right]
$$

Portanto, o desvio $\delta\left(x_{n}\right)$ de (3.9) pode ser expresso em forma matricial como

$$
\boldsymbol{\delta}=\boldsymbol{E} \boldsymbol{a}+\boldsymbol{D} \boldsymbol{b}-\boldsymbol{y}
$$


e o erro quadrático total como

$$
\varepsilon(\boldsymbol{c})=\boldsymbol{\delta}^{T} \boldsymbol{\delta} .
$$

Substituindo o vetor de desvios $\boldsymbol{\delta}$ na expressão do erro quadrático total e expandindo esta forma quadrática, chega-se a

$$
\begin{aligned}
\varepsilon(\boldsymbol{c}) & =\boldsymbol{a}^{T} \boldsymbol{E}^{T} \boldsymbol{E} \boldsymbol{a}+\boldsymbol{a}^{T} \boldsymbol{E}^{T} \boldsymbol{D} \boldsymbol{b}-\boldsymbol{a}^{T} \boldsymbol{E}^{T} \boldsymbol{y}+\boldsymbol{b}^{T} \boldsymbol{D}^{T} \boldsymbol{E} \boldsymbol{a}+\boldsymbol{b}^{T} \boldsymbol{D}^{T} \boldsymbol{D} \boldsymbol{b}-\boldsymbol{b}^{T} \boldsymbol{D}^{T} \boldsymbol{y} \\
& -\boldsymbol{y}^{T} \boldsymbol{E} \boldsymbol{a}-\boldsymbol{y}^{T} \boldsymbol{D} \boldsymbol{b}+\boldsymbol{y}^{T} \boldsymbol{y},
\end{aligned}
$$

em que os termos com os produtos de matrizes $\boldsymbol{E}^{T} \boldsymbol{D}=\left[\begin{array}{l}\boldsymbol{X}_{\boldsymbol{u}} \\ \mathbf{0}_{(N-M) \times 4}\end{array}\right]^{\boldsymbol{T}}\left[\begin{array}{l}\mathbf{0}_{M \times 4} \\ \boldsymbol{X}_{\boldsymbol{d}}\end{array}\right]$ e $\boldsymbol{D}^{T} \boldsymbol{E}=\left[\begin{array}{l}\mathbf{0}_{M \times 4} \\ \boldsymbol{X}_{\boldsymbol{d}}\end{array}\right]^{\boldsymbol{T}}\left[\begin{array}{l}\boldsymbol{X}_{\boldsymbol{u}} \\ \mathbf{0}_{(N-M) \times 4}\end{array}\right]$ são nulos e iguais à matriz $\left[\mathbf{0}_{4 \times 4}\right]$. Além disso, os termos $\boldsymbol{a}^{T} \boldsymbol{E}^{T} \boldsymbol{y}$ e $\boldsymbol{y}^{T} \boldsymbol{E} \boldsymbol{a}$ são iguais porque a transposta de um escalar é o próprio escalar. A mesma propriedade é aplicada aos termos $\boldsymbol{b}^{T} \boldsymbol{D}^{T} \boldsymbol{y}$ e $\boldsymbol{y}^{T} \boldsymbol{D} \boldsymbol{b}$.

Simplificando a expressão do erro quadrático, obtém-se

$$
\varepsilon(\boldsymbol{c})=\boldsymbol{a}^{T} \boldsymbol{E}^{T} \boldsymbol{E} \boldsymbol{a}+\boldsymbol{b}^{T} \boldsymbol{D}^{T} \boldsymbol{D} \boldsymbol{b}-2 \boldsymbol{a}^{T} \boldsymbol{E}^{T} \boldsymbol{y}-2 \boldsymbol{b}^{T} \boldsymbol{D}^{T} \boldsymbol{y}+\boldsymbol{y}^{T} \boldsymbol{y} .
$$

Definindo a matriz de correlação entre os valores de potência truncadas à direita e à esquerda como

$$
\boldsymbol{\Phi}=\left[\begin{array}{ll}
\boldsymbol{E}^{T} \boldsymbol{E} & \mathbf{0}_{4 \times 4} \\
\mathbf{0}_{4 \times 4} & \boldsymbol{D}^{T} \boldsymbol{D}
\end{array}\right]
$$

e o vetor de correlação cruzada entre os valores de potência truncadas e as opiniões como

$$
\boldsymbol{\theta}=\left[\begin{array}{l}
\boldsymbol{E}^{T} \\
\boldsymbol{D}^{T}
\end{array}\right] \boldsymbol{y}
$$

obtemos a expressão matricial do erro quadrático

$$
\varepsilon(\boldsymbol{c})=\boldsymbol{c}^{T} \boldsymbol{\Phi} \boldsymbol{c}-2 \boldsymbol{c}^{T} \boldsymbol{\theta}+\boldsymbol{y}^{T} \boldsymbol{y} .
$$

O encontro mais suave dos polinômios acontece na situação de osculação. As condições para essa situação são as igualdades de todas as derivadas não trivialmente nulas dos dois polinômios no nó $\xi$

$$
\hat{y}_{e}^{(m)}(\xi)=\hat{y}_{d}^{(m)}(\xi)
$$


para $m=0,1,2$ que representa a ordem da derivada.

Para realizar a minimização da função objetiva $\varepsilon(\boldsymbol{c})$ sujeita à condição $g(x)=0$ inserida pelos multiplicadores de Lagrange $\lambda$, é usado o lagrangiano

$$
J(\boldsymbol{c}, \lambda)=\varepsilon(\boldsymbol{c})+\lambda g(\boldsymbol{c}) .
$$

Nesse caso, temos as três condições definidas em (3.22), resultando no lagrangiano

$$
J(\boldsymbol{c}, \lambda)=\varepsilon(\boldsymbol{c})+\sum_{m=0}^{2} \lambda_{m+1}\left(\hat{y}_{d}^{(m)}(\xi)-\hat{y}_{e}^{(m)}(\xi)\right)
$$

Resolvendo as derivadas de ordem $m=0,1,2$ para os correspondentes polinômios da esquerda e da direita no nó $\xi$, obtemos

$$
\begin{gathered}
J(\boldsymbol{c}, \lambda)=\varepsilon(\boldsymbol{c})+\lambda_{1}\left(b_{0}+\xi b_{1}+\xi^{2} b_{2}+\xi^{3} b_{3}-a_{0}-\xi a_{1}-\xi^{2} a_{2}-\xi^{3} a_{3}\right) \\
+\lambda_{2}\left(b_{1}+2 \xi b_{2}+3 \xi^{2} b_{3}-a_{1}-2 \xi a_{2}-3 \xi^{2} a_{3}\right) \\
+\lambda_{3}\left(2 b_{2}+6 \xi b_{3}-2 a_{2}-6 \xi a_{3}\right) .
\end{gathered}
$$

Para representar os multiplicadores de Lagrange e as condições em forma matricial, são definidos o vetor dos multiplicadores de Lagrange $\lambda=\left[\begin{array}{lll}\lambda_{1} & \lambda_{2} & \lambda_{3}\end{array}\right]^{T}$, e a matriz

$$
\boldsymbol{T}=\left[\begin{array}{ccc}
1 & 0 & 0 \\
\xi & 1 & 0 \\
\xi^{2} & 2 \xi & 2 \\
\xi^{3} & 3 \xi^{2} & 6 \xi
\end{array}\right]
$$

dos coeficientes do polinômio à direita do nó $\xi$, que também compõe a matriz como $\boldsymbol{B}=$ $\left[\begin{array}{r}-\boldsymbol{T} \\ \boldsymbol{T}\end{array}\right]$ em que $\boldsymbol{B}$ é a matriz dos coeficientes das derivadas de ordem $m$ de ambos os polinômios.

Deste modo, obtemos a expressão matricial do lagrangiano

$$
J(c, \lambda)=\boldsymbol{c}^{T} \Phi \boldsymbol{c}-2 \boldsymbol{c}^{T} \boldsymbol{\theta}+\boldsymbol{y}^{T} \boldsymbol{y}+\boldsymbol{c}^{T} \boldsymbol{B} \lambda
$$

Com o propósito de encontrar os pontos críticos do lagrangiano $J(c, \lambda)$, é necessário que o seu gradiente $\nabla J(c, \lambda)$ se torne zero, encontrando desta forma o ponto mínimo da função objetiva $\varepsilon(\boldsymbol{c})$ dentro das condições. O gradiente de $J(\boldsymbol{c}, \lambda)$ em relação a $\boldsymbol{c}$ é expresso como 


$$
\nabla_{c} J(c, \lambda)=2 \Phi c-2 \boldsymbol{\theta}+B \lambda
$$

Igualando $\nabla_{c} J(c, \lambda)$ ao vetor zero, chega-se a

$$
2 \boldsymbol{\Phi} \boldsymbol{c}+\boldsymbol{B} \boldsymbol{\lambda}=2 \boldsymbol{\theta} .
$$

Acrescenta-se ao sistema a equação do gradiente de $J(\boldsymbol{c}, \lambda)$ em relação a $\lambda$

$$
\nabla_{\lambda} J(c, \lambda)=R c
$$

também igualando ao vetor zero, resultando

$$
\left[\begin{array}{cl}
2 \boldsymbol{\Phi} & \boldsymbol{B} \\
\boldsymbol{R} & \mathbf{0}_{3 \times 3}
\end{array}\right] \boldsymbol{\alpha}=\left[\begin{array}{l}
2 \boldsymbol{\theta} \\
\mathbf{0}_{3 \times 1}
\end{array}\right]
$$

em que $\boldsymbol{\alpha}=\left[\begin{array}{l}\boldsymbol{C} \\ \lambda\end{array}\right]$ é o vetor dos parâmetros de saída, e $\boldsymbol{R}=\boldsymbol{B}^{T}$ é a matriz dos coeficientes de ambos polinômios em condições de osculação.

Pode-se calcular o erro quadrático mínimo $\varepsilon_{\min }(\boldsymbol{c})$ igualando a zero o gradiente do erro quadrático $\nabla \varepsilon(\boldsymbol{c})$. O gradiente de $\varepsilon(\boldsymbol{c})$ é expresso como

$$
\nabla \varepsilon(\boldsymbol{c})=2 \boldsymbol{\Phi} \boldsymbol{c}-2 \boldsymbol{\theta}
$$

que igualando $\nabla \varepsilon(\boldsymbol{c})$ ao vetor zero e rearranjando os termos, chega-se a

$$
\boldsymbol{\Phi} \boldsymbol{c}=\boldsymbol{\theta},
$$

que é substituída na expressão matricial do erro quadrático $\varepsilon(\boldsymbol{c})$ de (3.21), obtendo-se o erro quadrático mínimo

$$
\varepsilon_{\min }(\boldsymbol{c})=\boldsymbol{y}^{T} \boldsymbol{y}-\boldsymbol{c}^{T} \boldsymbol{\theta}
$$

Uma vez determinados os coeficientes $\boldsymbol{c}$ da função de estimação de qualidade $\hat{y}(x)$ para $L$ valores de $\xi$, é selecionado o valor do nó $\xi$ com o menor erro quadrático total $\bar{\varepsilon}_{m}$ entre todos os possíveis $\left\{\varepsilon_{\min }\left(\boldsymbol{c}_{1}, \xi_{1}\right), \varepsilon_{\min }\left(\boldsymbol{c}_{2}, \xi_{2}\right), \ldots, \varepsilon_{\min }\left(\boldsymbol{c}_{L}, \xi_{L}\right)\right\}$. O menor erro quadrático total determina-se como

$$
\bar{\varepsilon}_{\mathrm{m}}=\min _{l=1,2, \ldots, L} \varepsilon_{\min }\left(\boldsymbol{c}_{l}, \xi_{l}\right)
$$

e ainda devemos identificar as condições em que ele ocorre, que podem ser recuperadas a partir de 


$$
l_{\mathrm{m}}=\underset{l=1,2, \ldots, L}{\operatorname{argmin}} \varepsilon_{\min }\left(\boldsymbol{c}_{l}, \xi_{l}\right)
$$

como sendo os parâmetros $\boldsymbol{c}=\boldsymbol{c}_{l_{\mathrm{m}}}$ e $\xi=\xi_{l_{\mathrm{m}}}$, que determinam a função de estimação de qualidade com o menor erro quadrático total.

Em suma, o projeto da função de estimação de qualidade é realizado através da minimização do erro quadrático entre as opiniões $y_{n}$ e a função de estimação de qualidade $\hat{y}(x)$ ainda com parâmetros desconhecidos no início da fase de projeto. Obtêm-se ao final do projeto os coeficientes $\boldsymbol{c}$ dos polinômios e o nó $\xi$ que definem a função de qualidade com o menor erro quadrático.

Na Figura 3.2, é mostrado o diagrama da função de estimação de qualidade para a métrica sem referência (NR), nesta representa-se os dois polinômios cúbicos mutuamente exclusivos, que são escolhidos de acordo as condições representadas pela posição do nó $\xi$.

Figura 3.2 - Diagrama da função de estimação de qualidade da métrica NR proposta, constituída por uma spline definida por dois polinômios cúbicos com um ponto de interseção $\xi$.

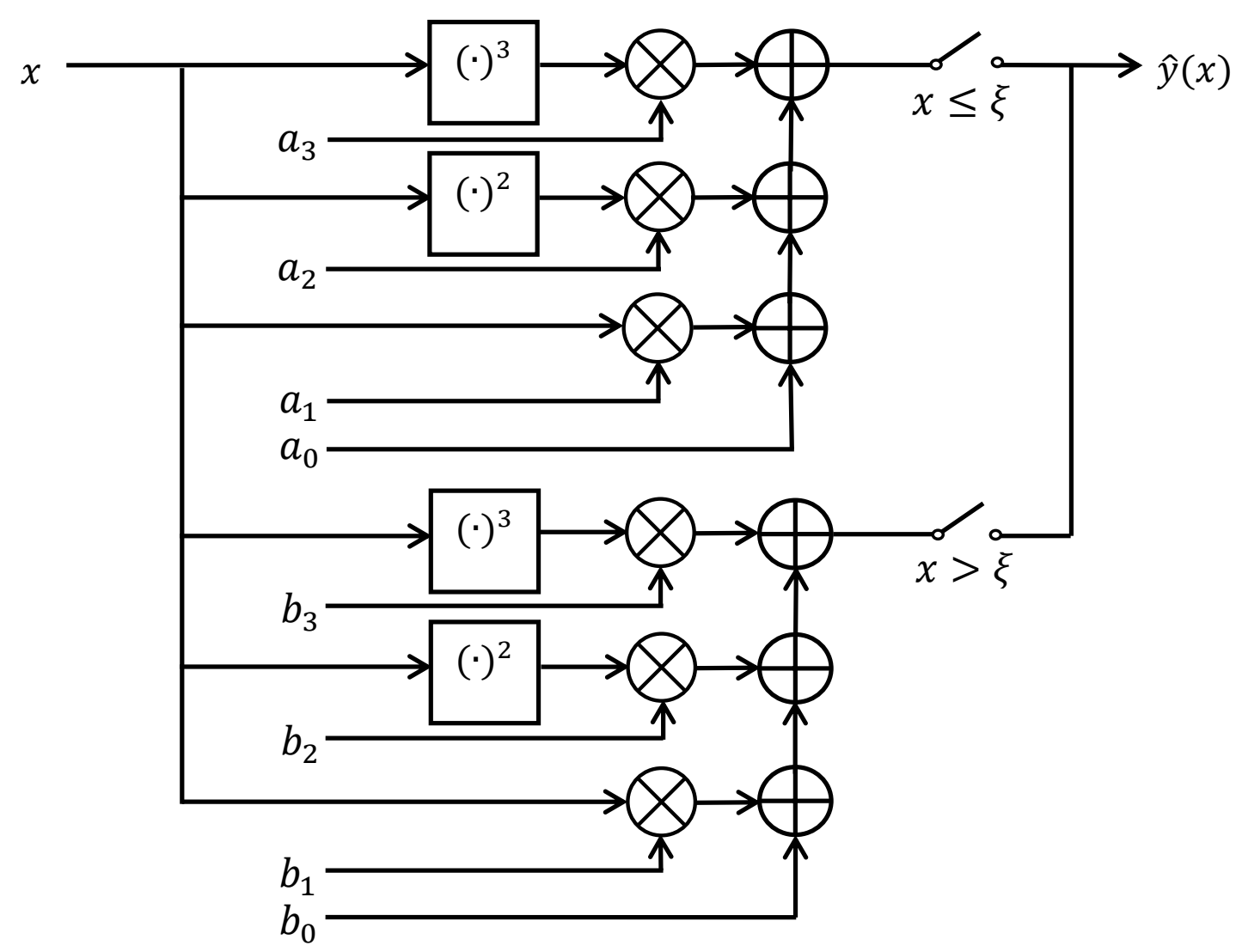

Fonte: Autor. 


\subsection{Função de estimação de qualidade para métrica FR}

Estudos anteriores mostram que a PSNR tem-se estabelecido como uma medida de qualidade útil quando as distorções são pequenas. Além disso, a PSNR produz boas estimativas de qualidade quando a degradação é ruído aditivo [AVCIBAS; SANKUR; SAYOOD, 2002]. No entanto, a PSNR tem dificuldades na estimação e qualidade de imagens ou vídeos com artefatos adicionados pela codificação, como o efeito de bloco, porque não considera a relação espacial entre pixels (WINKLER et al.,2008).

Uma medida que analisa a imagem como uma estrutura e que considera a interdependência dos pixels é a SSIM, como visto no Capítulo 2, que se baseia em três fatores, que são a perda de correlação entre o vídeo de referência e o degradado, a distorção de luminância e a distorção de contraste. A combinação de fatores é uma técnica importante na derivação de métricas de qualidade de vídeo. Apesar disso, a SSIM tem dificuldades na estimação de qualidade de vídeos degradados com problemas de transmissão [REIBMAN; POOLE, 2007].

Além disso, foi constatada uma correlação linear forte entre a PSNR e a SSIM na faixa de valores da SSIM entre 0,2 e 0,8 [HORÉ; ZIOU, 2013]. Isto é, existem divergências principalmente nos extremos da escala da SSIM.

Por isso foram criadas as métricas hibridas [WINKLER; MOHANDAS, 2008], que combinam três tipos de informação, que são sobre pacotes, sobre sequências de bit de transmissão, e sobre o sinal de vídeo. A PSNR e a SSIM enquadram-se nessa última categoria.

Em complemento à métrica sem referência VQOM, resolvemos propor uma métrica com referência baseada no sinal de vídeo. Nessa via de pesquisa percebemos que a combinação das métricas PSNR e SSIM, ambas baseadas nos quadros do sinal de vídeo, poderia dar resultados melhores do que cada uma individualmente.

A pesquisa começou com a combinação linear da PSNR e SSIM com pesos treinados, percebemos que dado o comportamento, as vezes divergente de ambas métricas, a fidelidade da estimativa aumentava ao aumentar o grau do polinômio de duas variáveis que efetua a combinação. Com isso, chegou-se à função de estimação de qualidade $\hat{y}(\rho, \varsigma)$ para a métrica 
com referência completa (FR) que é definida por um polinômio completo de segundo grau de duas variáveis. A nossa função de estimação de qualidade está definida por

$$
\hat{y}(\rho, \varsigma)=c_{0}+c_{1} \rho+c_{2} \varsigma+c_{3} \rho \varsigma+c_{4} \rho^{2}+c_{5} \varsigma^{2}
$$

em que $\rho$ e $\varsigma$ são as variáveis independentes que representam os valores de PSNR e SSIM, respectivamente, e $c_{0}, c_{1}, \ldots, c_{5}$ são os coeficientes do polinômio quadrático, sendo que

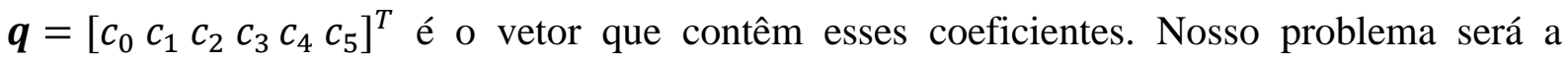
determinação dos coeficientes $\boldsymbol{c}$ da função de estimação de qualidade $\hat{y}(\rho, \varsigma)$.

Na fase de treinamento, tomam-se os pontos de treino $\left(\rho_{n}, \varsigma_{n}, y_{n}\right)$, para $n=0,1, \ldots, N-1$, em que $\rho_{n}$ e $\zeta_{n}$ são os valores das variáveis de controle, e $y_{n}$ é a opinião do espectador nessa condição. Para esses valores da variável de controle, determinam-se algebricamente os valores correspondentes da função de qualidade, que ficam dados em função dos parâmetros $\boldsymbol{q}$. Dessa forma, a diferença entre a função de qualidade e as opiniões é definida como

$$
\delta\left(\rho_{n}, \varsigma_{n}\right)=\hat{y}\left(\rho_{n}, \varsigma_{n}\right)-y_{n}
$$

Assim, o erro quadrático total pode-se escrever em função do desvio $\delta\left(\rho_{n}, \varsigma_{n}\right)$ como

$$
\varepsilon(\boldsymbol{q})=\sum_{n=0}^{N-1}\left(\delta\left(\rho_{n}, \varsigma_{n}\right)\right)^{2}
$$

O vetor das opiniões está representado por $\boldsymbol{y}=\left[y\left(\rho_{0}, \varsigma_{0}\right) y\left(\rho_{1}, \varsigma_{1}\right) \ldots y\left(\rho_{N-1}, \varsigma_{N-1}\right)\right]^{T}$.

Os valores hipotéticos da função de estimação de qualidade são designados por $\hat{y}\left(\rho_{n}, \varsigma_{n}\right)$ e agrupados no vetor $\hat{\boldsymbol{y}}=\left[\hat{y}\left(\rho_{0}, \varsigma_{0}\right) \hat{y}\left(\rho_{1}, \varsigma_{1}\right) \ldots \hat{y}\left(\rho_{N-1}, \varsigma_{N-1}\right)\right]^{T}$. Para representá-los, tomam-se nos pontos de treino os valores da função de estimação de qualidade $\hat{y}\left(\rho_{n}, \varsigma_{n}\right)$ representados na matríz $\boldsymbol{F}$ como

$$
\boldsymbol{F}=\left[\begin{array}{cccccc}
1 & \rho_{0} & \varsigma_{0} & \rho_{0} \varsigma_{0} & \rho_{0}^{2} & \varsigma_{0}^{2} \\
1 & \rho_{1} & \varsigma_{1} & \rho_{1} \varsigma_{1} & \rho_{1}^{2} & \varsigma_{1}^{2} \\
\vdots & \vdots & \vdots & \vdots & \vdots & \vdots \\
1 & \rho_{N-1} & \varsigma_{N-1} & \rho_{N-1} \varsigma_{N-1} & \rho_{N-1}^{2} & \varsigma_{N-1}^{2}
\end{array}\right]
$$

Portanto, o desvio $\delta\left(\rho_{n}, \varsigma_{n}\right)$ de (3.38) pode ser expresso em forma matricial como

$$
\delta=F q-y
$$

e o erro quadrático total como 


$$
\varepsilon(\boldsymbol{q})=\boldsymbol{\delta}^{T} \boldsymbol{\delta}
$$

Substituindo o vetor de desvios $\boldsymbol{\delta}$ na expressão do erro quadrático total e expandindo esta forma quadrática, chega-se a

$$
\varepsilon(\boldsymbol{q})=\boldsymbol{q}^{T} \boldsymbol{F}^{T} \boldsymbol{F} \boldsymbol{q}-\boldsymbol{q}^{T} \boldsymbol{F}^{T} \boldsymbol{y}-\boldsymbol{y}^{T} \boldsymbol{F} \boldsymbol{q}+\boldsymbol{y}^{T} \boldsymbol{y}
$$

em que os termos $\boldsymbol{q}^{T} \boldsymbol{F}^{T} \boldsymbol{y}$ e $\boldsymbol{y}^{T} \boldsymbol{F} \boldsymbol{q}$ são iguais porque a transposta de um escalar é o próprio escalar.

Simplificando a expressão do erro quadrático, obtém-se

$$
\varepsilon(\boldsymbol{q})=\boldsymbol{q}^{T} \boldsymbol{F}^{T} \boldsymbol{F} \boldsymbol{q}-\mathbf{2} \boldsymbol{q}^{T} \boldsymbol{F}^{T} \boldsymbol{y}+\boldsymbol{y}^{T} \boldsymbol{y} .
$$

Definindo a matriz de correlação entre os valores da função de estimação de qualidade $\hat{y}\left(\rho_{n}, \varsigma_{n}\right)$ como

$$
\boldsymbol{\Phi}=\boldsymbol{F}^{T} \boldsymbol{F},
$$

e o vetor de correlação cruzada entre os valores da função de estimação de qualidade $\hat{y}\left(\rho_{n}, \varsigma_{n}\right)$ e as opiniões como

$$
\boldsymbol{\theta}=\boldsymbol{F}^{T} \boldsymbol{y}
$$

obtemos a expressão matricial do erro quadrático

$$
\varepsilon(\boldsymbol{q})=\boldsymbol{q}^{T} \boldsymbol{\Phi} \boldsymbol{c}-2 \boldsymbol{q}^{T} \boldsymbol{\theta}+\boldsymbol{y}^{T} \boldsymbol{y} .
$$

Pode-se calcular o erro quadrático mínimo $\varepsilon_{\min }(\boldsymbol{q})$ igualando a zero o gradiente do erro quadrático $\nabla \varepsilon(\boldsymbol{q})$. O gradiente de $\varepsilon(\boldsymbol{q})$ é expresso como

$$
\nabla \varepsilon(\boldsymbol{q})=2 \boldsymbol{\Phi} \boldsymbol{q}-2 \boldsymbol{\theta},
$$

que igualando $\nabla \varepsilon(\boldsymbol{q})$ ao vetor zero e rearranjando os termos, chega-se a

$$
\boldsymbol{\Phi} \boldsymbol{q}=\boldsymbol{\theta},
$$

que é substituída na expressão matricial do erro quadrático $\varepsilon(\boldsymbol{q})$ de (3.47), obtendo-se o erro quadrático mínimo

$$
\varepsilon_{\min }(\boldsymbol{q})=\boldsymbol{y}^{T} \boldsymbol{y}-\boldsymbol{q}^{T} \boldsymbol{\theta} .
$$


Em suma, o projeto da função de estimação de qualidade é realizado através da minimização do erro quadrático entre as opiniões $y_{n}$ e a função de estimação de qualidade $\hat{y}(\rho, \varsigma)$ ainda com parâmetros desconhecidos no início da fase de projeto. Obtêm-se ao final do projeto os coeficientes $\boldsymbol{q}$ dos polinômios que definem a função de qualidade com o menor erro quadrático.

Na Figura 3.3, é mostrado o diagrama da função de estimação de qualidade $\hat{y}(\rho, \varsigma)$ para a métrica de referência completa $(\mathrm{FR})$, em que se representa o polinômio completo de segundo grau de duas variáveis.

Figura 3.3 - Diagrama da função de estimação de qualidade da métrica FR proposta, representada pelo polinômio completo de segundo grau de duas variáveis.

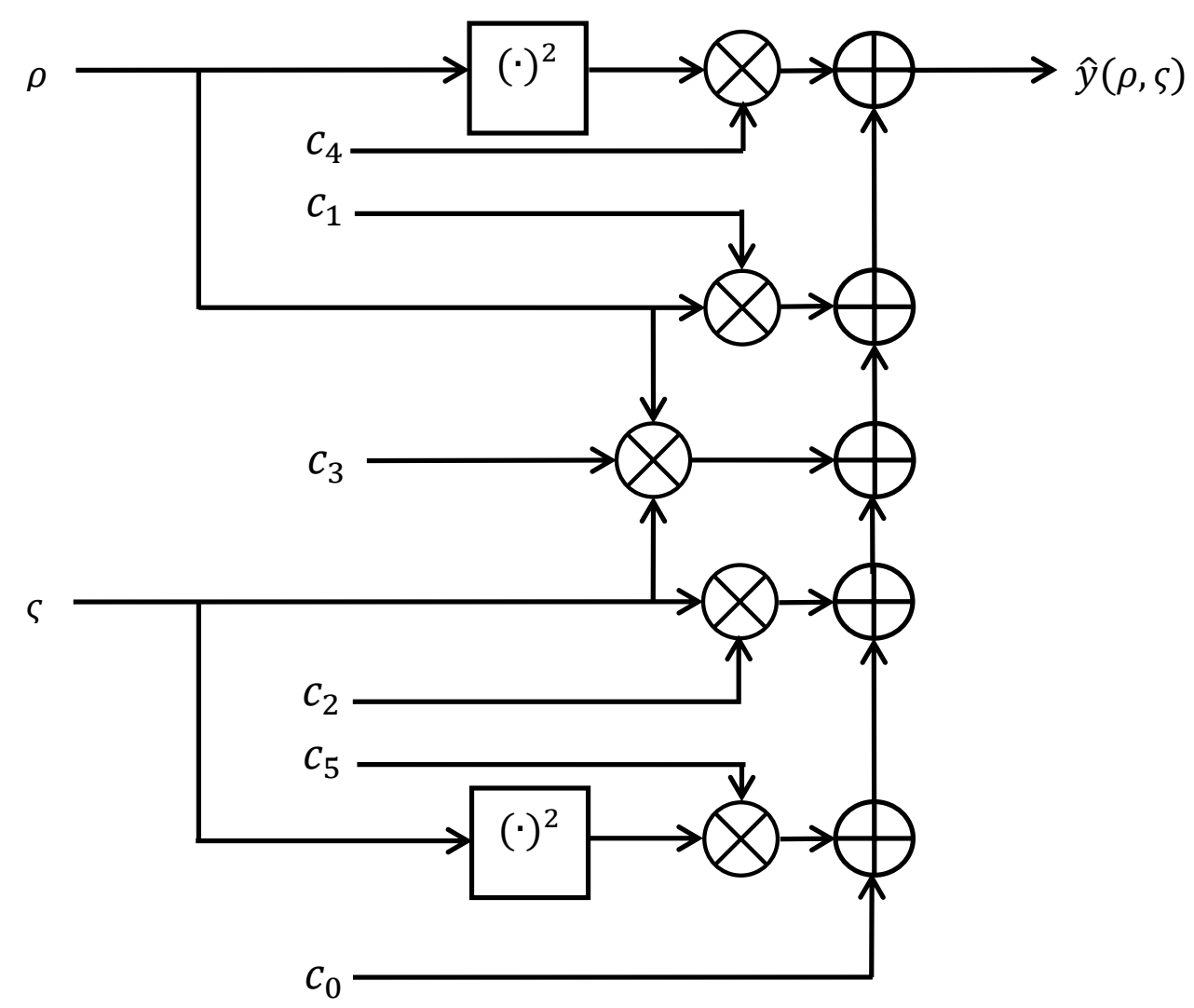

Fonte: Autor. 


\section{METODOLOGIA}

Neste capítulo, apresenta-se o processo de obtenção de vídeos degradados afetados pelo fator de variação de atraso de pacotes, para um cenário controlado. Em seguida, com os vídeos degradados obtidos, é descrita a elaboração dos testes subjetivos realizados com as mesmas condições para todos os espectadores. Além disso, com as opiniões obtidas do teste subjetivo é realizado o teste das funções de estimação de qualidade propostas nesta Tese.

\subsection{Degradação de Vídeos}

No processo de degradação de vídeos foram usados três vídeos em formato CIF (Common Intermediate Format), Akiyo, Foreman e Football, disponíveis na base de dados XIPH (XIPH, 2010), apresentado-se quadros destes vídeos na Figura 4.1. Os vídeos apresentam uma resolução de $352 \times 288$ pixels, em uma taxa de quadros de 29,97 fps, e uma relação entre a luminância e a crominância de 4:2:0, com tempo de duração de $10 \mathrm{~s}$ e um número de quadros de 300 para Akiyo e Foreman, e 8 s e 260 quadros para Football.

Figura 4.1 - Imagens dos vídeos de referência de Akiyo, Foreman e Football (ordenados da esquerda para a direita).

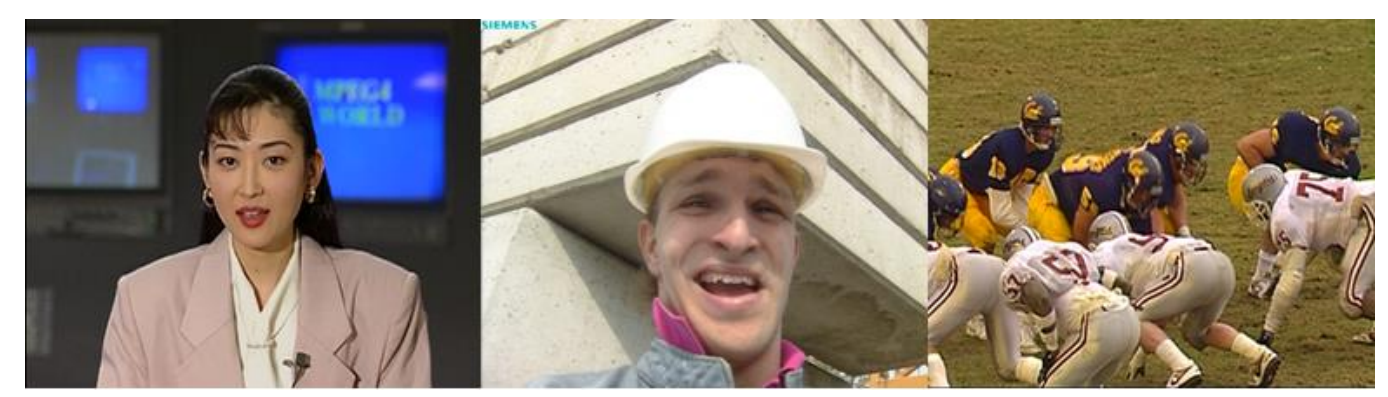

Fonte: XIPH (2010).

Os vídeos foram escolhidos pela diferença de conteúdo em relação à intensidade de movimento, sendo que Akiyo é considerado muito lento, Foreman é lento, e Football é rápido. (ITU-T P.910, 2008). A heterogeneidade das sequências de vídeo escolhidas é comprovada através do plano espaço temporal mostrado na Figura 4.2, os valores da informação temporal (TI - Temporal Information) e da informação espacial (SI - Spatial Information) são calculados conforme a recomendação ITU-T P.910 (2008). 
Figura 4.2 - Plano espaço temporal para os vídeos akiyo, foremam e football.

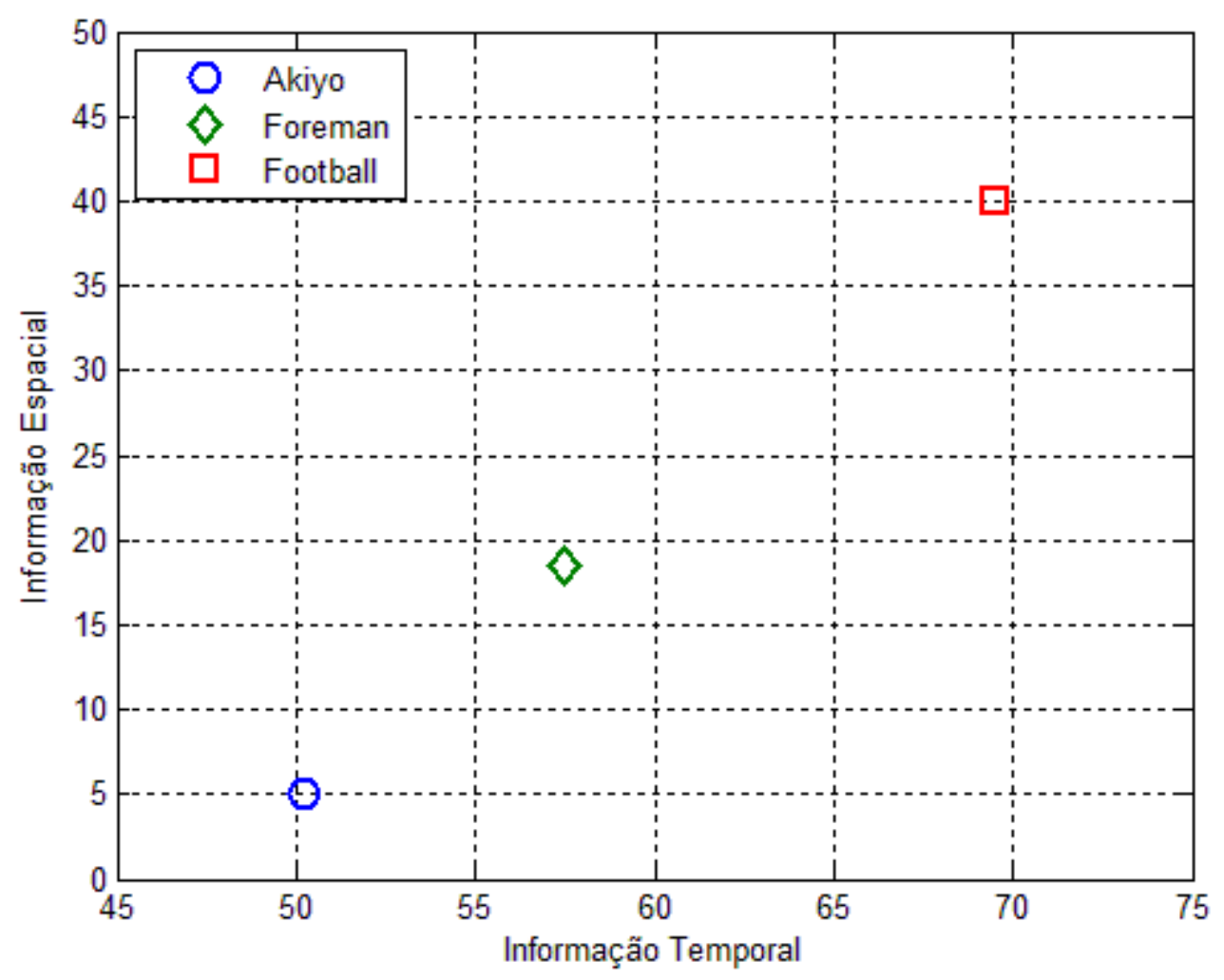

Fonte: Autor.

Os vídeos de referência foram degradados utilizando um cenário de emulação de rede afetada pelo fator de degradação de variação de atraso de pacotes. $\mathrm{O}$ cenário é totalmente controlado por não apresentar outro tipo de tráfego adicional que afete as avaliações. Para montar o cenário, foram utilizados três PC's com funções diferentes, sendo que o primeiro é o servidor de streaming de vídeos, o segundo é o emulador de rede pelo qual são inseridas as variações de atraso de pacotes, e o terceiro é o usuário final do serviço. Os PC's estão conectados em uma rede LAN (Local Area Network) usando o protocolo de rede Ethernet.

O experimento consiste na transmissão de streams de vídeo do servidor ao cliente, usando o protocolo UDP (User Datagram Protocol), amplamente usado para aplicações em tempo real. Para esse propósito, foi utilizado o emulador de rede NetEm (Network Emulator) (NETEM, 1991), o qual insere as variações de atraso de pacotes dentro de um conjunto de 11 distribuições uniformes sobre os respectivos intervalos de $100 \pm 2 p$ ms para $p=0,1, \ldots, 10$ $\mathrm{ms}$, em que $100 \mathrm{~ms}$ é o valor do atraso fixo, e $2 p$ representa a variação de atraso de pacotes (ITU-T Y.1540, 2016). 
Também, usa-se a ferramenta VLC (VideoLan Client) media player (VLC, 2001) no servidor e no cliente, configurado para usar o formato recipiente MPEG-TS (MPEG transport stream) para o codificador de vídeo H.264/AVC com uma taxa de bits de $800 \mathrm{kbit} / \mathrm{s}$ e uma taxa de quadros de 25 fps. Para o tamanho dos buffers de leitura e escrita foi utilizado o valor de 16384 bytes, a encriptação e desencriptação foi realizada em pacotes TS (Transport Stream) de 188 bytes, que formam os PES (Packetized Elementary Stream) (DWARAKA; KILARI, 2010). Na transmissão, a interface de rede empacota os dados em uma unidade de transmissão máxima (MTU - Maximum Transmission Unit) de 1500 bytes, sendo formada por sete TS.

Figura 4.3 - Imagens dos vídeos degradados de Akiyo com PDV de 8, 12, 16 e 20 ms (ordenados da esquerda para a direita).

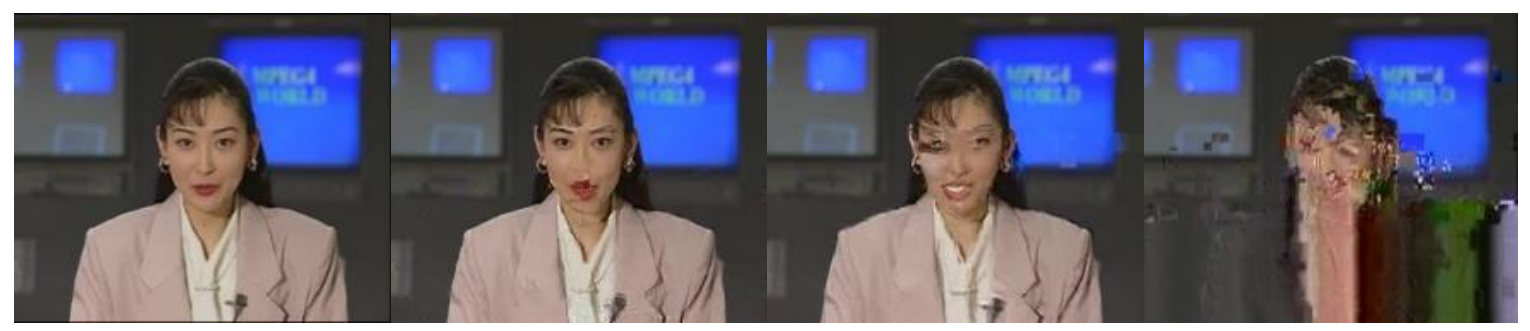

Fonte: Autor.

Como resultado deste experimento, obteve-se 33 vídeos degradados de formato TS, que formam a base de dados denominada de PDV_DB (Packet Delay Variation_Data Base). Nas Figuras 4.3, 4.4 e 4.5, pode ser percebida a degradação dos vídeos afetados pela variação de atraso de pacotes, sendo que, quanto maior o valor de PDV, menor é a qualidade do vídeo.

Figura 4.4 - Imagens dos vídeos degradados de Foreman com PDV de 8, 12, 16 e 20 ms (ordenados da esquerda para a direita).

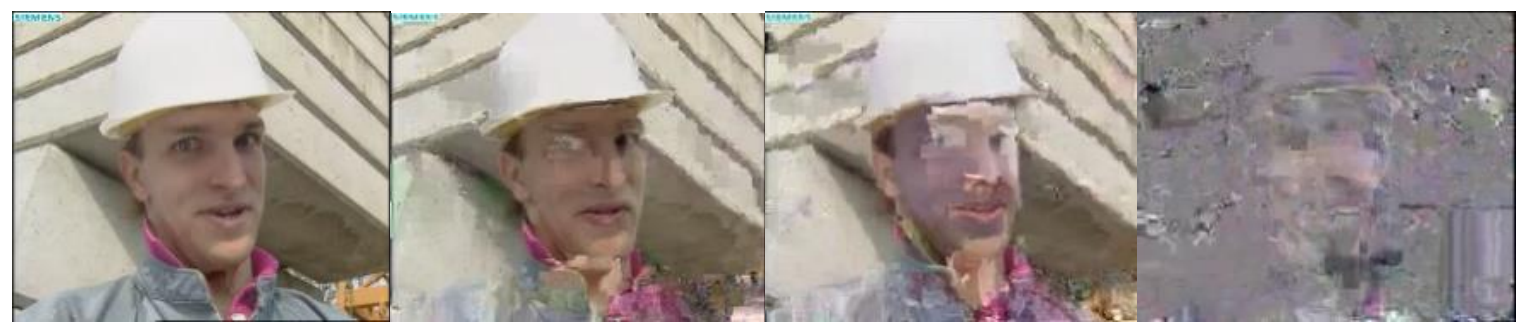

Fonte: Autor.

Também, percebe-se que o efeito da degradação é maior para os vídeos degradados com maior intensidade de movimento. 
Figura 4.5 - Imagens dos vídeos degradados de Football com PDV de 8, 12, 16 e 20 ms (ordenados da esquerda para a direita).

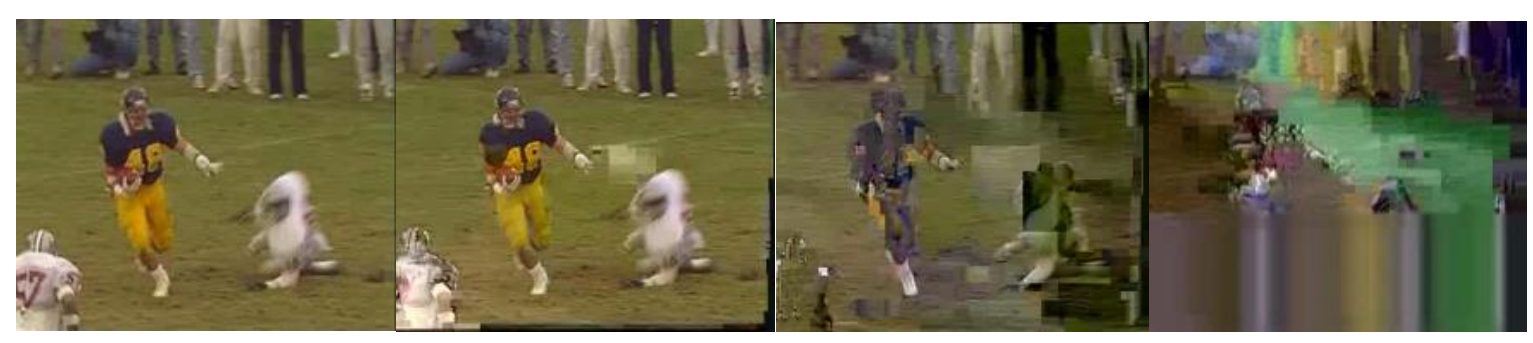

Fonte: Autor.

Também, foram usados os vídeos de referência e os vídeos degradados da base de dados ReTRiEVED (BATTISTI, 2017). Esta base de dados esta composta por 184 vídeos degradados obtidos de 8 vídeos de referência. Para a transmissão dos vídeos é usado o mesmo cenário que foi usado na base de dados PDV_DB descrita acima.

Figura 4.6 - Imagens dos vídeos de referência de Crowdrun, Duckstakeoff, Harbour, Ice, Parkjoy, Soccer, Running e Restaurant (ordenados da esquerda para a direita e de cima para baixo).

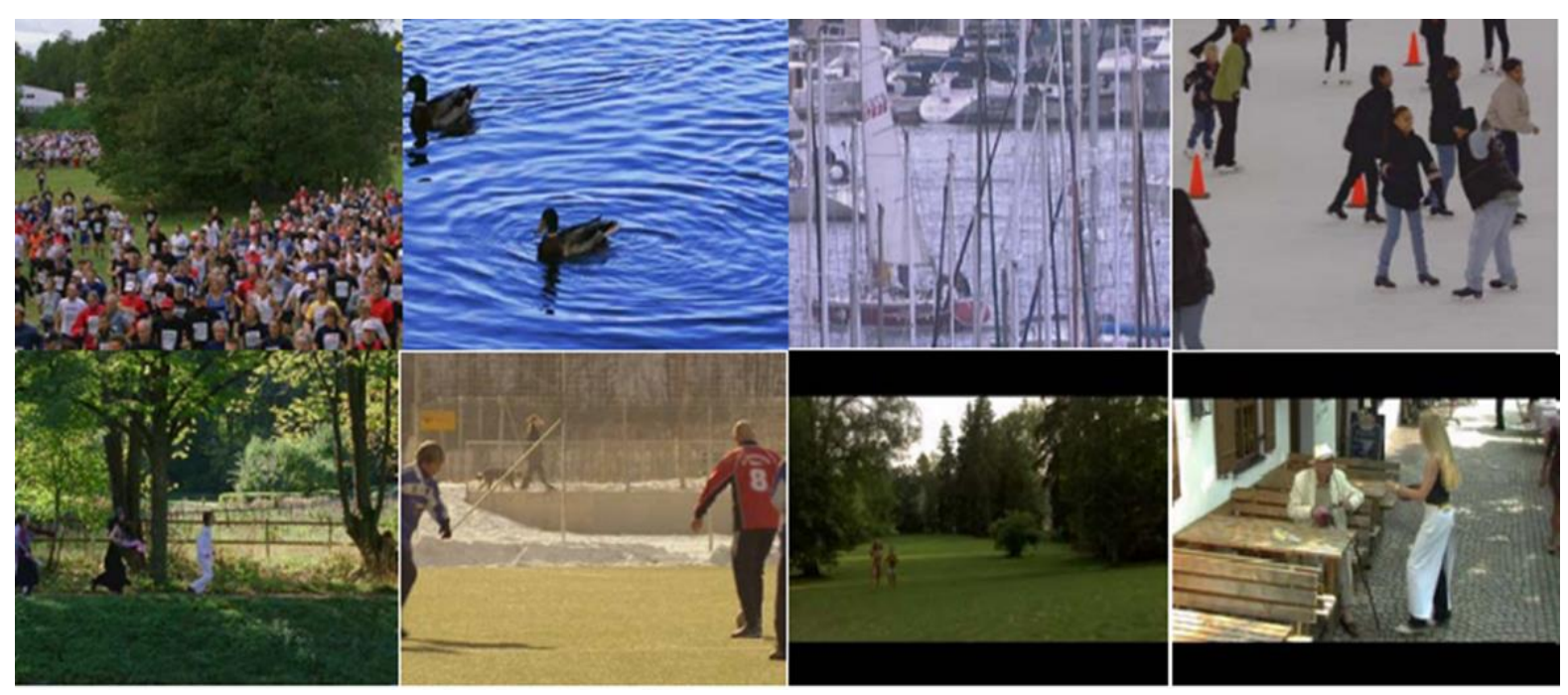

Fonte: BATTISTI (2017).

Na Figura 4.6 são mostrados quadros dos vídeos de referência da base de dados ReTRiEVED, e na Tabela 4.1 são apresentadas as características destes vídeos. 
Tabela 4.1 - Característicasdos dos vídeos de referência da base de dados ReTRiEVED.

\begin{tabular}{c|c|c|c}
\hline Vídeo & Resolução & Quadros/s & Duração (s) \\
\hline \hline Crowdrun & $704 \times 576$ & 25 & 9 \\
Duckstakeoff & $704 \times 576$ & 25 & 9 \\
Harbour & $704 \times 576$ & 30 & 9 \\
Ice & $704 \times 576$ & 30 & 7 \\
Parkjoy & $704 \times 576$ & 25 & 8 \\
Soccer & $704 \times 576$ & 30 & 7 \\
Running & $720 \times 576$ & 25 & 9 \\
Restaurant & $720 \times 576$ & 25 & 8 \\
\hline
\end{tabular}

Fonte: Autor.

Na Figura 4.7 são mostradas as informações temporal e espacial dos vídeos da base de dados ReTRiEVED, em que comprova-se a heterogeneidade das sequências de vídeo usadas nesta base de dados.

Figura 4.7 - Plano espaço temporal para os vídeos Crowdrun, Duckstakeoff, Harbour, Ice, Parkjoy, Soccer, Running e Restaurant da Base de Dados ReTRiEVED.

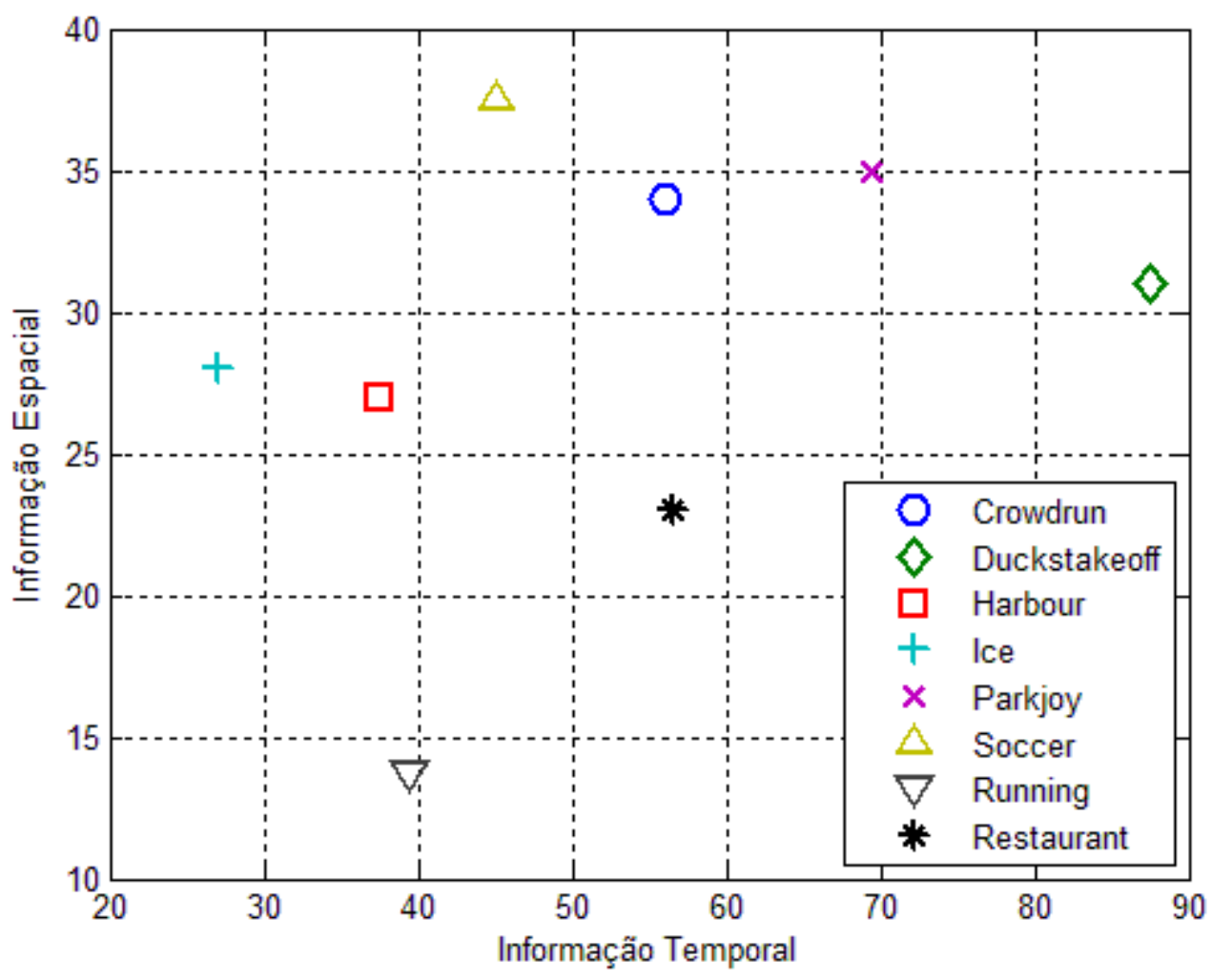

Fonte: Autor. 
Os vídeos degradados da base de dados ReTRiEVED foram obtidos adicionando diferentes fatores de rede que afetam a qualidade do serviço (QoS - Quality of Service) na transmissão das sequências de vídeo, sendo que 40 vídeos foram obtidos adicionando valores de vazão (throughput) de 0,5; 1; 2; 3 e 5 MB, em outros 40 vídeos foram adicionados valores de atraso (delay) de 100; 300; 500; 800 e $1000 \mathrm{~ms}$, nos seguintes 56 vídeos foram adicionados valores de porcentagem de perda de pacotes (PLR - Packet Loss Rate) de 0,1; 0,$4 ; 1 ; 3 ; 5 ; 8$ e $10 \%$, e nos restantes 40 vídeos foram adicionados valores de PDV ou jitter de 1; 2; 3; 4 e 5 ms. Estes últimos 40 vídeos foram usados nesta Tese.

\subsection{Teste Subjetivo}

Os testes subjetivos para avaliar os vídeos degradados da base de dados PDV-DB foram realizados utilizando o método absoluto de atribuição de opinião ACR, descrito no Capítulo 2. O ambiente de teste é controlado. Dessa forma, evita-se a interferência de fatores externos durante o teste (ITU-T Rec. P.910, 2008).

Para realizar o teste subjetivo, usou-se um computador com um processador Intel(R) Core (TM) I7 2600 de 3.4 GHz de 8 MB de memória cache, com 16 GB de RAM (Random Access Memory) e com Sistema Operacional Windows 7 de 64-bit. A placa de vídeo usada é do modelo dual AMD (Advanced Micro Devices) Radeon HD 6450 de 1 GB. Também, foram utilizados dois monitores LCD (Liquid Crystal Display) de 21.5" com uma resolução de tela de $1920 \times 1080$ pixels, luminosidade de $250 \mathrm{~cd} / \mathrm{m}^{2}$, tempo de resposta cinza a cinza de 8 ms, taxa de contraste dinâmico de 10000: 1, taxa de proporção Widescreen de 16: 9, e com tecnologia IPS (In Plane Switching) que permite um melhor ângulo de visão e maior fidelidade das cores.

Para o teste subjetivo, usou-se um ambiente com fundo branco para que não exista qualquer interferência visual, e sem ruído externo para que não gere distração dos observadores na avaliação subjetiva. Na Figura 4.8, pode-se observar o ambiente usado no teste subjetivo. 
Figura 4.8 - Ambiente usado na avalaição subjetiva.

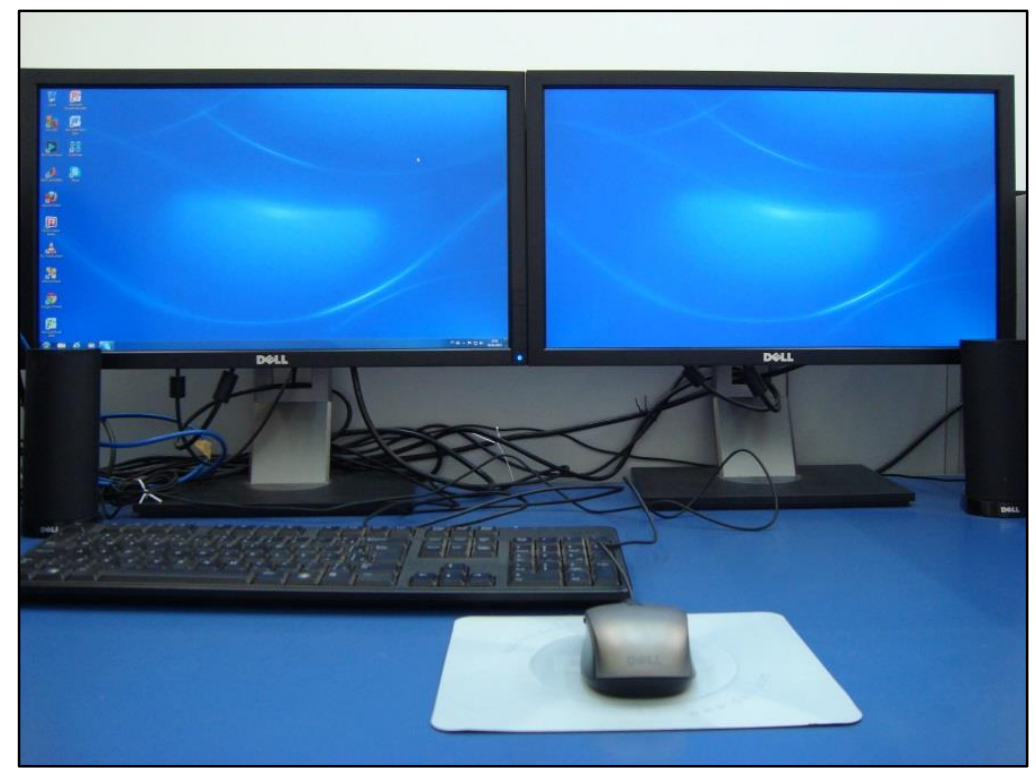

Fonte: Autor.

Como parte do ambiente de teste, usa-se nos monitores um fundo da cor cinza em volta da moldura do vídeo, para que não exista nenhuma interferência visual no monitor, ressaltando o vídeo a ser avaliado, como visto na Figura 4.9.

Figura 4.9 - Ambiente do monitor na avalaição subjetiva.

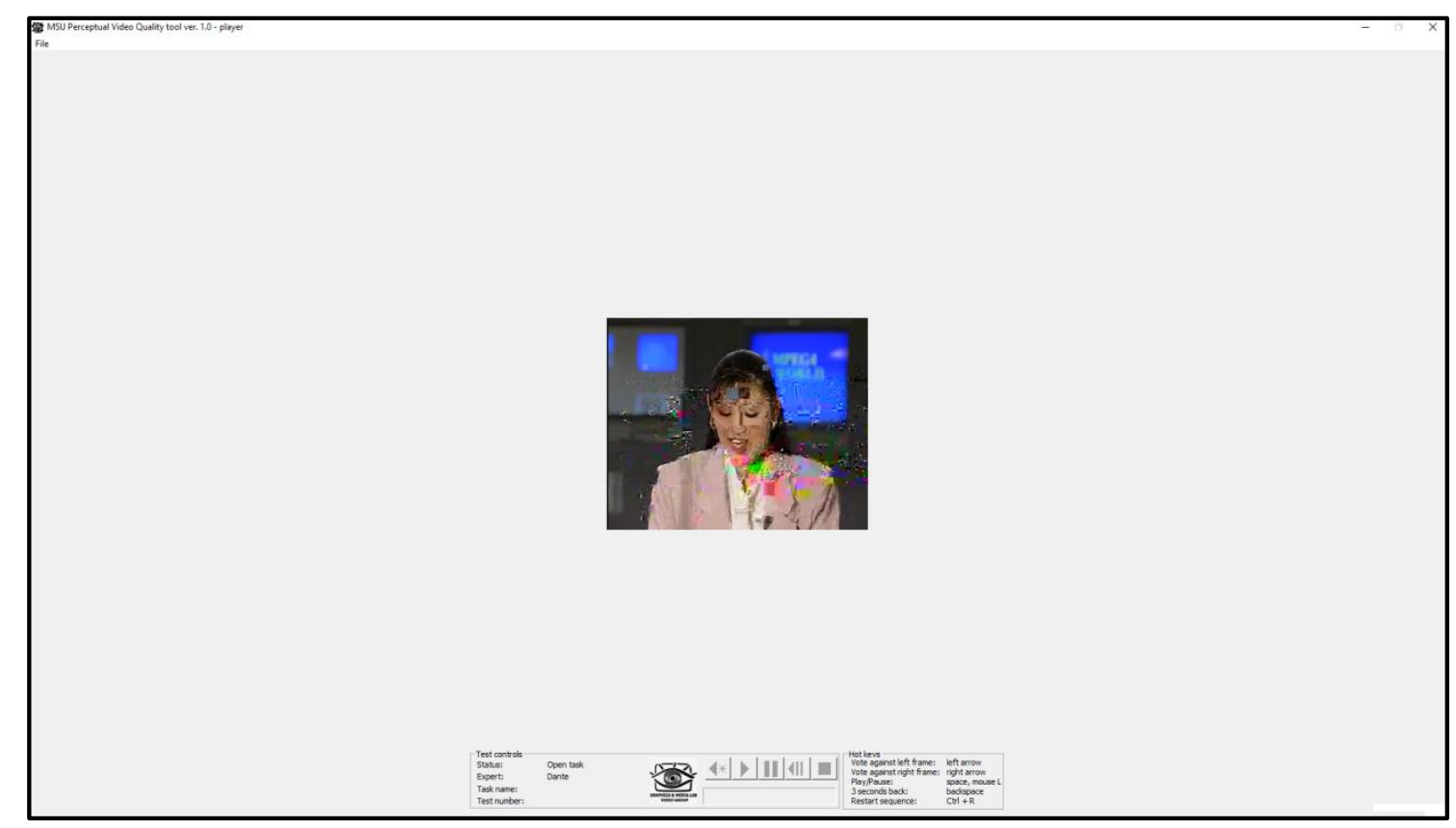

Fonte: Autor. 
A avaliação subjetiva foi realizada por 15 mulheres e 22 homens, totalizando um número de 37 observadores, com idades compreendidas entre 23 e 54 anos, sem deficiências visuais.

Na avaliação subjetiva foram utilizados dois softwares, o MSU Perceptual Video Quality Task Manager para gerar uma sequência aleatória de reprodução dos vídeos, com a finalidade de não polarizar a avaliação, e o MSU Perceptual Video Quality Player para a reprodução dos vídeos e o armazenamento automático das opiniões dadas pelos observadores (MSU, 2011).

A distância de observação entre o observador e o monitor foi de $50 \mathrm{~cm}$. No início do teste, são dadas as instruções inicias para os observadores, realizando uma breve explicação do processo de avaliação, dando maior ênfase na escala de qualidade de cinco valores. Em seguida, os observadores assistem um vídeo de cada vez e os avaliam após cada reprodução. O tempo de duração do teste para cada observador foi em torno de 20 a 25 min, sendo que após os 30 minutos os observadores não realizam avaliações confiáveis devido à fadiga e ao aborrecimento (ITU-T Rec. P.910, 2008). Estas condições foram as mesmas para todos os observadores.

Uma vez finalizadas todas as avaliações, o programa usado na avaliação subjetiva armazena em uma base de dados os índices de qualidade de forma automática, sem indicar o nome do observador, sendo identificado como sujeito (ITU-T Rec. P.910, 2008). Estes resultados foram usadas para o treinamento e para o teste da métrica proposta sem referência, e para o teste da métrica proposta sem referência (NR).

Um procedimento importante na avaliação subjetiva é a determinação da fiabilidade dos observadores, que é realizada qualitativamente, analisando o comportamento dos observadores quando, sem ser avisados, comparam o mesmo vídeo de referência. A fiabilidade dos 37 observadores foi avaliada, obtendo-se como resultado que os observadores são fiáveis por ter dado pontuações muito próximas de 5 ao mesmo vídeo.

Outra forma de selecionar observadores é o método de rejeição de pontuações incoerentes (ITU-R BT.500-13, 2012), baseado no coeficiente de curtose que determina se a distribuição para cada apresentação é uma distribuição normal ou não. Para a distribuição normal, o coeficiente de curtose se encontra entre 2 e 4. Uma vez determinado o tipo de distribuição, usam-se duas condições para rejeitar o observador, a primeira condição contabiliza o número de vezes que as avaliações de um observador ficam fora do intervalo de confiança, sendo que 
em 5\% dos casos o observador é rejeitado; e a segunda condição é baseada na análise de dispersão da distribuição das avaliações, em que o observador é rejeitado se a taxa for maior do que $30 \%$. Os resultados obtidos para a primeira e segunda condição foram 0,0303 e 1 respectivamente, verificando-se que os observadores não foram rejeitados.

Na base de dados ReTRiEVED, os testes subjetivos para vídeos afetados por PDV, PLR e atraso foram realizados por 41 observadores, dos quais 16 são mulheres e os restantes 25 são homens, com idades compreendidas entre 21 e 51 anos. A avaliação subjetiva, segue o mesmo procedimento usado nos testes subjetivos da métrica sem referência (NR), descrito acima. Os resultados obtidos são usados no treinamento e validação da métrica proposta com referência completa (FR).

Em um procedimento ACR costuma-se tirar a média das opiniões individuais de todos os observadores (MOS), porém, em ambos casos resolveu-se manter todo o conjunto de opiniões para não perder sua distribuição, tanto no treinamento como no teste da métrica objetiva.

\subsection{Teste da função de estimação de qualidade sem referência}

Para realizar o teste da função de estimação, comparam-se as $N_{t}$ opiniões $y_{t_{n}}$ levantadas para a fase de teste com a função de estimação de qualidade obtida da fase de treinamento $\hat{y}\left(x_{t_{n}}\right)$, sendo que $x_{t_{n}}$ é o fator de degradação associado à opinião $y_{t_{n}}$. A comparação é realizada através do cálculo do erro quadrático $\varepsilon_{\boldsymbol{t}}$, como visto na Figura 4.10.

Figura 4.10 - Diagrama de blocos do erro quadrático para a fase de teste.

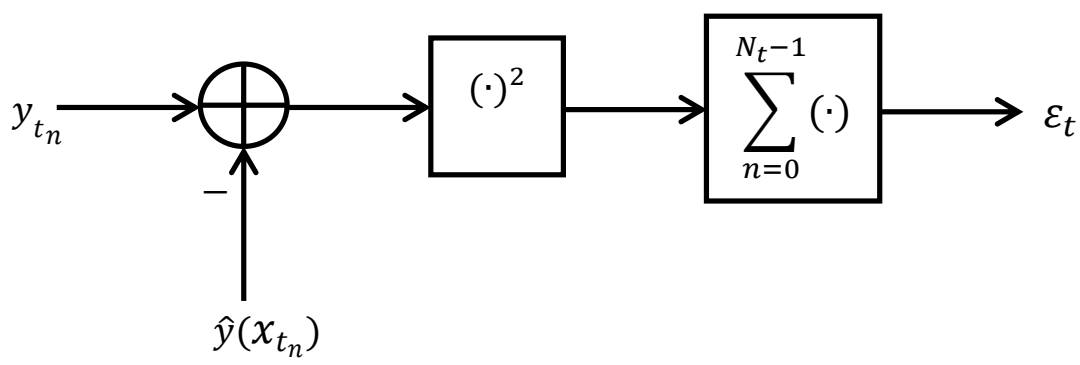

Fonte: Autor. 
O erro quadrático de teste em comparação com o erro quadrático de treinamento permite avaliar o poder de generalização da métrica, isto é visto em detalhe no Capítulo 5.

\subsection{Treino, validação e teste da função de estimação de qualidade com referência}

Para realizar o treino e validação da função de estimação de qualidade da métrica proposta foi utilizado o método de validação cruzada $k$-fold (HASTIE, 2009). O método consiste em dividir em $k$ partições o conjunto de dados, por uma questão prática assumimos que $k=4$, sendo que os 40 vídeos degradados são agrupados aleatoriamente em 4 grupos de 10 vídeos, mantendo-se os vídeos degradados de mesma sequência de vídeo de referência juntos. Uma vez selecionados os quatro grupos, é realizada a validação cruzada, sendo que três grupos são utilizados para o treino e o restante para a validação ou teste. Obtendo-se no total quatro combinações possíveis, conforme visto na Figura 4.11.

Figura 4.11 - Diagrama do método de validação cruzada k-fold para $k=4$, usado na função de estimação de qualidade da métrica com referência.

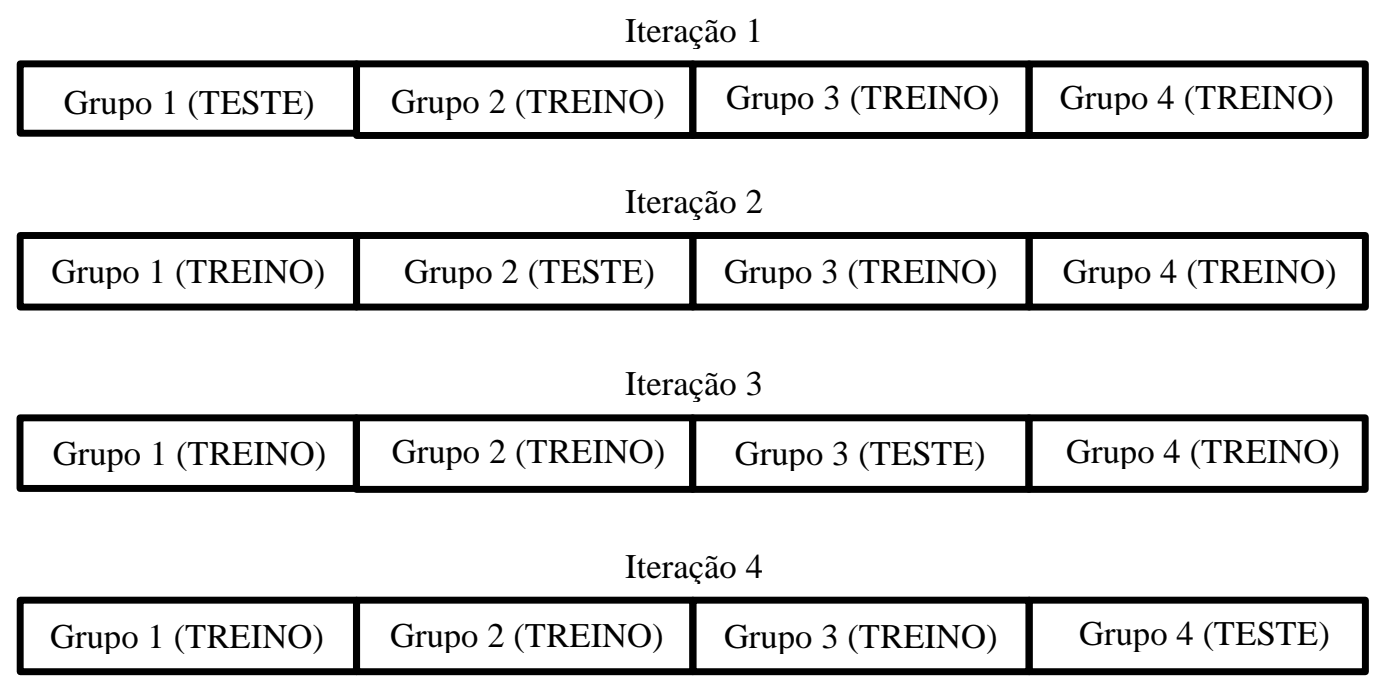

Fonte: Autor. 


\subsection{Cenários de Aplicação das Métricas Propostas}

As métricas propostas nesta Tese foram desenvolvidas com o intuito de ajudar na avaliação de qualidade de vídeo em tempo real, específicamente para serviços de transporte de vídeo através de redes IP afetadas com o fator de degradação PDV.

Para poder aplicar as métricas propostas, foi realizada uma pesquisa de campo através de entrevistas com gerenciadores de redes da Escola Politécnica e da STI (Superintendência de Tecnologia da Informação) da USP. No STI é controlado o desempenho do serviço de IPTV da USP.

O controle é realizado através do analisador de rede OptiView XG, que é um dispositivo portátil pelo qual são realizadas medidas dos parâmetros que afetam o desempenho a rede como a perda de pacotes e o PDV. Este dispositivo permite realizar medições ponto a ponto, ou é espelhado um ponto. As medidas são tomadas em diversos pontos da rede, como nos roteadores e nos switchs.

Para situações, em que são detetados valores superiores a $25 \mathrm{~ms}$ de PDV pico-pico é tomada uma medida corretiva que consiste em aumentar a taxa de transmissão do vídeo, ou aumentar o tamanho do pacote a ser enviado. Os valores das degradações que afetam a rede podem ser diferentes para cada rede porque apresentam infraestruturas diferentes.

Assim, a Anatel (Agência Nacional de Telecomunicações) através da resolução 574 do 28 de outubro de 2011, no artículo 19, indica que durante o período de maior tráfego (PMT) a prestadora deve garantir que a variação de latência (jitter ou PDV), tanto no download como no upload seja de até cinquenta milissegundos (50 ms).

Uma vez confirmada a relevância do efeito do PDV na qualidade do vídeo, as métricas propostas nesta tese são aplicadas em cenários de controle diferentes.

Para a métrica proposta sem referência (NR), o cenário de aplicação utilizado esta representado na Figura 4.12, em que os valores de PDV são extraídos da rede IP através do analisador de rede, e a métrica proposta NR é determinada como um valor MOS, sendo que este valor pode ser enviado ao servidor de vídeo através de um soquete (socket) para adaptar a taxa de transmissão de vídeo ou aumentar o tamanho de pacote. A métrica proposta NR é útil na fase e desenvolvimento de serviços. 
Figura 4.12 - Cenário de aplicação da métrica proposta NR.

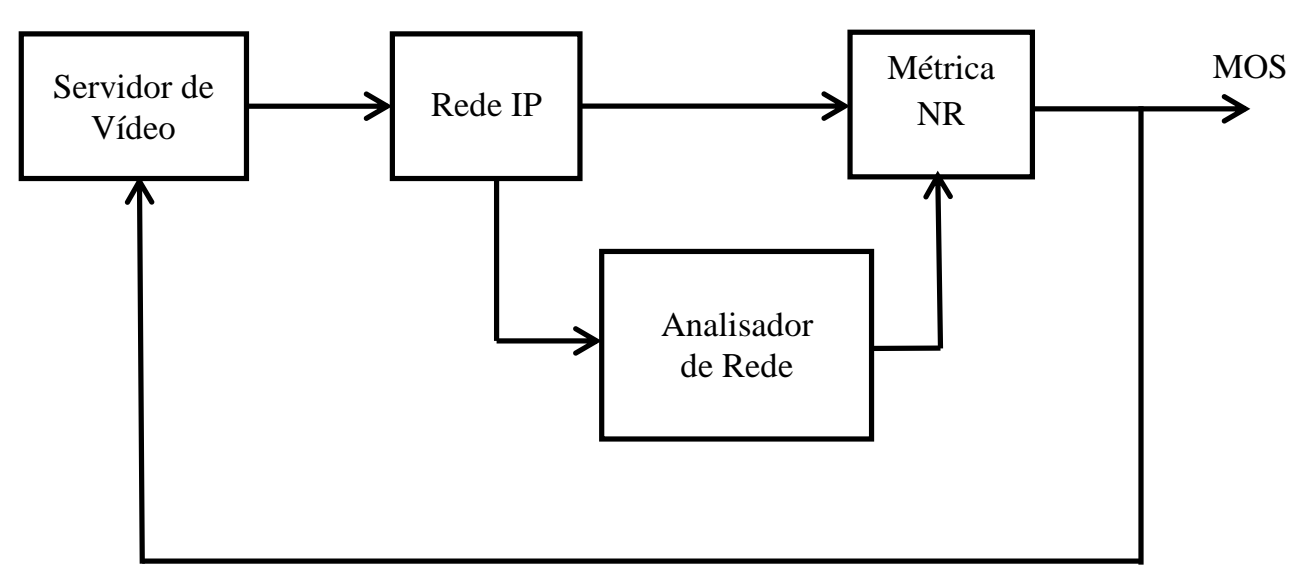

Fonte: Autor.

Na Figura 4.13 esta representado o cenário de aplicação para a métrica de referência completa (FR), em que o vídeo degradado é enviado pela rede IP, e o vídeo original é enviado por outro médio de transporte sem degradações, ambos vídeos são comparados usando as métricas PSNR e SSIM, e os valores são dados de entrada da métrica proposta FR que é determinada como um valor MOS, sendo que este valor pode ser enviado ao servidor de vídeo através de um soquete (socket) para adaptar a taxa de transmissão de vídeo ou aumentar o tamanho de pacote quando o valor de MOS não seja de boa qualidade. A métrica proposta FR é usada como apoio no desenvolvimento de codificadores de serviço de redes.

Figura 4.13 - Cenário de aplicação da métrica proposta FR.

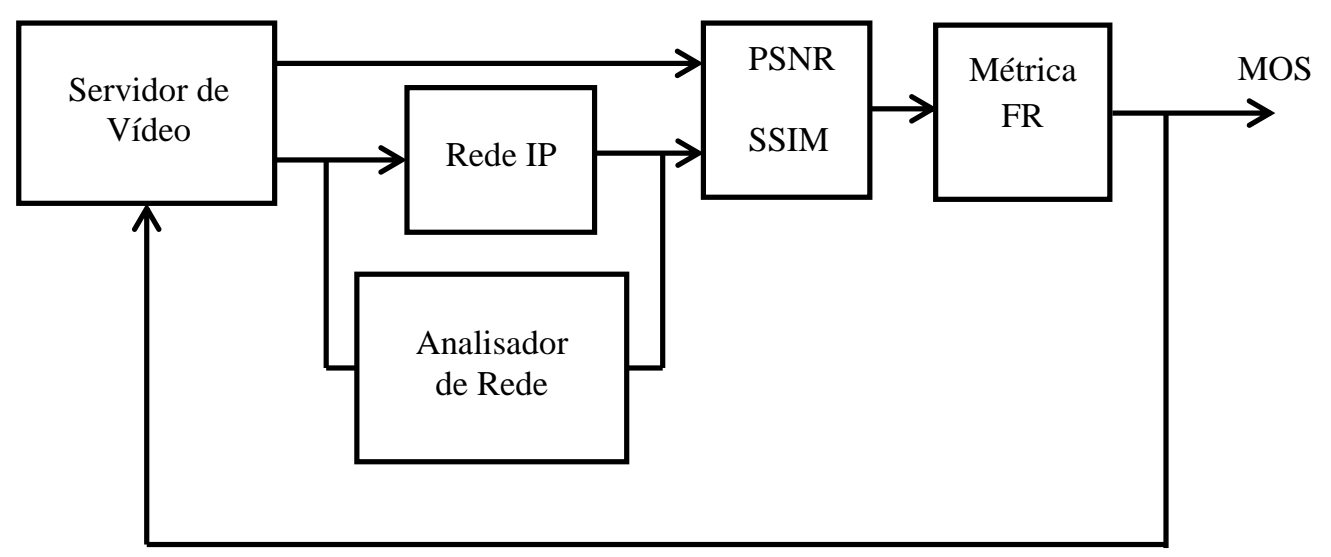

Fonte: Autor. 


\section{RESULTADOS}

Neste capítulo, são apresentados e analisados os resultados do comportamento das métricas objetivas sem referência (NR) e de referência completa (FR) propostas, chamadas de VQOM (Viewing Quality Objective Metric) e QCM (Quadratic Combinational Metric), respectivamente. Estas métricas foram projetadas para um cenário de rede afetado pelo fator de degradação de rede PDV. Inicialmente, são mostrados os resultados do treino realizado para projetar a função de estimação de qualidade com o menor erro quadrático. Em seguida, são apresentados os resultados do teste utilizando a função de qualidade projetada para um conjunto de opiniões diferente dos utilizados no treino. Além disso, são comparadas as opiniões de treino e de teste com as métricas propostas através do erro quadrático médio e dos coeficientes de correlação de Pearson (PCC - Pearson Correlation Coefficient) e de Spearman (SRCC - Spearman Rank Correlation Coefficient).

\subsection{Resultados para VQOM}

Dados os pontos de treino $\left(x_{n}, y_{n}\right)$, sendo $x_{n}$ a condição e $y_{n}$ as opiniões dos observadores, para $n=0,1, \ldots, N-1$, sendo os pares ordenados em ordem não-decrescente de valores de condição, o projeto da função de estimação de qualidade é realizado através da minimização do erro quadrático entre as opiniões e a função de qualidade, condicionada à interseção dos polinômios no nó de abscissa $x=\xi$, como observado no Capítulo 3.

Inicialmente, obtêm-se os coeficientes $\boldsymbol{a}$ e $\boldsymbol{b}$ dos polinômios cúbicos para valores de $\xi$ compreendidos entre os valores mínimo e máximo de PDV. Logo após, é selecionada a spline com o menor erro quadrático em relação às opiniões, conseguindo desta forma determinar a função de qualidade através dos coeficientes $\boldsymbol{a}, \boldsymbol{b}$, e o valor de $\xi$.

O algoritmo foi treinado considerando 11 valores de PDV que variam de 0 a $20 \mathrm{~ms}$ em torno de um atraso de $100 \mathrm{~ms}$, representados pelo vetor $\boldsymbol{x}=2 p$, para $p=0,1, \ldots, 10 \mathrm{~ms}$. Obteve-se um conjunto de 825 opiniões, representadas pelo vetor $\boldsymbol{y}$, e os valores do nó $\xi$, mostrados no vetor $\xi=0,5 ; 1,5 ; \ldots ; 19,5$.

Na Figura 5.1, são mostradas as opiniões em função de PDV representadas no boxplot; e os resultados do treinamento para obter a métrica proposta VQOM em função de PDV 
representadas pelas splines. A spline grossa representa a métrica proposta VQOM e as splines finas mostram as outras tentativas.

Figura 5.1 - Opiniões de Treinamento (boxplots) e métrica proposta VQOM (spline grossa) para $\xi=$ 5,5 ms, e as funções de estimação de qualidade (splines finas) para $\xi=0,5 ; 1,5 ; \ldots ; 19,5$, em função do PDV.

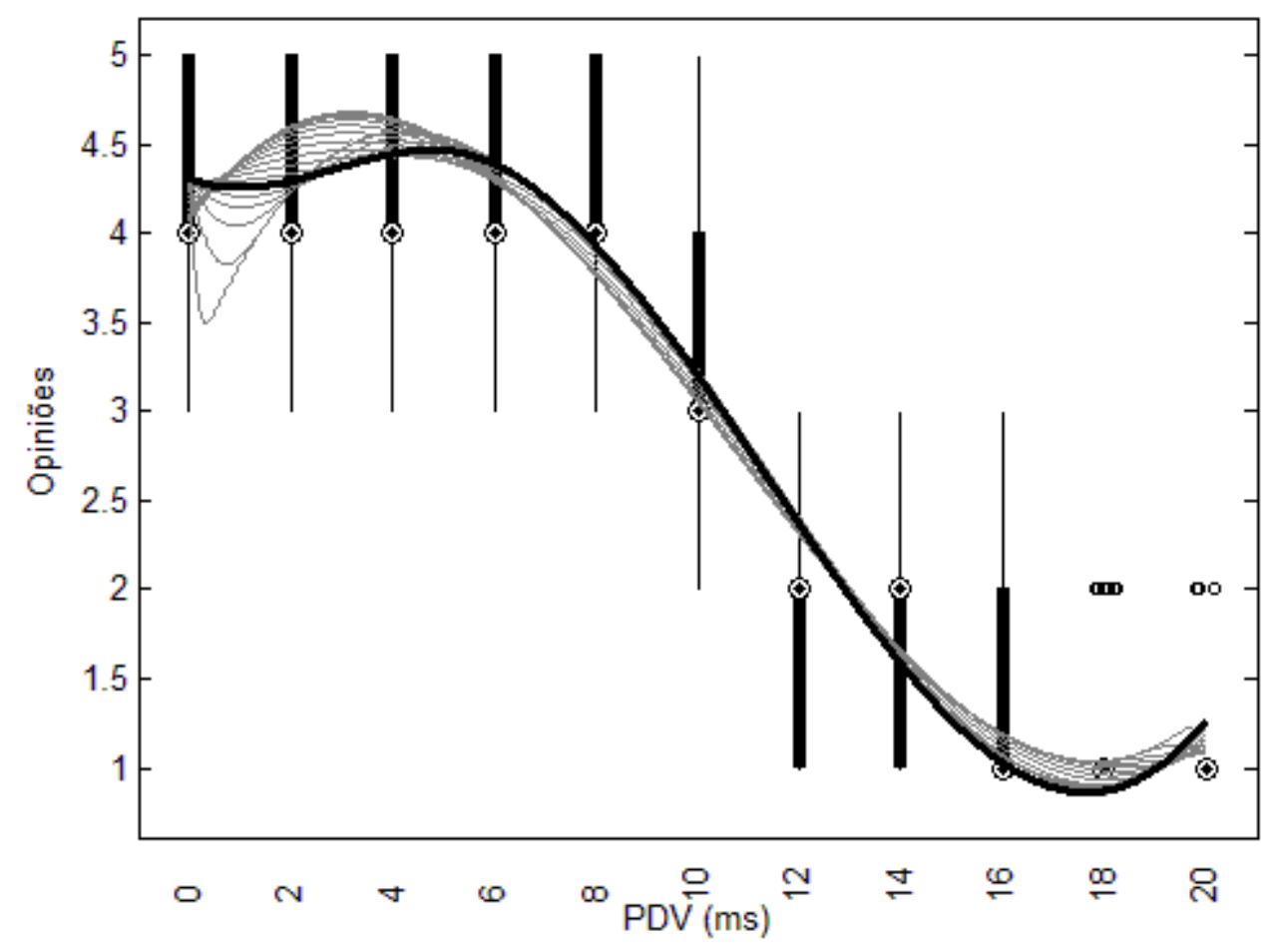

Fonte: Autor.

Nos boxsplots estão representadas as 825 opiniões de 3 sequências de vídeo afetadas por 11 valores de PDV avaliadas por 25 observadores, em função de PDV, utilizadas no treinamento. Na representação do boxplot, os círculos com ponto no meio são as medianas, as caixas estão delimitadas pelos primeiro e terceiro quartils; os bigodes são representados pelas retas verticais, e os outliers pelos círculos vazios.

$\mathrm{Na}$ Figura 5.1, os valores das medianas coincidem com o valor do quartil superior, ou inferior, ou com ambos, indicando que existe uma baixa variabilidade de dados, mas com um maior número de valores com o mesmo valor da mediana.

Pode-se observar que, quanto maior é o valor de PDV, piores são as avaliações dos observadores. Deste modo, a qualidade de vídeo se torna menor à medida que a variação de 
atraso de pacotes aumenta. Pode-se notar que, para valores menores de PDV entre 0 e $8 \mathrm{~ms}$, a mediana e as distribuições de dados são iguais, indicando que a qualidade dos vídeos, considerada entre razoável e excelente, é a mesma para esse intervalo de valores para PDV. Para os vídeos degradados com $10 \mathrm{~ms}$ de PDV, tem-se a maior variabilidade, indicando que a qualidade dos vídeos começa a diminuir sem ser percebida por todos os observadores. A partir $12 \mathrm{~ms}$, a qualidade dos vídeos decresce rapidamente, obtendo avaliações entre razoável e péssimo, sendo que, para os vídeos degradados com valores de PDV de 18 e 20 ms, obtém-se o maior número de avaliações de péssima qualidade. Para esses valores, podem-se identificar outliers que representam valores extremos, às vezes considerados como avaliações pouco confiáveis por estar representados em menor quantidade.

As funções de estimação de qualidade obtidas no treinamento para vários valores do nó estão representadas nas splines da Figura 5.1, sendo que a spline grossa, com o menor erro quadrático em relação às opiniões devido à melhor localização do seu nó, é selecionada para representar a métrica proposta VQOM, expressa por

$$
V(x)=\left\{\begin{array}{ll}
a_{3} x^{3}+a_{2} x^{2}+a_{1} x+a_{0} & \text { para } x \leq \xi \\
b_{3} x^{3}+b_{2} x^{2}+b_{1} x+b_{0} & \text { para } x>\xi
\end{array},\right.
$$

em que a posição do nó é $\xi=5.5 \mathrm{~ms}$, e os coeficientes do polinômio da esquerda $a_{i}$ são $-0,0078 ; 0,0689 ;-0,1179$ e 4,3121, e os coeficientes $b_{i}$ do polinômio da direita são 0,$0035 ;-0,1177 ; 0,9086$ e 2,4302, ordenados em ordem descendente, começando pelo coeficiente de potência cúbica. O mínimo erro quadrático médio de treinamento para a métrica proposta VQOM é igual a 0,3868, e o coeficiente de correlação de treinamento é igual a 0,9502. A spline que representa a métrica proposta VQOM ajusta-se melhor à distribuição de pontos de treino passando mais próxima dos valores das medianas dos boxplots que representam as opiniões.

Para o teste, foram utilizadas 396 opiniões de 3 sequências de vídeo afetadas por 11 valores de PDV avaliadas por 12 observadores, sendo que os observadores de teste são diferentes dos observadores de treinamento. No teste, é comparada a função da métrica proposta VQOM com as opiniões de teste, obtendo-se o erro quadrático médio de teste igual a 0,4852 e o coeficiente de correlação de teste é igual a 0,9154. 


\subsection{Comparação de Resultados para VQOM}

Os resultados obtidos da métrica proposta VQOM são comparados com duas funções de estimação de qualidade, a primeira é formada por um único polinômio cúbico, representado por

$$
P(x)=p_{3} x^{3}+p_{2} x^{2}+p_{1} x+p_{0},
$$

em que os coeficientes do polinômio são 0,$0022 ;-0,0702 ; 0,3824$ e 4,0822, ordenados em ordem descendente, começando pelo coeficiente de potência cúbica, com o mínimo erro quadrático de treinamento igual a 0,4125 , e o coeficiente de correlação de treinamento é igual a 0,9095 .

No teste, a função da métrica proposta VQOM e as 396 opiniões de teste são comparadas, obtendo-se o erro quadrático médio de teste igual a 0,5407 e o coeficiente de correlação de teste igual a 0,8918 .

Figura 5.2 - Opiniões de Treinamento (boxplots) e métrica proposta (spline contínua) para $\xi=5,5 \mathrm{~ms}$, e spline de um polinômio cúbico (linha tracejada) em função do PDV.

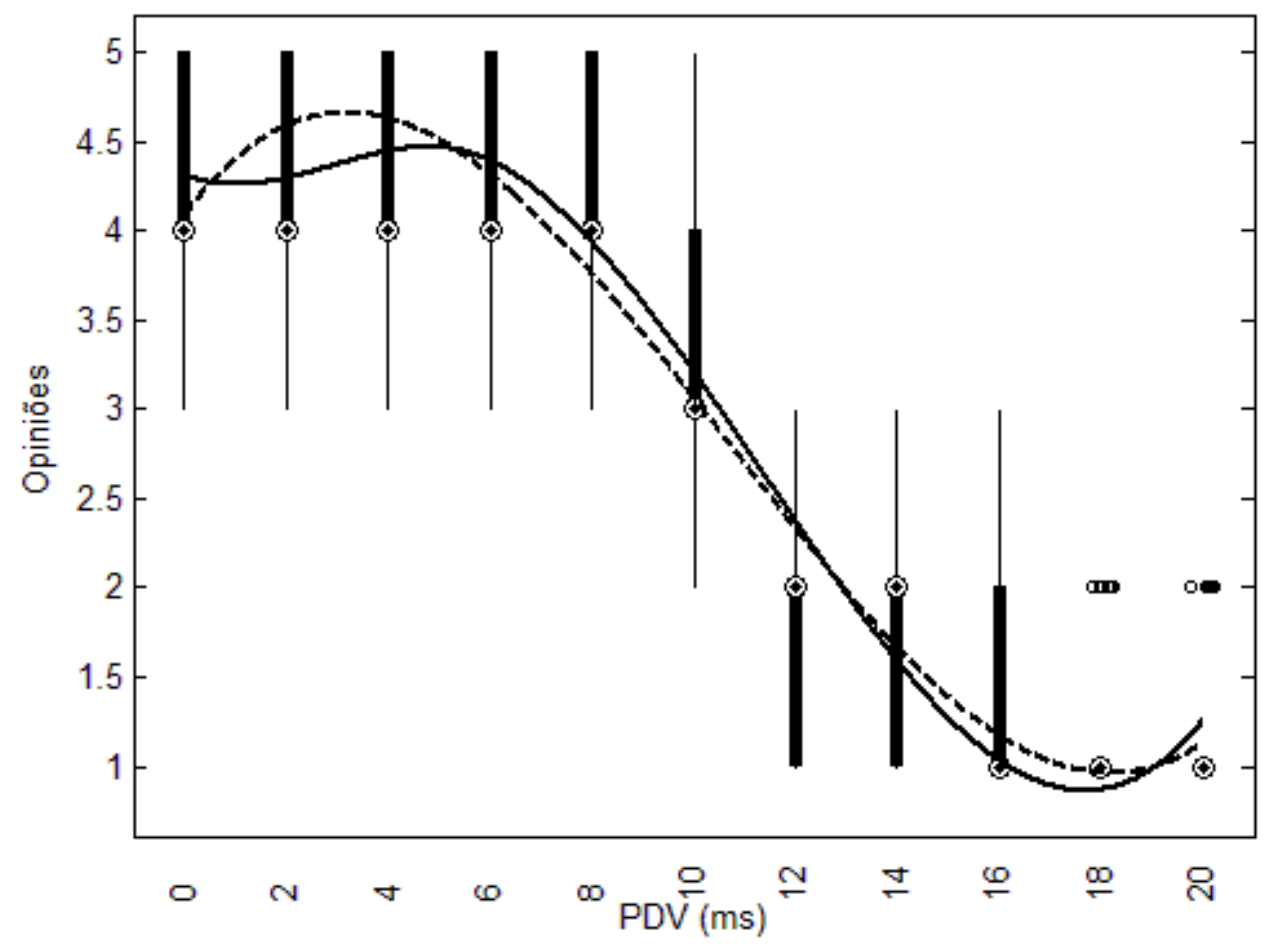

Fonte: Autor. 
Na Figura 5.2, são representadas as opiniões em função de PDV e mostradas no boxplot, a spline contínua que representa a métrica proposta VQOM, e a linha tracejada que representa a função de qualidade formada pelo polinômio $P(x)$ em função dos valores de PDV. Pode-se observar que a métrica proposta VQOM realiza uma melhor aproximação em relação às opiniões, passando mais próxima dos valores das medianas dos boxplots, podendo ser confirmado através do erro quadrático médio de ambas funções, sendo que o valor do erro para a métrica proposta VQOM é menor que o erro da função com um único polinômio cúbico.

A segunda função de estimação de qualidade, utilizada para comparar com a métrica proposta VQOM, é formada por um único polinômio de grau oito, representado por

$$
Q(x)=p_{8} x^{8}+p_{7} x^{7}+p_{6} x^{6}+p_{5} x^{5}+p_{4} x^{4}+p_{3} x^{3}+p_{2} x^{2}+p_{1} x+p_{0},
$$

em que os coeficientes do polinômio são $8 \times 10^{-8} ;-5 \times 10^{-6} ; 9 \times 10^{-5} ;-0,0003$; $-0,0091 ; 0,1081 ;-0,4072 ; 0,4787$ e 4,3035 , ordenados em ordem descendente, começando pelo coeficiente de grau oito, com o mínimo erro quadrático de treinamento igual a 0,3338, e o coeficiente de correlação de treinamento é igual a 0,9274.

No teste, foram utilizadas 396 opiniões de teste, que foram comparadas com a função da métrica proposta VQOM, obtendo-se o erro quadrático médio de teste igual a 0,4211 e o coeficiente de correlação de teste igual a 0,9169.

Na Figura 5.3, as opiniões em função de PDV são representadas no boxplot, a métrica proposta VQOM representada pela spline contínua, e a função de qualidade formada pelo polinômio $Q(x)$ em função dos valores de PDV está representada pela linha tracejada. Podese observar que a função de estimação representada pelo polinômio de grau oito tem um comportamento oscilatório acentuado nas regiões laterais que sugerem um sobreajuste (overfitting). Verifica-se que as opiniões são melhor representadas pela métrica proposta VQOM, confirmando-se através dos resultados obtidos para o erro quadrático médio e para o coeficiente de correlação de Pearson de ambas funções. Assim, o valor do coeficiente de correlação para a métrica proposta VQOM é maior que o coeficiente de correlação da função com um único polinômio de grau oito. 
Figura 5.3 - Opiniões de Treinamento (boxplot) e métrica proposta VQOM (spline contínua) para $\xi=$ 5,5 ms, e spline de um polinômio de grau oito (linha tracejada) em função do PDV.

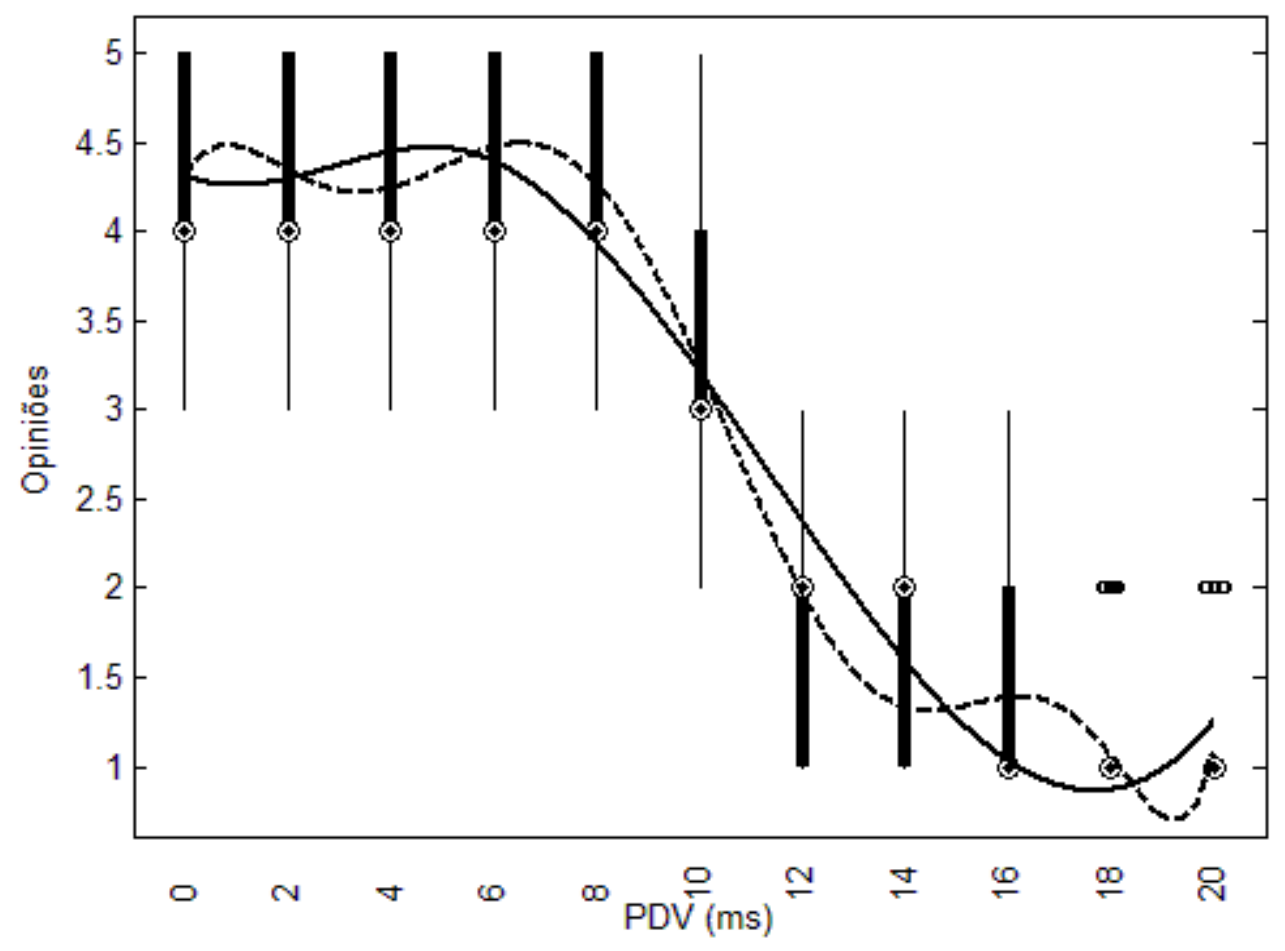

Fonte: Autor.

A Tabela 5.1 mostra os resultados obtidos no treinamento para a métrica proposta VQOM e para as métricas representadas pelos polinômios de grau três $P(x)$ e de grau oito $Q(x)$. Considerando que a função de estimação representada pelo polinômio de grau 8 apresenta oscilações que sugerem um sobreajuste, pode-se concluir que a métrica proposta VQOM obteve os melhores valores de correlação e de erro quadrático médio.

Tabela 5.1 - Desempenho da métrica VQOM e as funções de estimação de qualidade representadas pelos polinômios de grau três (P3) e de grau oito (P8) em relação às opiniões de treino.

\begin{tabular}{c|c|c|c|c}
\hline Métrica & PCC & SRCC & MSE & RMSE \\
\hline VQOM & 0,9154 & 0,8434 & 0,3868 & 0,6219 \\
P3 & 0,9095 & 0,8474 & 0,4125 & 0,6423 \\
P8 & 0,9274 & 0,8432 & 0,3338 & 0,5778 \\
\hline
\end{tabular}

Fonte: Autor.

Na Tabela 5.2 são apresentados os resultados obtidos no teste para a métrica proposta VQOM e para as métricas representadas pelos polinômios de grau três $P(x)$ e de grau oito 
$Q(x)$. Como podemos ver a métrica P8 apresenta um bom desempenho, mas isso não garante que não tenha havido sobreajuste no treino, porque apareceram oscilações fora das regiões em que há dados de treino, podendo ocorrer desajuste com os dados de teste, originando-se desvios que nas splines não acontece. A métrica proposta VQOM obteve valores de coeficientes de correlação e de erro quadrático médio que mostram um bom desempenho e não apresenta sobreajuste na estimação.

Tabela 5.2 - Desempenho da métrica VQOM e as funções de estimação de qualidade representadas pelos polinômios de grau três (P3) e de grau oito (P8) em relação às opiniões de teste.

\begin{tabular}{c|c|c|c|c}
\hline Métrica & PCC & SRCC & MSE & RMSE \\
\hline \hline VQOM & 0,9016 & 0,8308 & 0,4852 & 0,6966 \\
P3 & 0,8918 & 0,8238 & 0,5407 & 0,7353 \\
P8 & 0,9169 & 0,8400 & 0,4211 & 0,6489 \\
\hline
\end{tabular}

Fonte: Autor.

Também, realizou-se a comparação da métrica proposta VQOM com métricas tradicionais de referência completa (FR) de avaliação de qualidade de imagem como a PSNR e a SSIM, com métricas sem referência (NR) de avaliação de distorção de imagem como NIQE e BRISQUE, e com métricas FR de avaliação de qualidade de vídeo como VQM e VMAF, sendo esta última desenvolvida para sistemas de transporte de vídeo.

Tabela 5.3 - Desempenho das métricas VQOM, PSNR, SSIM, VQM, NIQE, BRISQUE e VMAF em relação às opiniões de teste da base de dados PDV_DB.

\begin{tabular}{c|c|c}
\hline Métrica & PCC & SRCC \\
\hline \hline VQOM & 0,9016 & 0,8308 \\
PSNR & 0,8680 & 0,8221 \\
SSIM & 0,8404 & 0,8188 \\
VQM & $-0,8768$ & $-0,8392$ \\
NIQE & $-0,1559$ & $-0,0227$ \\
BRISQUE & $-0,1812$ & $-0,2168$ \\
VMAF & 0,8893 & 0,8200 \\
\hline
\end{tabular}

Fonte: Autor.

A Tabela 5.3 mostra os resultados da comparação do desempenho da métrica VQOM com métricas objetivas usadas na avaliação de qualidade de vídeo e de imagem. Verifica-se que a métrica proposta VQOM é melhor correlacionada com as opiniões, e as métricas sem referência (NR) obtiveram os piores resultados. Os valores negativos na tabela mostram que 
as métricas VQM, NIQE e BRISQUE são correlacionadas negativamente com as opiniões, porque são métricas de degradação, sendo que para baixa qualidade o valor destas métricas aumenta e para alta qualidade o valor das métricas diminui.

\subsection{Resultados para QCM}

Conforme visto no capítulo 3, a QCM combina os valores das métricas objetivas PSNR e SSIM com a finalidade de obter uma métrica objetiva mais precisa, mantendo os pontos vantajosos de ambas métricas que a conformam. A diferença de outras métricas combinatórias (LI et al., 2016), a métrica QCM está representada pela adição dos produtos das métricas que a conformam. Dados os pontos de treino $\left(\rho_{n}, \varsigma_{n}, y_{n}\right)$, sendo $\rho_{n}$ os valores de PSNR, $\varsigma_{n}$ os valores de SSIM e $y_{n}$ as opiniões dos observadores, para $n=0,1, \ldots, N-1$, é realizado o projeto de estimação de qualidade através da minimização do erro quadrático entre as opiniões e a função de qualidade $C(\rho, \varsigma)$ representada pelo polinômio completo de segundo grau de duas variáveis. Obtendo-se os coeficientes $\boldsymbol{c}$ do polinômio quadrático.

A métrica QCM é expressa como

$$
C(\rho, \varsigma)=c_{5} \varsigma^{2}+c_{4} \rho^{2}+c_{3} \rho \varsigma+c_{2} \varsigma+c_{1} \rho+c_{0}
$$

O algoritmo foi treinado usando a base de dados de qualidade de vídeo ReTRiEVED (PAUDYAL et al., 2017). Usam-se os vídeos degradados pelo PDV que variam de 1 a $5 \mathrm{~ms}$ em torno de um atraso de 100 ms; obteve-se um conjunto de 1640 opiniões, representadas pelo vetor $\boldsymbol{y}$, e obtidas a partir da avaliação subjetiva de 40 vídeos degradados realizada por 41 observadores. Os vídeos degradados foram obtidos da degradação de 8 sequências de vídeos de referência afetados por 5 valores de PDV.

Para evitar o sobreajuste na função de estimação da métrica proposta QCM é utilizado o método de validação cruzada $k$-fold (HASTIE, 2009), descrito no Capítulo 4. Para a métrica proposta QCM usamos o valor de $k=4$, que representa o número de iterações usadas, obtendo-se o erro de validação igual a 1,0639.

Na Tabela 5.4 são apresentados os resultados obtidos da correlação cruzada de quatro iterações usada no treino e validação da métrica proposta QCM, para cada iteração. Pode-se observar que o melhor resultado na validação ou teste corresponde à terceira iteração. Por esse motivo, escolhem-se os coeficientes da função de estimação obtidos no treino da terceira 
iteração a ser utilizados no teste final. Os valores finais dos coeficientes selecionados para a métrica QCM são $-5,4970 ;-0,0105 ; 0,6575 ;-8,8446 ; 0,2464$ e 0,5721, ordenados em ordem descendente, começando pelos coeficientes de potência quadrática.

Tabela 5.4 -Desempenho da métrica QCM no treino (TR) e na validação ou teste (VT) usando o método de validação cruzada de 4 iterações (I).

\begin{tabular}{c|c|c}
\hline Iteração & PCC & SRCC \\
\hline TR_I1 & 0,4805 & 0,4497 \\
TR_I2 & 0,4582 & 0,4808 \\
TR_I3 & 0,4207 & 0,4375 \\
TR_I4 & 0,5446 & 0,4264 \\
VT_I1 & 0,3798 & 0,4663 \\
VT_I2 & 0,4925 & 0,3320 \\
VT_I3 & 0,6104 & 0,5609 \\
VT_I4 & 0,2762 & 0,3723 \\
\hline
\end{tabular}

Fonte: Autor.

A base de dados PDV_DB foi utilizada no teste final, e os resultados deste são mostrados na Tabela 5.5. Pode-se perceber que o melhor resultado é obtido usando os coeficientes da função de estimação da terceira iteração, confirmando-se a escolha realizada no processo de validação.

Tabela 5.5 -Desempenho da métrica QCM para o teste final usando a base de dados PDV_DB.

\begin{tabular}{c|c|c}
\hline Métrica & PCC & SRCC \\
\hline \hline QCM_I1 & 0,8972 & 0,8584 \\
QCM_I2 & 0,8955 & 0,8423 \\
QCM_I3 & 0,9128 & 0,8509 \\
QCM_I4 & 0,9118 & 0,8567 \\
\hline
\end{tabular}

Fonte: Autor.

\subsection{Comparação de Resultados para QCM}

Os resultados obtidos da métrica proposta QCM são comparados com outra função de estimação de qualidade baseada no polinômio completo de terceiro grau de duas variáveis, expressa como

$$
O(\rho, \varsigma)=o_{9} \varsigma^{3}+o_{8} \rho^{3}+o_{7} \rho \varsigma^{2}+o_{6} \rho^{2} \varsigma+o_{5} \varsigma^{2}+o_{4} \rho^{2}+o_{3} \rho \varsigma+o_{2} \varsigma+o_{1} \rho+o_{0},
$$


que é saturado porque verificou-se que houve valores fora da faixa das opiniões quando calculados. Assim, a saturação inferior para valores de $O(\rho, \varsigma)<1$ é realizada a partir de $\min (\max (O(\rho, \varsigma), 5), 1))$, e a saturação superior para valores de $O(\rho, \varsigma)>5$ é realizada a partir de $\max (\min (O(\rho, \varsigma), 1), 5))$.

O treinamento e validação para esta função de estimação foi realizada usando o método de validação cruzada $k$ - fold com 4 iterações, com a mesma divisão de grupos usada na métrica proposta QCM. Obtem-se o erro de validação igual a 1,2192.

Tabela 5.6 - Desempenho da métrica CCM no treino (TR) e na validação ou teste (VT) usando o método de validação cruzada de 4 iterações (I).

\begin{tabular}{c|c|c}
\hline Iteração & PCC & SRCC \\
\hline \hline TR_I1 & 0,7054 & 0,6012 \\
TR_I2 & 0,6523 & 0,4779 \\
TR_I3 & 0,6645 & 0,5132 \\
TR_I4 & 0,6022 & 0,4309 \\
VT_I1 & 0,4209 & 0,2650 \\
VT_I2 & 0,5887 & 0,5387 \\
VT_I3 & 0,6975 & 0,5869 \\
VT_I4 & 0,4233 & $-0,0640$ \\
\hline
\end{tabular}

Fonte: Autor.

Os resultados obtidos na validação e no teste para a função de estimação de qualidade $O(\rho, \varsigma)$ saturada são mostrados na Tabela 5.6. Pode-se observar que a métrica representada pela função de estimação de qualidade $O(\rho, \varsigma)$ saturada, denominada de CCM (Cubic Combinational Metric), obtém melhores resultados na validação ou teste da terceira iteração. Por essa razão, são escolhidos os valores dos coeficientes da função de estimação obtidos no treino da correspondente iteração.

Tabela 5.7 -Desempenho das métricas QCM e CCM na terceira iteração da validação cruzada de 4 iterações (I) no treino (TR) e na validação ou teste (VT).

\begin{tabular}{c|c|c}
\hline Métrica & PCC & SRCC \\
\hline \hline QCM_TR_I3 & 0,4207 & 0,4375 \\
QCM_VT_I3 & 0,6104 & 0,5609 \\
CCM_TR_I3 & 0,6645 & 0,5132 \\
CCM_VT_I3 & 0,6975 & 0,5869 \\
\hline
\end{tabular}

Fonte: Autor. 
Os valores finais dos coeficientes selecionados para a métrica CCM são $-81,9751$; $-0,0036 ;-3,3205 ; 0,1138 ; 123,4601 ; 0,2396 ;-0,8864 ;-32,0516 ;-4,8217$ e 33,5730 , ordenados em ordem descendente, começando pelos coeficientes de potência cúbica.

A comparação do desempenho das métricas QCM e CCM é apresentado na Tabela 5.7. Pode-se observar que a métrica QCM é menos correlacionado com as opiniões em comparação com a métrica CCM, no entanto, a métrica CCM apresenta um erro de validação maior em comparação com a métrica QCM, que mostra uma menor precisão do modelo CCM. Assim, a métrica QCM realiza uma melhor estimação das opiniões.

O desempenho da métrica proposta QCM é comparado com as métricas de referência completa (FR) que a compõem, PSNR e SSIM, e com a métrica VMAF que realiza combinação de métricas e foi desenvolvida para sistemas de transporte de vídeo em redes de pacotes.

Tabela 5.8 - Desempenho das métricas QCM, PSNR, SSIM e VMAF em relação às opiniões de teste da base de dados PDV_DB.

\begin{tabular}{c|c|c}
\hline Métrica & PCC & SRCC \\
\hline \hline QCM_I3 & 0,9128 & 0,8509 \\
PSNR & 0,9021 & 0,8582 \\
SSIM & 0,8696 & 0,8557 \\
VMAF & 0,9080 & 0,8263 \\
\hline
\end{tabular}

Fonte: Autor.

A Tabela 5.8 mostra os resultados da comparação do desempenho da métrica VQOM com métricas objetivas usadas na avaliação de qualidade de vídeo e de imagem. Pode-se observar que a métrica proposta QCM obtém a melhor correlação PCC com as opiniões em comparação com as métricas que a compõem, e uma boa correlação SRCC. Verifica-se que as métricas PSNR e SSIM apresentam um melhor desempenho combinadas do que individualmente, obtendo-se melhores resultados em comparação com a métrica VMAF. 


\section{CONCLUSÕES E TRABALHOS FUTUROS}

Esta Tese tem como resultados principais duas métricas propostas, capazes de auxiliar na operação de serviços de transporte vídeo afetados pelo fator de degradação de variação de atraso de pacotes, durante a execução do serviço. A inspiração desta Tese foi o comportamento das degradações causadas pelo fator de degradação PDV sobre a qualidade dos vídeos, e a viabilidade da execução de avaliações de qualidade para serviços em tempo real, considerando aspectos da percepção da degradação causada pela variação de atraso de pacotes.

\subsection{Conclusões}

Os fatores de degradação de rede, como a variação de atraso de pacotes, afetam a avaliação de qualidade de vídeo, conforme os resultados obtidos da avaliação subjetiva utilizados no projeto da função de estimação de qualidade.

Desenvolveram-se duas métricas objetivas VQOM e QCM incorporando aspectos da percepção da degradação causada pela variação do atraso de pacotes. Na primeira métrica, um método de otimização baseado em multiplicadores de Lagrange foi utilizado na fase de projeto para determinar os parâmetros de uma spline que representa a função de qualidade para a métrica proposta.

Nos resultados para a métrica VQOM, obteve-se a melhor aproximação da função de estimação de qualidade em relação com as opiniões com o critério de otimização elaborado. Projetou-se a métrica buscando o menor valor do lagrangiano de otimização e validou-se a métrica proposta comparando os erros quadráticos totais de treino e de teste. Além disso, realizou-se a comparação da função de estimação de qualidade da métrica proposta com outras duas funções de estimação de qualidade formadas por um único polinômio de graus três e oito, obtendo-se uma melhor aproximação para a métrica proposta nesta Tese. Também foi comparado o desempenho com outras métricas de avaliação de qualidade de imagem e de dados, obtendo o melhor resultado.

Na segunda métrica, uma combinação não-linear das métricas PSNR e SSIM foi utilizada na fase de projeto para determinar os coeficientes da função de estimação de qualidade com o menor erro quadrático médio em relação às opiniões de observadores. 
Para o treino e validação da métrica QCM, usou-se o método de validação cruzada $k$-fold para 4 iterações, escolhendo-se a função de estimação de qualidade mais correlacionada com as opiniões. No teste foi usada uma base de dados diferente à utilizada no treino, obtendo-se os melhores resultados de desempenho em comparação com as métricas que a compõem e com outras métricas usadas em sistemas de transporte de vídeo.

Cabe ressaltar que o emprego das métricas propostas não dispensa a execução de avaliações subjetivas, fornecendo sim uma indicação mais rápida do que seria a opinião subjetiva média, especialmente em serviços em tempo real, em que as avaliações subjetivas não podem ser executadas em larga escala durante a execução do serviço de transmissão de vídeo por rede de pacotes.

\subsection{Trabalhos Futuros}

Diante das contribuições e conclusões expostas, são propostas sugestões de trabalhos futuros a seguir:

- O método do projeto que se baseia em multiplicadores de Lagrange pode ser usado para outros tipos de degradações, como perda de pacotes, atraso de pacotes, ou latência da rede;

- Implementar um algoritmo de controle para diminuir o efeito da degradação causada pela variação de atraso de pacotes, durante a realização do serviço de transmissão de vídeo.

- Utilizar o algoritmo proposto nesta Tese para outras topologias de rede, bem como com conexão sem fio entre os nós, por exemplo, a rede de área local sem fio (WLAN - Wireless Local Area Network). 


\section{REFERÊNCIAS}

ABCIBAS, I.; SANKUR, B; SAYOOD, K. Statistical evaluation on image quality measures. In: Journal of Electronic Imaging, 2002, vol. 11, p. 206-223. doi: 10.1117/1.1455011.

BEGAZO, D. C. Avaliação objetiva e subjetiva de qualidade de video via rede IP com variação de atraso. 2012. Dissertação de Mestrado em Engenharia de Sistemas Eletrônicos Escola Politécnica, Universidade de São Paulo, São Paulo, 2012. Disponível em: $<$ http://www.teses.usp.br/teses/disponiveis/3/3142/tde-16072013-122005/>. Acesso em: 2017-09-30.

BEGAZO, D. C.; RODRIGUEZ, D. Z.; RAMÍREZ, M. A. Avaliação de qualidade de vídeo sobre uma rede IP usando métricas objetivas. Revista Iberoamericana de Sistemas, Cibernética e Informática, RISCI 2011, vol. 8, n. 1, p. 25-29. Disponível em: <http://www.iiisci.org/journal/risci/FullText.asp?var=\&id=HCA940MZ>. Acesso em: 201709-30.

BEGAZO, D. C.; RODRIGUEZ, D. Z.; RAMÍREZ, M. A. No-reference video quality metric based on the packet delay variation parameter. In: International Symposium on Consumer Electronics. ISCE 2016. São Paulo, Brazil, 2016, p. 83-84. doi: 10.1109/ISCE.2016.7797383.

BONDZULIC, B. P.; PAVLOVIC, B. Z.; PETROVIC, V. S.; ANDRIC, M. S. Performance of peak signal-to-noise ratio quality assessment in video streaming with packet losses. In: Electronics Letters, 2016, vol.52, p. 454-456. doi: 10.1049/el.2015.3784.

BRUNET, D.; VRSCAY, E. R.; WANG, Z. On the Mathematical Properties of the Structural Similarity Index. In: IEEE Transactions on Image Processing, 2012, vol. 21, p. 1488-1499. doi: 10.1109/TIP.2011.2173206.

CHIKKERUR, S.; SUNDARAM, V.; REISSLEIN, M.; KARAM, L. J. Objective Video Quality Assessment Methods: A Classification, Review, and Performance Comparison. In: IEEE Transactions on Broadcasting, 2011, vol. 57, p. 165-182. doi: 10.1109/ТBC.2011.2104671.

DE BOOR, C. A Practical Guide to Splines. New York, USA: Springer-Verlag, 1978. 
DWARAKA, V.; S. KILARI. Effect of Delay/Delay Variable on QoE in Video Streaming. 2010. Master Thesis in Electrical Engineering - Karlskrona: Blekinge Institute of Technology, 2010.

FARIAS, M. Q. No-Reference and Reduced Reference Video Quality Metrics: New Contributions. 2004. Ph.D. Dissertation - Department of Electrical and Compoter Engineering, University of California, Santa Barbara, CA, USA, 2004.

GOUDARZI, P.; HOSSEINPOUR, M. Video transmission over MANETs with enhanced quality of experience. In: IEEE Transactions on Consumer Electronics, 2010, vol. 56, p. 2217-2225. doi: 10.1109/TCE.2010.5681093.

GREEN, P. J.; SILVERMAN B. W. Nonparametric Regression and Generalized Linear Models. New York, USA: Chapman \& Hall, 1994.

HAMMING, R. W. Numerical Methods for Scientists and Engineers. New York, USA: Dover, 1986.

HASTIE, T.; TIBSHIRANI, R.; FRIEDMAN, J. The Elements of Statistical Learning: Data Mining, Inference, and Prediction. New York, USA: Springer, 2005.

HORÉ, A.; ZIOU, D. Is there a relationship between peak-signal-to-noise ratio and structural similarity index measure?. 2013. In: IET Image Processing, 2013, vol. 7, p. 1224. doi: 10.1049/iet-ipr.2012.0489.

ICKIN, S; DE VOGELEER, K; FIEDLER, M.; ERMAN, D. The effects of packet delay variation on the perceptual quality of video. In: IEEE 35th Conference on Local Computer Networks. LCN 2010. Denver, Colorado, USA, 2010, p. 663-668. doi: 10.1109/LCN.2010.5735791.

ITU-R BT.500-13. Methodology for the subjective assessment of the quality of television pictures. In: ITU-R Recommendation. 2012. Disponível em: < www.itu.int/rec/R-RECBT.500 >. Acesso em: 2017-09-30.

ITU-T J.144. Objective perceptual video quality measurement techniques for digital cable television in the presence of a full reference. In: ITU-R Recommendation. 2004. Disponível em: <http://www.itu.int/rec/T-REC-J.144>. Acesso em: 2017-09-30. 
ITU-T P.910. Subjective video quality assessment methods for multimedia applications. In: ITU-T Recommendation. 2008. Disponível em: < www.itu.int/rec/T-REC-P.910>. Acesso em: 2017-09-30.

ITU-T Y.1540. Internet protocol data communication service - IP packet transfer and availability performance parameters. In: ITU-T Recommendation. 2016. Disponível em: <http://www.itu.int/rec/T-REC-Y.1540/>. Acesso em: 2017-09-30.

JAGADISH, S.; MANIVASAKAN, R. Analysis of jitter control algorithms in QoS networks. In: 2011 Second Asian Himalayas International Conference on Internet (AH-ICI). Kathmundu, Nepal, 2011, p. 1-5. doi: 10.1109/AHICI.2011.6113947.

JAYANT, N. S.; NOLL, P. Digital Coding of Waveforms: Principles and Applications to Speech and Video. Englewood Cliffs, USA: Prentice Hall, 1984.

KUROSE, F.; ROSS, K. W. Computer Networking: A Top-Down Approach. Boston, USA: Addison- Wesley, 2010.

LI, S.; ZHANG, F.; MA, L.; NGAN, K. N. Image Quality Assessment by Separately Evaluating Detail Losses and Additive Impairments. In: IEEE Transactions on Multimedia, 2011, vol. 13, p. 935-949. doi: 10.1109/TMM.2011.2152382.

LI, Z.; AARON, A.; KATSAVOUNIDIS, I.; MOORTHY, A.; MANOHARA, M. Toward A Practical Perceptual Video Quality Metric. In: Netflix Technology Blog, 2016. Disponível em: < http://techblog.netflix.com/2016/06/toward-practical-perceptual-video.html >. Acesso em: 2018-01-10.

MITTAL, A.; MOORTHY, A. K.; BOVIK, A. C. Blind/Referenceless Image Spatial Quality Evaluator. In: 45th Asilomar Conference on Signals, Systems and Computers. ASILOMAR 2011. Pacific Grove, USA, 2011, p. 723-727. doi: 10.1109/ACSSC.2011.6190099.

MITTAL, A.; MOORTHY, A. K.; BOVIK, A. C. No-Reference Image Quality Assessment in the Spatial Domain. In: IEEE Transactions on Image Processing, 2012, vol. 21, p. 46954708. doi: 10.1109/TIP.2012.2214050. 
MITTAL, A.; SOUNDARARAJAN, R.; BOVIK, A. C. Making a "Completely Blind" Image Quality Analyzer. In: IEEE Signal Processing Letters, 2013, vol. 20, p. 209-212. doi: 10.1109/LSP.2012.2227726.

MSU. MSU Video Quality Measurements tools. MSU Graphics \& Media Laboratory 2011. Disponível em: <http://compression.ru/video/quality_measure >. Acesso em: 2017-09-30.

NETEM. Network Emulator. 1991. Disponível em: <http://www.linuxfoundation.org/>. Acesso em: 2017-09-30.

PAUDYAL, P.; BATTISTI, F; CARLI, M. Evaluation of the effects of transmission impairments on perceived video quality by exploiting ReTRiEVED dataset. In: Journal of Electronic Imaging, 2017, vol. 26, 023003. doi: 10.1117/1.JEI.26.2.023003.

PINSON, M. H.; WOLF, S. A new standardized method for objectively measuring video quality. In: IEEE Transactions on Broadcasting, 2004, vol. 50, p. 312-322. doi: 10.1109/TBC.2004.834028.

REIBMAN, A. R.; POOLE, D. Characterizing packet-loss impairments in compressed video. In: IEEE International Conference on Image Processing, 2007. ICIP 2007. San Antonio, Texas, USA 2007, p. 77-80. doi: 10.1109/ICIP.2007.4379769.

REINSCH, C. H. Smoothing by spline functions. In: Numerische Mathematik, vol. 10, p. 177-183. Springer-Verlag, 1967. doi: 10.1007/BF02162161.

SCHOENBERG, I. J. On Interpolation by Spline Functions and its Minimal Properties. In: International Series of Numerical Mathematics On Appoximation Theory, vol. 5, p. 109129. Springer-Basel, 1964. doi: 10.1007/978-3-0348-4131-3_12.

SHEIKH, H. R.; BOVIK, A. C. Image Information and Visual Quality. In: IEEE Transactions on Image Processing, 2006, vol. 15, p. 430-444. doi: 10.1109/TIP.2005.859378.

VERSCHEURE, O.; FROSSARD, P.; HAMDI, M. User-Oriented QoS Analysis in MPEG2 Video Delivery. In: Real-Time Imaging Journal, 1999, vol.5, p.305-314. doi: 10.1006/rtim.1999.0175.

VLC. VideoLAN Client. 2001. Disponível em: <http://www.videolan.org/>. Acesso em: 2017-09-30. 
WANG, Z.; BOVIK, A. C; SHEIKH, H. R.; SIMONCELLI, E. P. Image quality assessment: from error visibility to structural similarity. In: IEEE Transactions on Image Processing, 2004, vol. 13, p. 600-612. doi: 10.1109/TIP.2003.819861.

WANG, Z.; SHEIKH, H. R.; BOVIK, A. C. Objective video quality assessment. In: The Handbook of Video Databases: Design and Applications, ch. 41, p. 1041-1078. Florida, USA: CRC Press, 2003.

WINKLER, S. Digital Video Quality: Vision Models and Metrics. Blackwell, United Kingdom: Wiley, 2005.

WINKLER, S; MOHANDAS, P. The Evolution of Video Quality Measurement: From PSNR to Hybrid Metrics. In: IEEE Transactions on Broadcasting, 2008, vol. 54, p. 660-668. doi: 10.1109/TBC.2008.2000733.

XIPH. Xiph.org Video Test Media [derf's collection]. 2010. Disponível em: <http://media.xiph.org/video/derf/>. Acesso em: 2017-09-30.

ZHANG, L.; ZHENG, L.; NGEE, K. Effect of delay and delay jitter on voice/video over IP. In: Computer Communications Journal, 2002, vol.25, p.863-873. doi: 10.1016/S01403664(01)00418-2. 


\title{
APÊNDICES
}

\author{
APÊNDICE I - $\quad$ Transporte de Vídeo \\ APÊNDICE II - $\quad$ Validação Cruzada $k$-fold \\ APÊNDICE III - $\quad$ Emulador de Rede NetEm \\ APÊNDICE IV - $\quad$ Kit de Desenvolvimento VMAF \\ APÊNDICE V - Configuração e uso das métricas BRISQUE e NIQE
}




\section{APÊNDICE I}

\section{Transporte de Vídeo}

O transporte de vídeo é uma transmissão encapsulada do sinal de vídeo. Para aplicações em tempo real, em que procura-se enviar a informação com a maior rapidez e melhor qualidade possíveis, usa-se o protocolo de transporte RTP (Real Time Protocol) executados em cima do protocolo UDP, que não realiza a retransmissão dos pacotes corrompidos ou perdidos, sendo mais rápida na transmissão em comparação com outros protocolos como o $\mathrm{TCP}$ (Transmission Control Protocol).

O sinal de vídeo é previamente codificada, partindo do principio que o vídeo é composto de quadros ou imagens, que são representadas por uma matriz de pixels que são agrupados em blocos. Estes blocos compõem os macroblocos que ordenados em fila formam os pedaços (slices) que combinados constituem os grupos de figuras ( $\mathrm{GoP}-$ Group of Pictures).

Figura A.1 - Protocolos usados no transporte de vídeo.

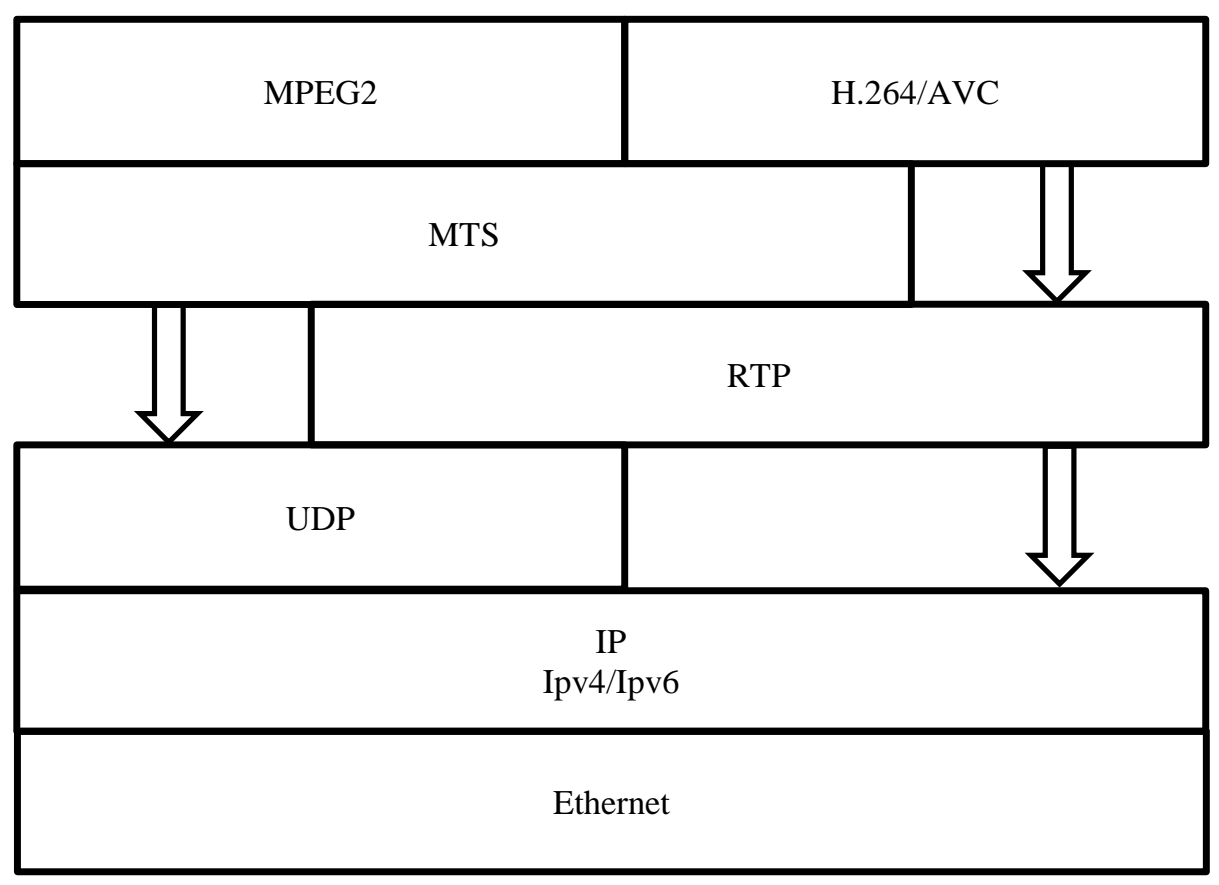

Fonte: Adaptado de (KUROSE, 2010).

Na Figura A.1 são apresentados os protocolos utilizados no transporte de vídeo através de redes de pacotes. 
Cada macrobloco em uma imagem é representado por códigos binários após a compressão sem perdas da sequência de bits da imagem, resultando em um fluxo elementar de bits. Este fluxo é dividido em PES (Packetized Elementary Stream) que são divididos em pacotes TS de 188 bytes, que formam o fluxo de transporte MPEG MTS (MPEG Transport Stream). Este fluxo é transportado sobre IP, usando o RTP para transportar os pacotes TS, que compõem os pacotes IP (Internet Protocol) com uma unidade máxima de transmissão (MTU - Maximum Transmission Unit) de 1500 bytes, sendo que 7 pacotes TS formam 1 pacote IP, resultando em pacotes IP de 1316 bytes sem informação de cabeçalho.

No transporte de vídeo codificado em uma rede IP, cada TS tem 184 bytes de dados e 4 bytes de cabeçalho, sendo que para os 7 TS, que formam o pacote IP, obtem-se 1288 bytes de dados e 28 bytes de cabeçalho TS. Adiciona-se ao pacote IP os cabeçalhos RTP de 20 bytes, UDP de 8 bytes e do próprio IP de 20 bytes, resultando em que os pacotes IP com cabeçalho são de 1356 bytes. Na Figura A.2 é representado o pacote IP com informação dos cabeçalhos.

Figura A.2 - Pacote IP com informação dos cabeçalhos para dados de transporte de vídeo.

\begin{tabular}{|c|c|c|c|}
\hline & & \\
Cabeçalho & Cabeçalho & Cabeçalho & \\
IP & UDP & RTP & MTS \\
20 bytes & 8 bytes & 8 bytes & Cabeçalho TS (7x4=28 bytes) \\
& & Dados TS (1288 bytes) \\
\hline
\end{tabular}

Fonte: Adaptado de (KUROSE, 2010). 


\section{APÊNDICE II}

\section{Validação Cruzada $k$-fold}

A técnica de validação cruzada usa-se na avaliação dos resultados de uma análise estatística, amplamente usado na estimação do erro de predição. Esta avaliação consiste em determinar o quão preciso é um modelo paramêtrico quando é testado com um outro conjunto de dados diferente ao de treino.

Na validação cruzada $k$-fold o conjunto total de dados é dividido em $k$ subconjuntos mutuamente exclusivos, com o mesmo tamanho, seguidamente é selecionado um subconjunto e é usado para teste, e os restantes $k-1$ subconjuntos são usados no treino para estimar os parâmetros do modelo. O processo descrito acima é realizado para $k$ iterações, selecionando de forma rotatória o conjunto de teste.

Como resultado final das $k$ iterações é calculado o erro médio entre a função real $y_{i} \mathrm{e}$ função do modelo estimado $\hat{y}_{i}$, denominado de erro de validação e é representado como

$$
e_{v}=\frac{1}{k} \sum_{i=1}^{k}\left(y_{i}-\hat{y}_{i}\right)^{2}
$$

Esta técnica permite detetar o sobreajuste que é gerado por uma quantidade de dados pequena, ou quando o modelo estimado apresenta um número eleado de parâmetros. 


\section{APÊNDICE III}

\section{Emulador de Rede NetEm}

O emulador de rede está disponível no kernel do linux e na versão iproute2 de Linux. O NetEm é controlado pela ferramenta de linha de comando tc do pacote iproute2. O comando tc usa bibliotecas e arquivos de dados no diretorio /usb/lib/tc.

O NetEm emula cenários de rede com diferentes fatores de degradação de rede, como atraso ponto a ponto, perda de pacotes, variação de atraso de pacotes, duplicação e pacotes, corrupção e pacotes e reordenamento de pacotes, podendo escolher o tipo de distribuição do atraso.

A seguir são dados exemplos para adicionar atraso fixo, variação de atraso e o tipo de distribuição do atraso na linha de comando.

Adicionando um atraso fixo de 100 ms para os pacotes que estão sendo transmitidos

\# tc qdisc add dev etho root netem delay $100 \mathrm{~ms}$

Adicionando a variação de atraso de pacotes de $10 \mathrm{~ms}$ para um atraso fixo de $100 \mathrm{~ms}$, $100 \pm 10 \mathrm{~ms}$

\# tc qdisc change dev etho root netem delay $100 \mathrm{~ms} 10 \mathrm{~ms}$

Adicionando a variação e atraso de pacotes de $20 \mathrm{~ms}$ para um atraso fixo de $100 \mathrm{~ms}$ com uma distribuição normal

\# tc qdisc change dev etho root netem delay $100 \mathrm{~ms} 20 \mathrm{~ms}$ distribution normal 


\section{APÊNDICE IV}

\section{Kit de Desenvolvimento VMAF}

O kit de desenvolvimento VMAF (VDK - VMAF Development Kit) contém a implementação do algoritmo da métrica VMAF, como também de ferramentas que permitem ao usuário treinar e testar o próprio modelo VMAF.

O VDK está escrito em sua grande maioria em código C, e o restante em Python, sendo necessário instalar compiladores de $\mathrm{C}$ e o pacote de Python2, de preferência as versões mais recentes. Adicionalmente, devem ser instalados os pacotes de Phyton numpy, scipy, maplotlib, pandas, scikit-learn, h5py, que precisam um compilador de fortran. Estes pacotes são ferramentas matemáticas que permitem programar matricialmente, desenhar gráficos de funções em duas dimensões, analisar os dados e as estruturas de dados, usar lenguagem de máquina, entre outras facilidades.

A métrica VMAF tem dois modos de execução, modo único e modo múltiple. No modo único são comparados um vídeo de referência com um vídeo degradado como

./run_vmaf format width height reference_path distorted_path [--out-fmt output_format]

A métrica VMAF usa formatos de vídeo YUV, de qualquer tipo de resolução. Adicionam-se na linha de comando os vídeos de referência e degradado, e pode-se escolher o formato do arquivo de saída com os resultados obtidos usando a métrica VMAF.

./run_vmaf yuv420p 352288 akiyo_a0_j0.00.yuv akiyo_a100_j0.00.yuv --out-fmt json

O métrica compara quadro por quadro ambos vídeos, e retorna a média dos valores das métricas que a compõem e a média da própria métrica.

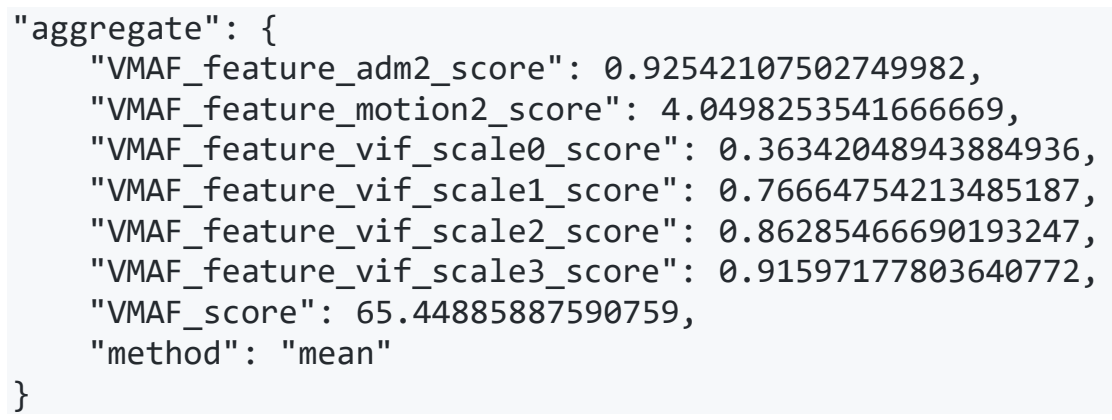




\section{APÊNDICE V}

\section{Configuração e uso das métricas BRISQUE e NIQE}

As métricas NR BRISQUE e NIQE são escritas em C/C++ e em Matlab, sendo necessário a instalação de um compilador de $\mathrm{C}++$ para Matlab. Ambas métricas podem ser treinadas e testadas para o próprio modelo BRISQUE e NIQE.

O código usado para ambas métricas foi obtido do site dos desenvolvedores de forma gratuita. Atualmente as métricas estão implementadas na versão R2017b do Matlab no toolbox de Qualidade de Imagem. Ambas métricas são métricas de imagens, motivo pelo qual é considerada a média das pontuações obtidas por quadro.

$\mathrm{Na}$ versão disponibilizada pelos autores da métrica BRISQUE, são adicionados outros programas que realizam a extração das características da imagem, que estimam os parâmetros da distorção usando a distribuição AGGD, e que realiza a predição usando SVM. Para obter o valor da métrica usa-se a função brisquescore, dando como entrada a imagem a ser avaliada (image).

vs = brisquescore(image);

Para a métrica BRISQUE também são adicionadas programas complementares que realizam a extração das características da imagem, que estimam os parâmetros de distorção, e estimam o parâmetro do modelo. Para obter o valor da métrica usa-se a função computequality, dando como entrada a imagem a ser avaliada (image), e parâmetros iniciais, que representam os tamanhos dos fragmentos que são usados para a construção do modelo Gaussiano Multivariado.

$$
\begin{aligned}
\text { vs }= & \text { computequality(image,blocksizerow,blocksizecol,blockrowoverlap,blockcoloverlap, } \\
& \text { mu_prisparam,cov_prisparam); }
\end{aligned}
$$

Os valores dos parâmetros iniciais são, para altura do bloco blocksizerow = 96; para largura do bloco blocksizecol $=96$; blocos sobrepostos entre a vertical e a horizontal blocksizerow $=0$ e blocksizecol $=0$. 